INSTITUTO DE PESQUISAS ENERGÉTICAS E NUCLEARES

Autarquia associada à Universidade de São Paulo

AVALIAÇÃO DA TENSÃO RESIDUAL EM ALUMINIO 7050 CONFORMADO PELO PROCESSO PEEN FORMING

RENE RAMOS DE OLIVEIRA

SÃO PAULO 
INSTITUTO DE PESQUISAS ENERGÉTICAS E NUCLEARES

Autarquia associada à Universidade de São Paulo

AVALIAÇÃO DA TENSÃO RESIDUAL EM ALUMINIO 7050

CONFORMADO PELO PROCESSO PEEN FORMING

RENE RAMOS DE OLIVEIRA

Dissertação apresentada como parte dos requisitos para a obtenção do grau de Mestre em Ciências na área de Tecnologia Nuclear - materiais

Orientador: Nelson Batista de Lima

SÃO PAULO 


\section{AGRADECIMENTOS}

Aos amigos de laboratório Amanda Abati Aguiar e ao Dr. Nelson Batista de Lima, que porventura é o meu orientador, pela sua dedicação e empenho durante o decorrer deste trabalho.

Aos técnicos do CCTM: Celso Vieira de Morais, Nildemar Aparecido Messias Ferreira, Glauson Aparecido Ferreira, Olandir Vercino Correia, Dileusa Alves da Silva Galissi, Mariano Castagnet.

Ao técnico do CQMA: Marcos Antonio Scapin

A Engenheira Ana Paola Villalva Braga - IPT-SP

Em especial a minha família:

A minha esposa Olivia Cristina Passos Oliveira;

A minha mãe Hilda Giovannini de Oliveira;

Em memória de meu pai Martinho Ramos de Oliveira 


\title{
AVALIAÇÃO DA TENSÃO RESIDUAL EM ALUMÍNIO 7050 CONFORMADO PELO PROCESSO PEEN FORMING
}

\author{
Rene Ramos de Oliveira
}

\begin{abstract}
RESUMO
O tratamento superficial de shot peening tem por objetivo aumentar a resistência à fadiga sendo comparada pelas medidas de tensão residual. $\mathrm{O}$ processo peen forming é uma variante do processo shot peening onde se obtém uma curvatura na placa produzida pelo jateamento das esferas através da compressão dos grãos localizados próximos à superfície. Foi estudado neste trabalho a influência dos parâmetros pressão e tamanho de granalha, utilizado no processo de peen forming, no perfil de tensão residual e no raio de curvatura em amostras de alumínio 7050. A avaliação do perfil de tensão de residual foi efetuada por difração de raios-x utilizando o método de $\operatorname{sen}^{2} \psi$.

Os resultados mostram que a formação da altura do arco de curvatura é proporcional a pressão de jateamento e ao tamanho das esferas e inversamente proporcional a espessura da amostra, e que o fator de concentração de tensões é maior para amostras jateadas com menores esferas. Na seção final deste trabalho apresenta um estudo complementar sobre microdeformação e tamanho médio de cristalito, podendo avaliar o perfil das amostras após jateamento.
\end{abstract}

Palavras Chave: shot peening; peen forming; difração de raios- $X$; tensão residual 


\title{
RESIDUAL STRESS EVALUATION AND CURVATURE BEHAVIOR OF ALUMINUN 7050 PEEN FORMING PROCESSED
}

\author{
Rene Ramos de Oliveira
}

\begin{abstract}
Shot peening is a superficial cold work process used to increase the fatigue life evaluated by residual stress measurements. The peen forming process is a variant of the shot peening process, where a curvature in the plate is obtained by the compression of the grains near to the surface. In this paper, the influence of the parameters such as: pressure of shot, ball shot size and thickness of aluminum 7050 samples with respect to residual stress profile and resulting arc height was studied. The evaluation of the residual stress profile was obtained by $\sin ^{2} \psi$ method.

The results show that the formation of the curvature arc height is proportional to the shot peening pressure, of spheres size and inversely proportional to the thickness of the sample, and that stress concentration factor is larger for samples shot peened with small balls. On final of this paper presents an additional study on microstrain and average crystallite size, which can evaluate the profile of the samples after blasting.
\end{abstract}

Keywords: shot peening; peen forming; $x$-ray diffraction, residual stress. 


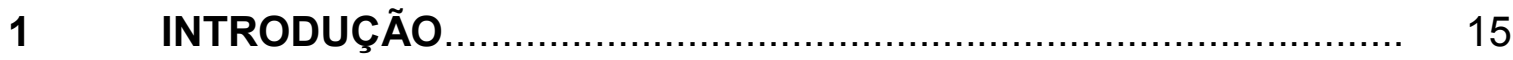

2 OBJETIVO

3 REVISÃO DA LITERATURA .................................................... 19

3.1 A história do alumínio......................................................... 20

3.2 Especificações do alumínio....................................................... 21

3.3 Ligas de alumínio................................................................. 22

3.4 Classificação dos tipos de tratamentos adotada pela Aluminum Association ...................................................................... 25

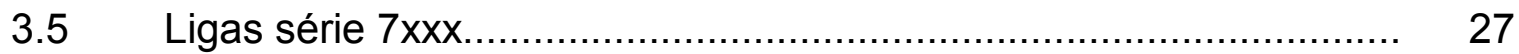

3.6 Propriedades de corrosão das ligas de alumínio............................... 29

3.7 Microestrutura das ligas de alumínio trabalháveis............................. 31

3.8 Composição e propriedades da liga AA7050-T7451 ....................... 33

3.9 Laminação......................................................................... 34

3.10 Laminação a quente............................................................... 35

3.11 Laminação a frio.................................................................... 38

3.12 Shot Peening ……......................................................... 40

3.13 Variáveis do processo de shot peening......................................... 43

3.14 Esferas utilizadas no shot peening ............................................. 45

3.15 Velocidade da esfera.......................................................... 45

3.16 Ângulo de impacto...................................................................... 45

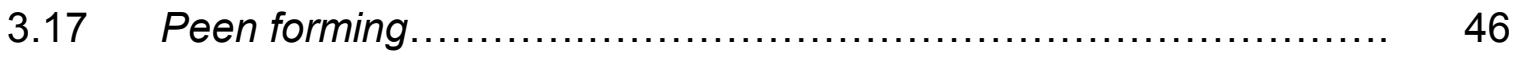

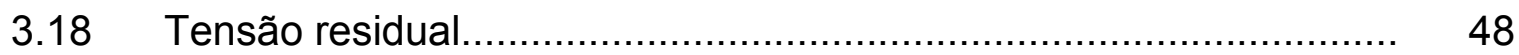

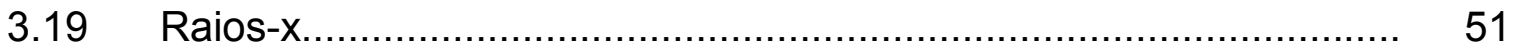

3.20 Radiação característica.......................................................... 54

$3.21 \quad$ Gerador de raios-x........................................................... 57

3.22 Medidas da microdeformação por raios-x....................................... 59

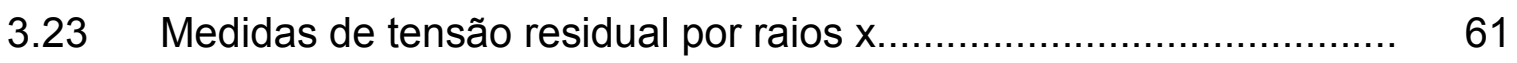

3.23.1 Análise unidimensional............................................................... 62

3.23.2 Análise Bidimensional.............................................................. 66

$4 \quad$ MATERIAIS E MÉTODOS .................................................... 70

$4.1 \quad$ O material.......................................................................... 70 
4.2 Análise química do material recebido.............................................. 71

4.3 Aplicação do peen forming ............................................................. 71

4.4 Análise de tensão residual em profundidade ao longo da espessura.................................................................... 74

4.5 Caracterização da seção transversal............................................. 75

4.6 Determinação da altura do arco de curvatura.................................. 76

4.7 Determinação do fator de concentração de tensão........................... 77

4.8 Determinação da microdureza....................................................... 78

4.9 Determinação da velocidade média das granalhas........................... 78

4.10 Medidas de microdeformação e tamanho médio de cristalito............ 79

$5 \quad$ RESULTADOS E DISCUSSÃO.................................................. 81

5.1 Alumínio no estado como recebido............................................... 81

5.2 Resultados da determinação da velocidade média, energia cinética e momento das granalhas........................................................ 82

5.3 Medição da altura do arco de curvatura.......................................... 84

5.4 Resultados obtidos em fator de concentração de tensão.................. 85

5.5 Resultados das análises de microdureza....................................... 89

5.6 Resultados da distribuição da tensão residual................................ 90

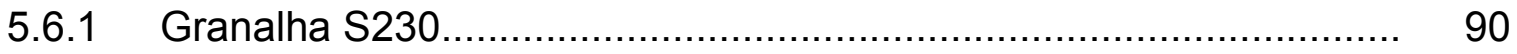

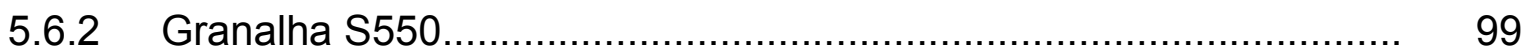

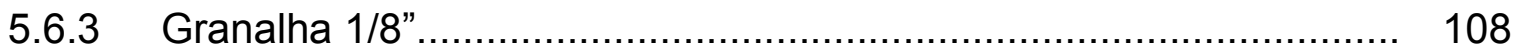

5.7 Estudos complementares sobre microdeformação........................... 117

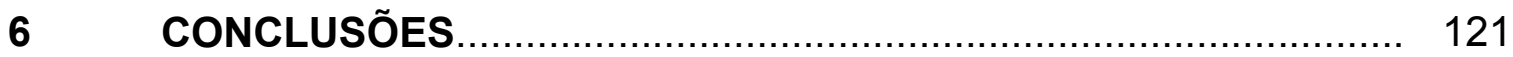

APÊNDICE A - Trabalho apresentado em congresso............................... 122

REFERÊNCIAS BIBLIOGRÁFICAS...................................................... 123 


\section{LISTA DE FIGURAS}

Figura 1 Propriedades mecânicas relativas aos segmentos na estrutura de uma aeronave.

Figura 2 Diagrama ilustrando o processo de corrosão em ligas de alumínio (Van Horn, 1967).................................................. 29

Figura 3 Tipos de laminadores utilizados para laminação (ABAL,2010) 35

Figura $4 \quad$ Etapas da laminação a quente (ABAL,2010).......................... 36

Figura $5 \quad$ Etapas da laminação a frio (ABAL,2010)............................... 38

Figura $6 \quad$ Laminação contínua (ABAL,2010)........................................ 39

Figura 7 Demonstração do impacto da esfera sobre uma superfície (MIC, 2006)

Figura 8 Distribuição de tensões após a aplicação do shot peening (MIC, 2006)

Figura 9 Perfil típico de tensões residuais (Torres, 2002).

Figura 10 Três métodos para a aplicação do peen forming em uma placa metálica (O'hara, 2002).

Figura 11 Tensão residual induzida pela deformação plástica (Cullity e Stock, 2001).

Figura 12 Nomenclatura das direções das tensões em eixos e chapas (Wulpi, 1985).

Figura 13 Colisão entre elétron de energia E1 e núcleo do átomo do alvo dando origem a um fóton de energia hv pelo processo Bremsstrahlung (Bottaro, 2007)

Figura 14 O Elétron incidente ejeta o elétron orbital de um átomo do alvo (Bottaro, 2007).

Figura 15 Tipos de radiação em função da mudança do elétron, de camada energética, (Cienfuegos e Vaitsman, 2000)...

Figura 16 Espectro contínuo de raios $\mathrm{x}$. A figura mostra o aspecto emergente do alvo e o espectro filtrado (Bottaro, 2007).

Figura 17 Esquema de uma seção de um tubo de raios-X selado a vácuo, (USGS, 2008). 
Figura 18 Barra cilíndrica tensionada por uma força (F) (Regone, 2000).

Figura 19 Difração dos grãos tensionados no eixo vertical. $N_{p}$ é o plano normal refletido (Regone, 2000)

Figura 20 O espaçamento interplanar $d_{0}$ é o mesmo para todas as famílias de planos, em qualquer direção, quando o material está livre de tensões, (François at al., 1996)

Figura 21 O espaçamento interplanar varia em todas as direções na presença de uma tensão, (François at al., 1996).................... 67

Figura 22 Direções da tensão e deformação principais, (Rigaku, 2003).. 68

Figura 23 Dimensões dos corpos de prova para testes.......................... 70

Figura 24 Equipamento para jateamento de granalhas (IPT-SP)............ 72

Figura 25 Área interna do equipamento para jateamento de granalhas (IPT-SP)

Figura 26 Montagem da amostra no difratômetro de raios $X$ para análise de tensão residual (IPEN/CNEN-SP).

Figura 27 Características do equipamento para a realização de medição do arco de curvatura (Mitutoyo Sul Americana Ltda.)

Figura 28 Dispositivo de medição da velocidade média das granalhas (IPT-SP)

Figura 29 Diagrama do dispositivo de medição da velocidade média das granalhas

Figura 30 Micrografia em superfície jateada com granalha S230........... 87

Figura 31 Micrografia em superfície jateada com granalha S550........... 87

Figura 32 Micrografia em superfície jateada com granalha 1/8”............. 87

Figura 33 Resultado do ensaio de rugosidade para amostra jateada com granalha S230

Figura 34 Resultado do ensaio de rugosidade para amostra jateada com granalha S550.

Figura 35 Resultado do ensaio de rugosidade para amostra jateada com granalha $1 / 8$ ".

Figura 36 Distribuição de microdureza Vickers em amostras jateadas a 20 psi com granalhas S230, S550 e 1/8" 
Figura 37 Distribuição de tensão residual em amostras de $2 \mathrm{~mm}$ de espessura com a aplicação do pré tensionamento.

Figura 38 Distribuição de tensão residual em amostras de $2 \mathrm{~mm}$ de espessura sem a aplicação do pré tensionamento.

Figura 39a Micrografias em MO das amostras $2 \mathrm{~mm}$, jateadas a pressão de 20 psi em condição de carregamento pré tensionado..........

Figura 39b Micrografias em MO das amostras $2 \mathrm{~mm}$, jateadas a pressão de 60 psi em condição de carregamento pré tensionado.

Figura 40 Distribuição de tensão residual em amostras de $5 \mathrm{~mm}$ de espessura com a aplicação do pré tensionamento em granalha S230.

Figura 41 Distribuição de tensão residual em amostras de $5 \mathrm{~mm}$ de espessura sem a aplicação do pré tensionamento em granalha S230..

Figura 42a Micrografias em MO das amostras $5 \mathrm{~mm}$, jateadas a pressão de 20 psi em condição de carregamento pré tensionado......... 96

Figura 42b Micrografias em MO das amostras $5 \mathrm{~mm}$, jateadas a pressão de 60 psi em condição de carregamento pré tensionado.

Figura 43 Formação da altura do arco pelo peen forming em amostras de $2 \mathrm{~mm}$ jateadas em $\mathrm{S} 230$.

Figura 44 Formação da altura do arco pelo peen forming em amostras de $5 \mathrm{~mm}$ jateadas em S230..

Figura 45 Distribuição de tensão residual em amostras de $5 \mathrm{~mm}$ de espessura com a aplicação do pré tensionamento em granalha S550

Figura 46 Distribuição de tensão residual em amostras de $5 \mathrm{~mm}$ de espessura sem a aplicação do pré tensionamento em granalha S550.

Figura 47a Micrografia em MO de luz polarizada de Al 7050 jateada com granalha S550 em 10 psi.

Figura 47b Micrografia em MO de luz polarizada de Al 7050 jateada com granalha S550 em 20 psi. 
Figura 48 Distribuição de tensão residual em amostras de $10 \mathrm{~mm}$ de espessura com a aplicação do pré tensionamento em granalha S550

Figura 49 Distribuição de tensão residual em amostras de $10 \mathrm{~mm}$ de espessura sem a aplicação do pré tensionamento em granalha S550.

Figura 50 Formação da altura do arco pelo peen forming em amostras de $5 \mathrm{~mm}$ jateadas em S550.

Figura 51 Formação da altura do arco pelo peen forming em amostras de $10 \mathrm{~mm}$ jateadas em S550.

Figura 52 Distribuição de tensão residual em amostras de $10 \mathrm{~mm}$ de espessura com a aplicação do pré tensionamento em granalha $1 / 8$ "

Figura 53 Distribuição de tensão residual em amostras de $10 \mathrm{~mm}$ de espessura sem a aplicação do pré tensionamento em granalha $1 / 8$ "

Figura 54 Distribuição de tensão residual em amostras de $15 \mathrm{~mm}$ de espessura com a aplicação do pré tensionamento em granalha $1 / 8$ "

Figura 55 Distribuição de tensão residual em amostras de $15 \mathrm{~mm}$ de espessura sem a aplicação do pré tensionamento em granalha 1/8"

Figura 56 Resultados obtidos por modelamento para jateamento com esferas de aço (Meguid, 1998).

Figura 57 Formação da altura do arco pelo peen forming em amostras de $10 \mathrm{~mm}$ jateadas em 1/8".

Figura 58 Formação da altura do arco pelo peen forming em amostras de $15 \mathrm{~mm}$ jateadas em 1/8".

Figura 59 Distribuição em profundidade da largura do pico a meia altura para amostras S230, $5 \mathrm{~mm}$ de espessura em regime de pressão de 20, 40 e 60 psi. 
Figura 60 Distribuição em profundidade da largura do pico a meia altura para amostras jateadas em 20 psi, S230, S550 e 1/8". 


\section{LISTA DE TABELAS}

Tabela 1 Comprimento de onda das radiações mais utilizadas em difração de raios $X$ (em Angstrom), (Padilha e Ambrozio

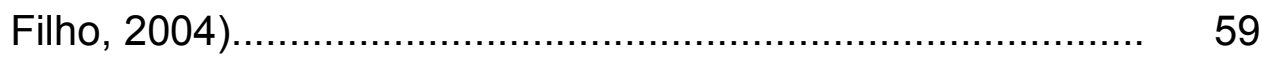

Tabela 2 Variáveis aplicadas ao processo peen forming........................ 74

Tabela 3 Resultado da análise química quantitativa da material............ 81

Tabela 4 Dados das granalhas obtidos pelo fornecedor.......................... 83

Tabela 5 Relação das granalhas e pressão de jateamento para cálculo de energia cinética e momento linear.................................... 83

Tabela 6 Resultados dos valores do raio de curvatura após o processo peen forming em parâmetros de regime de pressão e aplicação de pré tensão.

Tabela 7 Resultados dos fatores de concentração obtidos em relação ao regime de pressão e carregamento das amostras de alumínio 7050 em espessura de 2, 5, 10 e 15mm

Tabela 8 Relação entre pressão, tensão e profundidade para amostras $2 \mathrm{~mm}$ de espessura jateadas com $\mathrm{S} 230$.

Tabela 9 Relação entre pressão, tensão e profundidade para amostras $5 \mathrm{~mm}$ de espessura jateadas com $\mathrm{S} 230$.

Tabela 10 Resultados dos valores do raio de curvatura após o processo peen forming em parâmetros de regime de pressão e aplicação de pré tensão em amostras jateadas em S230.....

Tabela 11 Resultados dos fatores de concentração de tensão obtidos em relação ao regime de pressão e carregamento das amostras de alumínio 7050 nas espessuras de 2 e $5 \mathrm{~mm}$, S230.

Tabela 12 Relação entre pressão, tensão e profundidade para amostras $5 \mathrm{~mm}$ de espessura jateadas com $\mathrm{S} 550$.

Tabela 13 Relação entre pressão, tensão e profundidade para amostras $10 \mathrm{~mm}$ de espessura jateadas com $\mathrm{S} 550$ 
Tabela 14 Resultados dos valores da altura do arco de curvatura após o processo peen forming em parâmetros de regime de pressão e aplicação de pré tensão em amostras jateadas em S550.....

Tabela 15 Resultados dos fatores de concentração de tensão obtidos em relação ao regime de pressão e carregamento das amostras de alumínio 7050 nas espessuras de 5 e $10 \mathrm{~mm}$, S550.

Tabela 16 Relação entre pressão, tensão e profundidade para amostras $10 \mathrm{~mm}$ de espessura jateadas com granalhas de 1/8".

Tabela 17 Relação entre pressão, tensão e profundidade para amostras $15 \mathrm{~mm}$ de espessura jateadas com granalhas de 1/8".

Tabela 18 Resultados dos valores do raio de curvatura após o processo peen forming em parâmetros de regime de pressão e aplicação de pré tensão em amostras jateadas em 1/8".......

Tabela 19 Resultados dos fatores de concentração de tensão obtidos em relação ao regime de pressão e carregamento das amostras de alumínio 7050 nas espessuras de 10 e $15 \mathrm{~mm}$, $1 / 8 "$.

Tabela 20 Resultados dos alargamentos em relação a microdeformação e tamanho de cristalito 


\section{INTRODUÇÃO.}

A busca por novos processos de conformação é uma constante no setor industrial. Com o objetivo de diminuir custos de produção e aumentar a qualidade de produtos, diversas fontes de pesquisas são empregadas.

$\mathrm{Na}$ fabricação dos componentes de uma aeronave, um fator de grande relevância se encontra na obtenção de materiais cuja resistência se alia ao menor peso. Esta combinação proporciona ao conjunto a capacidade do veículo obter melhor desempenho com a utilização de propulsores de menor potência, ligado ao menor consumo de combustível, maior espaço de carga, ligado a utilização de elementos estruturais de menor volume e a mais importante, que se encontra na aplicabilidade do conjunto em situações adversas, como a variação de temperatura, pressão e umidade, que gera danos causados por corrosão e movimentos cíclicos.

Um material que apresenta a boa combinação destes fatores é o alumínio devido às suas propriedades e excelente desempenho para a maioria das aplicações. As técnicas de fabricação das ligas de alumínio permitem a manufatura do produto acabado a preços competitivos.

As ligas de alumínio oferecem grande variedade de combinações de resistência mecânica, resistência a corrosão, condutibilidade elétrica, usinabilidade, formabilidade, ductilidade, entre outros.

As ligas de alumínio de uso na indústria aeronáutica devem apresentar entre outras propriedades, alta resistência a fadiga, que pode ser obtida por meio de processos de fabricação, que induzem tensão residual compressiva na superfície do metal. A figura 1 mostra as propriedades mecânicas relativas aos segmentos na composição da estrutura de uma aeronave. 


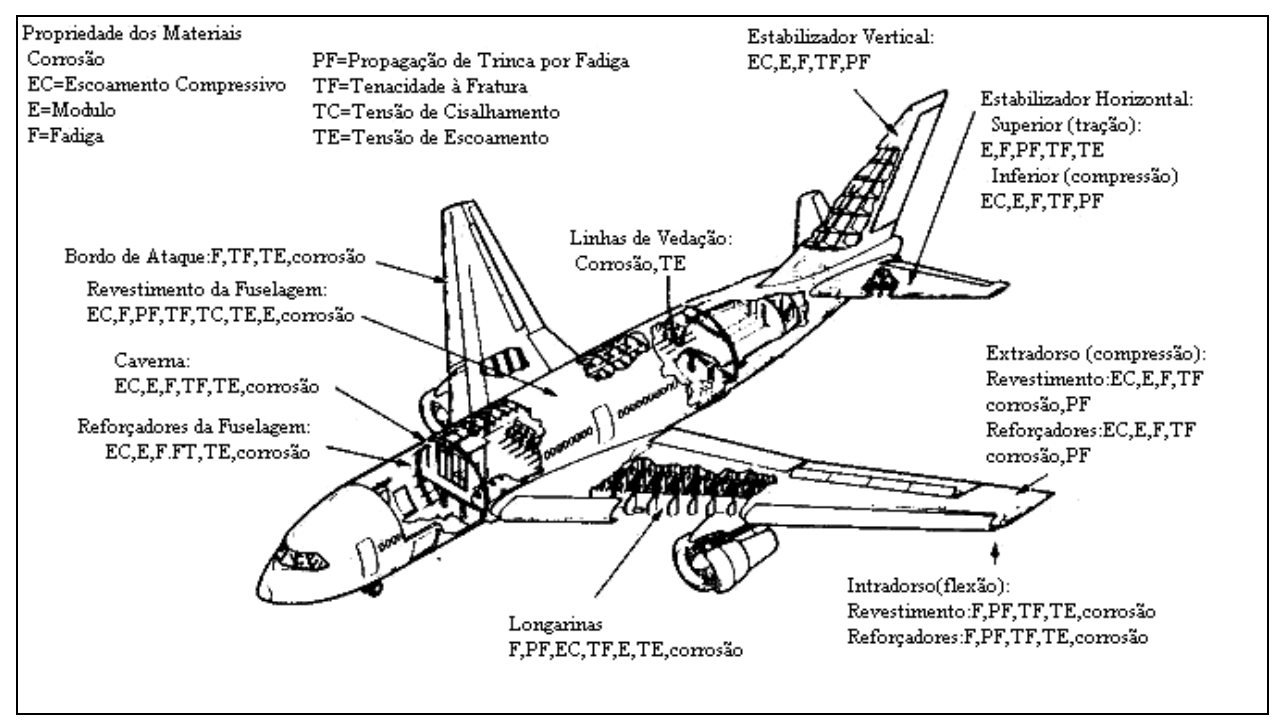

Figura 1: Propriedades mecânicas relativas aos segmentos na estrutura de uma aeronave.

Dentre as ligas de alumínio, a AA7050 é conformada para o uso em aplicações aeronáuticas nas asas (nervuras das empenagens, longarinas, rebites, reforçadores e revestimento), trem de pouso (partes de suporte), fuselagem (cavernas) e estabilizadores vertical e horizontal (reforçadores e longarinas).

No tocante ao processo de conformação, o propósito deste trabalho se encontra na associação dos benefícios gerados pelo processo de "shot peening" (aumento da tensão residual do material) e do "peen forming" (conformação pelo "shot peening").

Neste contexto, o processo de conformação denominado "peen forming" foi estudado variando os seguintes parâmetros de produção: pressão de jateamento, cobertura e tamanho de granalhas, espessura do material e pré carregamento da placa.

A distribuição de tensão residual, a altura do arco de curvatura e fator de concentração de tensão serão utilizados para avaliar a influência de diversos parâmetros na conformação de chapas.

Esta avaliação fornecerá um valioso banco de dados que futuramente poderá ser empregado em modelamento para a definição de parâmetros de conformação da chapas visando a busca dos melhores resultados em formação de arco de curvatura, tensão residual superficial, tensão residual 
máxima, profundidade de interação com a tensão residual e fator de concentração de tensão. 


\section{OBJETIVO}

Avaliar a influência dos parâmetros aplicáveis ao processo peen forming na liga de alumínio 7050 (pressão, espessura, tamanho de granalhas e carregamento externo) nos perfis de tensão residual, formação de arco de curvatura e fator de concentração de tensão, aplicando a técnica de difração de raios $X$. 


\section{REVISÃO DA LITERATURA}

O alumínio é um metal de grande abundancia na crosta terrestre, representando $8,1 \%$ da sua composição. É encontrado, normalmente combinado com silicatos e outros óxidos como em rochas ígneas, feldspatos, micas e em outros minerais. O minério utilizado para a produção do alumínio é a bauxita, onde o alumínio se encontra na forma de óxidos hidratados $\left(\mathrm{Al}_{2} \mathrm{O}_{3} \cdot \mathrm{nH}_{2} \mathrm{O}\right)$ ( $\mathrm{CRC}$ Handbook, 1968). Apesar de ser o segundo elemento metálico de maior abundancia na crosta terrestre, é o metal mais jovem na escala industrial, sendo produzido comercialmente há cerca de 150 anos (ABAL, 2010). É o metal não ferroso mais consumido do mundo e sua produção atual supera na soma de todos os outros metais não ferrosos. A variedade de aplicações do alumínio está relacionada com suas características físico-químicas, com destaque para o seu baixo peso específico $\left(2.7 \mathrm{~g} / \mathrm{cm}^{3}\right)$, quando comparado com outros metais de grande consumo, como o aço $\left(7.83 \mathrm{~g} / \mathrm{cm}^{3}\right)$, o cobre $\left(8.93 \mathrm{~g} / \mathrm{cm}^{3}\right)$ ou o bronze $\left(8.53 \mathrm{~g} / \mathrm{cm}^{3}\right)$, para a alta resistência à corrosão e alta condutividade térmica e elétrica (ASM Metals Handbook, 2009) É um material de grande aplicação em múltiplas atividades, sendo que o alumínio puro é mais dúctil que o aço, contudo, suas ligas com pequenas quantidades de cobre, manganês, silício, magnésio e outros elementos apresentam uma grande quantidade de características adequadas às mais diversas aplicações. Estas ligas constituem o material principal para a produção de muitos componentes na indústria de artefatos domésticos, na indústria automobilística e aeronáutica. Devido à sua grande reatividade química é utilizada quando pulverizada como combustível sólido para foguetes e produção de explosivos. Sua produção exige tecnologia avançada, capital intensivo e necessidade de grandes investimentos, além de grande quantidade de insumos consumidos em sua produção. Possui extraordinária versatilidade pelas formas de conformação, podendo ser fundido, extrudado em tubos, laminado em placas e até em folhas, conformado por metalurgia do pó e forjado e de 
grande variedade na preparação superficial como polimento e anodização (IAI, 2009).

\subsection{A história do alumínio}

Há sete milênios, ceramistas da Pérsia já produziam seus vasos com um tipo de barro que continha óxido de alumínio. Apesar de ser um elemento abundante do planeta a sua forma metálica pura não é encontrada naturalmente e o processo percorrido até conhecermos o alumínio na sua forma atual pode ser demonstrado ao longo do tempo:

Os persas em 6000 a.C. fabricavam potes e recipientes de argila que continham alumina. Os povos da Babilônia e do antigo Egito utilizavam este mesmo material na fabricação de cosméticos, medicamentos e corantes de tecido.

Somente em 1809 houve a primeira obtenção do que até então mais se aproximava do alumínio através da fusão de ferro na presença de alumina feito por Humphrey Davy. Em 1821 o francês P. Berthier descobre um minério avermelhado, que contém $52 \%$ de oxido de alumínio, perto da aldeia de Lês Baux, no sul da França conhecido hoje como Bauxita. O físico dinamarquês Hans Christian Oersted, em 1825 consegue isolar o alumínio a partir do cloreto de alumínio (ABAL, 2010). Em 1827 Friederich Wöhler desenvolveu na Alemanha um processo para produzir o alumínio em pó, (ABAL, 2004), reagindo potássio com cloreto de alumínio anidro e em 1845 o químico alemão determinou a massa específica do alumínio, sendo esta, uma de suas propriedades originais mais importantes. Na França, Henri Saite-Claire Deville em 1854 melhorou o método de Wöhler para criar o primeiro processo comercialmente viável. $\mathrm{O}$ preço do metal, inicialmente mais alto do que o do ouro e da platina baixou $90 \%$ nos 10 anos seguintes, ainda assim, alto para permitir sua utilização em larga escala pela indústria. O americano Hamilton Y. Cassner em 1885 melhora o processo de Deville, aumentando a produção anual para 15 toneladas. Em 1886 os cientistas Paul Louis Toussaint Héroult (França) e Charles Martin Hall (EUA), trabalhando separadamente, inventaram um processo eletrolítico, 
denominado Hall-Héroult, que é a base para toda a produção de alumínio da atualidade. Descobrindo que ao dissolver óxido de alumínio em criolita fundida $\left(\mathrm{Na}_{3} \mathrm{AlF}_{6}\right)$ e passar corrente elétrica intensa através deste banho, o alumínio no estado líquido se depositaria no fundo do banho. E, finalmente, em 1889, o austríaco Karl Josef Bayer, filho do fundador da companhia química Bayer inventou um processo para a produção de alumina a partir da bauxita (IAI, 2009).

Atualmente os Estados Unidos e o Canadá são os maiores produtores mundiais de alumínio, mesmo não possuindo jazidas de bauxita em seus territórios, dependendo exclusivamente da importação. A bauxita é o minério industrial mais importante para a produção de alumínio, contendo de 35 a $45 \%$ de óxido de alumínio (ABAL, 2004). O Brasil tem a terceira maior reserva de bauxita do mundo, sendo a maior parte localizada na região amazônica. Ainda pode ser encontrada no sudeste do Brasil, na região de Poços de Caldas (MG) e Cataguases (MG) e esta reserva abundante de bauxita, aliada ao alto potencial de geração de energia elétrica (insumo primordial para a obtenção de alumínio primário através da eletrólise) faz do Brasil um grande produtor de alumínio (o sexto no mundo) e de alumina (o quarto no mundo) (Vieira e Mazzolenis, 2000; Anuário Estatístico, 2007).

\subsection{Especificações do alumínio}

Nos Estados Unidos, os elementos químicos das ligas e tratamentos térmicos estão registrados pela Aluminum Association (EUA). A obtenção de especificações e padrões são desenvolvidas e mantidas por agências Federais e Militares pela ASTM, entre outras. Os métodos são freqüentemente referenciados e estão sujeitos à profunda inspeção além dos testes para determinação de propriedades química, mecânica e física e outros procedimentos requeridos.

As especificações para os elementos de liga em alumínio são definidas como:

Elementos de liga principais: Definem a série de elementos que controlam a fusibilidade e suas propriedades desenvolvidas. 
Elementos de liga secundários: Controlam o comportamento na solidificação, modificam a estrutura eutética, promove o refinamento das fases primárias, o controle do tamanho e forma do grão, promovem ou limitam a formação de fases e reduzem a oxidação.

Impurezas: Influenciam na fusibilidade e na forma das fases insolúveis, que às vezes limitam ou promovem propriedades desejadas (ASM Metals Handbook, 2009).

A designação do sistema e nomenclatura das ligas em alumínio não está internacionalmente padronizada. Muitos países têm desenvolvido e publicado seus próprios padrões. A maior parte deles utiliza o sistema norte americano desenvolvido e mantido pela Aluminum Association. Geralmente a obtenção destas especificações é publicada através de agências governamentais, associações técnicas e sociedades típicas que referenciam na nomenclatura descrita: (Davis, 1993).

$1 \times x x$ - Alumínio comercialmente puro.

2xxx - Ligas nas quais o cobre é o principal elemento ligante, além de outros elementos, como o magnésio, principalmente. .

$3 \mathbf{x x x}$ - Ligas nas quais o manganês é o principal elemento ligante.

$4 \mathbf{x x x}$ - Ligas nas quais o silício é o principal elemento ligante.

$5 \mathbf{x x x}$ - Ligas nas quais o magnésio é o principal elemento ligante.

6xxx Ligas nas quais o magnésio e o silício são os principais elementos ligantes

$7 \mathbf{x x x}$ - Ligas nas quais o zinco é o principal elemento ligante, mas outros elementos como o cobre, magnésio, cromo e zircônio podem ser especificados.

8xxx - Ligas que incluem algumas composições com estanho e lítio, caracterizando composições diversas.

9xxx - Reservado para uso futuro.

\subsection{Ligas de alumínio}

O alumínio fundido dissolve outros metais e substâncias metalóides. Quando o alumínio se resfria e se solidifica, alguns dos constituintes da liga 
podem ser retidos em solução sólida. Os átomos podem ser visualizados como sendo arranjados em uma rede cristalina regular formando moléculas de tamanhos diferentes daqueles do elemento de liga principal. A principal função das ligas de alumínio é aumentar a resistência mecânica sem prejudicar as outras propriedades. Assim, novas ligas têm sido desenvolvidas combinando as propriedades adequadas a aplicações específicas. (ABAL, 2010).

O metal quente pode manter mais elementos de liga em solução sólida do que quando frio, e conseqüentemente, quando resfriado, ele tende a precipitar o excesso dos elementos de liga da solução. Este precipitado pode ser na forma de partículas duras, consistindo de compostos intermetálicos, tais como: $\mathrm{CuAl}_{2}$ ou $\mathrm{Mg}_{2} \mathrm{Si}$. Estes agregados de átomos metálicos endurecem a liga.

A descoberta do "envelhecimento", das ligas que contém magnésio e silício conduziu ao desenvolvimento das principais ligas estruturais utilizadas hoje na engenharia. (ABAL, 2010).

Um dos aspectos que tornam as ligas de alumínio tão atraentes como materiais de construção mecânica é o fato de poder combinar-se com a maioria dos metais de engenharia, chamados de elementos de liga. Com essas associações, é possivel obter características tecnológicas ajustadas de acordo com a aplicação do produto final. Mas para isso, é preciso conhecer bem as vantagens e limitações de cada elemento para fazer a melhor seleção.

A composição química do alumínio e suas ligas são expressas em percentagem, obedecendo a Norma NBR 6834 da ABNT. Esta norma abrange sistemas de classificação das ligas trabalháveis, das ligas para fundição, peças, lingotes e de alumínio primário, além de densidade nominal das ligas trabalháveis de alumínio. (ABAL, 2010).

Entre as ligas trabalháveis, pode-se mencionar algumas aplicações relacionadas aos grupos:

As ligas da série $3 x x x$ são muito utilizadas devido a sua conformabilidade e resistência a corrosão serem similares a do alumínio comercialmente puro, porém as propriedades mecânicas maiores, particularmente quando deformadas a frio. 
As ligas da série $5 x x x$ são as mais resistentes e podem ser conformados em diversos formatos como lâminas, chapas, perfis, tubos, arames, etc. e possuem elevada resistência à corrosão.

Entre as ligas tratadas termicamente, pode-se mencionar as ligas da série 6xxx (magnésio e silício) cuja característica é a elevada resistência à corrosão, porém perdem um pouco da sua capacidade de serem trabalhadas e por isso denominada como uma liga tratada termicamente de média resistência. Já as ligas tratadas termicamente de elevada resistência têm no cobre (série 2xxx) ou zinco (série 7xxx) os principais elementos de liga. São tão resistentes quanto o aço estrutural e geralmente necessitam de proteção superficial. Estas ligas são utilizadas quando o fator resistência por peso for a principal característica, como na aviação.

Em particular algumas ligas trabalháveis têm suas aplicações e características definidas e como exemplo mencionadas as ligas 1050 e a 1100 como alumínios comercialmente puros, muito dúcteis no estado recozido, indicados para deformação a frio, possuem excelente resistência à corrosão, a qual é crescente com o aumento da pureza da liga e são aplicados na confeç̧ão de equipamentos para indústrias alimentícias, químicas, bebidas, trocadores de calor ou utensílios domésticos.

A liga 1350 possui $99,5 \%$ de pureza e condutibilidade mínima de $61 \%$, da qual confere aplicações na produção de barramentos elétricos e peças ou equipamentos que necessitam de alta condutibilidade elétrica.

As ligas 2017, 2024, 2117 e a 2219 tem o Cobre como elemento principal possuem elevada resistência mecânica, alta ductibilidade, média resistência à corrosão e boa usinabilidade, o que confere aplicação na usinagem de peças e forjamento, aplicação na indústria aeronáutica, transporte, máquinas e equipamentos.

A liga 3003 tem o Mn como elemento principal, proporciona boa resistência à corrosão, boa conformabilidade e moderada resistência mecânica. Sua aplicação está na produção de carrocerias de ônibus e de furgões, equipamentos rodoviários e veículos em geral, reboques, vagões, utensílios domésticos, equipamentos para indústria química e alimentícia, telhas, cumeeiras, rufos, calhas, forros, construção civil e fachadas. 
Para a fabricação de varetas de solda utilizam-se as ligas de Al-Si (4043 e 4047), aplicadas na soldagem de materiais compostos pelas ligas das séries 1xxx, 3xxx e 6xxx.

As ligas de Al-Mg, (5005, 5052 e 5056) tem por característica a ductilidade no estado recozido, mas endurecem rapidamente sob trabalho a frio. Possuem resistência à corrosão em ambientes marítimos e em geral a resistência mecânica aumenta com os teores crescentes de Mg. São aplicadas em produto similares às utilizadas com a liga 3003, além de estruturas solicitadas, elementos estruturais e embarcações.

As ligas 6053, 6061, 6063 e 6351 são compostas por Al-Mg-Si e tratáveis termicamente com excelente resistência mecânica e são aplicadas em produtos similares aos da liga Al-Mg (Série 5xxx).

As ligas $\mathrm{Al}-\mathrm{Zn}$ tratáveis termicamente possuem alta resistência mecânica, boa resistência à corrosão e boa conformabilidade. Alguns exemplos desta liga são a 7050, 7075 e a 7178 e são aplicadas em peças sujeitas a elevados esforços mecânicos na indústria aeronáutica em maquinas e equipamentos, em moldes para injeção de plástico e estruturas (ABAL, 2010).

\subsection{Classificação dos tipos de tratamentos adotada pela Aluminum Association}

F: Como fabricado: aplica-se aos produtos resultantes de conformação mecânica (laminação, extrusão e outros).

O: Recozido: aplica-se aos produtos inicialmente trabalhados e depois recozidos para obter a resistência mecânica mais baixa, e aos produtos fundidos que são recozidos com o objetivo de aumentar a ductilidade e a estabilidade dimensional.

W: Solubilizado: têmpera instável aplicável somente às ligas que envelhecem espontaneamente na temperatura ambiente (envelhecimento natural) após solubilização. Esta designação é especificamente usada quando o período de envelhecimento natural é indicado, como por exemplo, no caso de W 1 hora. 
T: Termicamente tratado para produzir têmperas estáveis diferentes de F, O ou W: Aplica-se aos produtos que são termicamente tratados, com ou sem deformação suplementar, para produzir têmperas estáveis.

A letra $T$ é sempre seguida por um ou mais dígitos. Um período de envelhecimento natural pode ocorrer entre as operações relacionadas para as têmperas $T$.

Exemplo: T7: solubilizado e estabilizado. Aplica-se a produtos que são estabilizados após solubilização para levá-los além do ponto de máxima resistência mecânica, de modo a permitir o controle de alguma característica especial. Para o caso específico do material utilizado neste estudo empregou-se o tratamento T7451.

T7451: Solubilização, resfriamento rápido, estiramento nominal permanente até $2 \%$ em relação às dimensões originais e duplo envelhecimento artificial.

O sistema de designação de têmperas utilizado para alumínio e ligas de alumínio é usado para todas as formas de produto (tanto trabalháveis como fundidas), com a exceção de lingotes. O sistema é baseado nas seqüências de tratamentos térmicos e mecânicos, ou ambos, usados para produzir as várias têmperas. A designação de têmpera segue a designação da liga e é separada dela por um hífen. Designações básicas de têmpera consistem em simples letras maiúsculas. Maiores subdivisões de têmperas básicas, quando requeridas, são indicadas por um ou mais dígitos seguindo a letra $T$ (tratada termicamente), aplicando-se a ligas cuja resistência seja estável dentro de alguns meses, se forem solubilizadas. O "T" é sempre seguido por um numeral de 1 a 10, cada um indicando uma seqüência específica de tratamentos básicos: (Davis, 1993; Conserva et al, 1992).

T1: Conformado em alta temperatura e envelhecido naturalmente.

T2: Conformado em alta temperatura, resfriado, deformado a frio e envelhecido naturalmente.

T3: Solubilizado, trabalhado a frio e envelhecido naturalmente.

T4: Solubilizado e envelhecido naturalmente.

T5: Conformado em alta temperatura e envelhecido artificialmente.

T6: Solubilizado e envelhecido artificialmente.

T7: Solubilizado e estabilizado. 
T8: Solubilizado, deformado a frio e envelhecido artificialmente.

T9: Solubilizado, envelhecido artificialmente e trabalhado a frio.

T10: Conformado em alta temperatura, resfriado, trabalhado a frio e envelhecido artificialmente.

Outros algarismos diferentes de zero podem ser adicionados para indicar uma variação de tratamento que altere significativamente as propriedades do produto (Conserva et al, 1992).

As principais preocupações na metalurgia física das ligas de alumínio incluem os efeitos da composição, trabalho mecânico e/ou tratamento térmico nas propriedades mecânicas e físicas. Em termos de propriedades, o aumento da resistência mecânica é um objetivo principal no desenvolvimento das ligas porque a baixa resistência do alumínio puro (cerca de $10 \mathrm{MPa}$ de limite de escoamento na condição recozida) limita a sua utilidade comercial (Davis, 1993).

Sabe-se que tenacidade à fratura e comportamento em fadiga, que são características importantes das ligas de alumínio de alta resistência utilizadas em aplicações aeroespaciais, são influenciadas pelos três tipos de partículas: constituintes $\left(\mathrm{Cu}_{2} \mathrm{FeAl}_{7}, \mathrm{CuAl}_{2}, \mathrm{FeAl}_{6}\right)$, dispersóides $\left(\mathrm{ZrAl}_{3}\right.$, $\mathrm{CrMg}_{2} \mathrm{Al}_{12}$ ) e precipitados endurecedores (zonas de Guinier-Preston). Conseqüentemente, o projeto de ligas de alumínio resistentes a danos, como 7475,7050 ou 2124, tem sido baseado primariamente no controle da microestrutura pela composição e processo de fabricação (ASM Metals Handbook, 1992).

\subsection{Ligas série $7 \mathrm{xxx}$}

O estudo das ligas Al-Zn-Mg teve por inicio por volta de 1920 por meio da avaliação das propriedades de resistência mecânica, mas foi notada a baixa resistência a corrosão sob tensão, o que levou somente há 20 anos mais tarde a introdução no meio industrial de uma liga contendo $7,5 \% \mathrm{Zn}$, $1,6 \% \mathrm{Mg}, 0,7 \% \mathrm{Cu}$ e $0,6 \% \mathrm{Mn}$, posteriormente denominada liga $7075-\mathrm{T} 6$, dando a possibilidade no processamento de novos produtos através da 
laminação, extrusão e forjamento. Tais propriedades despertaram grande interesse em aplicações em elementos estruturais em veículos aeronáuticos.

Estudos posteriores sob o efeito nas propriedades da liga com a adição de $\mathrm{Cu}$ e de Zr resultaram no desenvolvimento das ligas 7050 e 7010, aumentando a resistência mecânica e a resistência à corrosão sob tensão. Em particular, a liga 7050, composta de Al-Zn-Mg-Cu-Zr foi desenvolvida como propósito de combinar tais propriedades à resistência a fratura e aumento na dureza devido ao uso do $\mathrm{Zr}$ no lugar do $\mathrm{Cr}$ anteriormente utilizado aplicados em seções planas (MIL-Handbook-5J, 2003).

Após o surgimento da liga 7075 e seu posterior desenvolvimento iniciou um ciclo em aplicações especificas devido ao grande desempenho deste material, em destaque para a indústria aeronáutica e aeroespacial. Nas asas das aeronaves existe a necessidade em apresentar uma boa combinação de resistência mecânica com tolerância ao dano e resistência a fadiga, portanto os reforçadores obtiveram uma grande potencial de ganho com a utilização da liga 7085. Para revestimentos superiores aplicam-se projetos com a liga 7050-T74, podendo optar com a utilização da liga 7055T9, com maior disponibilidade no mercado, porém com limitações à espessura.

Devido às formas geométricas que demandam materiais com grandes espessuras, as longarinas das asas são manufaturadas e partir do forjamento, neste caso com a liga 7085-T76, em ganho à resistência mecânica e a tenacidade a fratura.

Os revestimentos da fuselagem utilizam-se as ligas 7075-T6, 7050-T7 e 7475-T6. Os painéis e armações da fuselagem, as ligas 7075-T6 e 7050T6. Nos revestimentos inferiores das asas, as ligas 7475-T73. Em nervuras e longarinas, as ligas 7010-T76, 7150-T77 e na empenagem (cauda): utilizamse as ligas 7075-T6, 7050-T76.

Para ligas 7050 , as especificações dos materiais estão correlacionadas com o método de conformação pelas normas da Aerospace Materials Standards - SAE International, como exemplo, para a confecção de chapas sem revestimento a liga 7050 AMS4050 e AMS4201, para perfis extrudados a AMS4340, AMS4341 e AMS4342 e para forjados AMS4108, 
AMS-A-22771 e para forjados em matriz a AMS4107 e AMS4333 (MILHandbook-5J, 2003).

\subsection{Propriedades de corrosão das ligas de alumínio}

A capacidade do alumínio em proteger da corrosão deve-se ao fato de ser um material de alta reatividade com o oxigênio que forma uma camada passivante, não permitindo que os elétrons produzidos por reação de oxidação atinjam a interface entre o óxido e o meio, evitando que ocorram reações catódicas (ASM Metals Handbook, 1990).

Para aplicações práticas, o alumínio sempre possui elementos de liga tais como $\mathrm{Cu}, \mathrm{Mg}, \mathrm{Mn}, \mathrm{Zn}$, $\mathrm{Li}$ e $\mathrm{Si}$ com a finalidade de aumentar sua resistência especifica. Entretanto, estes elementos formam compostos intermetálicos, os quais têm um efeito prejudicial às propriedades de corrosão do material, devido à formação de um filme óxido mais fino e mais condutor que permite que reações catódicas ocorram (Van Horn, 1967). A figura 2 apresenta uma representação esquemática de como estas reações ocorrem. Próximo às partículas intermetálicas, reações catódicas ocorrem, resultando num aumento do $\mathrm{pH}$ da solução ao redor. Os ânions hidroxila $(\mathrm{OH}-)$ que se formam dissolvem o filme de óxido, expondo o metal e permitindo que o processo de oxidação prossiga.

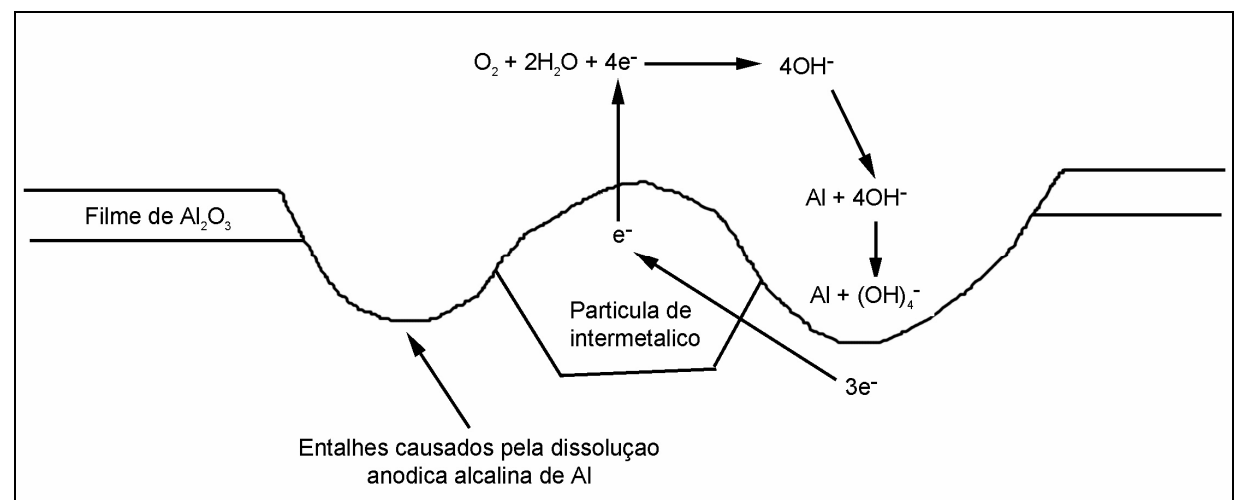

Figura 2: Diagrama ilustrando o processo de corrosão em ligas de alumínio (Van Horn, 1967). 
Por apresentar o cobre como elemento principal, as ligas de alumínio série 2xxx estão susceptíveis a corrosão em relação a ligas de outras séries. A formação de intermetálicos precipitados $\mathrm{Al}_{6}(\mathrm{Cu}, \mathrm{Fe}, \mathrm{Mn})$ e $\mathrm{Al}_{2} \mathrm{CuMg}$ promove a formação de pittings, corrosão intergranular e esfoliações, pois estas partículas possuem potenciais diferentes da matriz formando células galvânicas localizadas (Wei et al., 1998; Liao et al., 1998).

Devido à maior mudança de potencial do eletrodo com variações na quantidade de cobre na solução sólida e, sob mesmas condições, a presença de não uniformidade na solução sólida os efeitos eletroquímicos podem ser maiores na liga 2xxx que nas ligas 7xxx, devido à criação de células galvânicas pela formação de minúsculas partículas de cobre ou filmes depositados na superfície da liga como resultado de corrosão. Iniciado um processo de corrosão, os íons de cobre, que anteriormente se encontravam na liga, formam uma cobertura no material, dando origem a um cátodo metálico. A redução de íons cobre e o aumento da eficiência da reação de redução de $\mathrm{O}_{2}$ e $\mathrm{H}^{+}$acelera a taxa de corrosão (Hollingsworth e Hunsicker, 1987).

A localização da passagem anódica nas ligas da série 2xxx está uma faixa estreita, pobre em $\mathrm{Cu}$, de cada lado do contorno de grão, diferentemente das ligas da série $7 x x x$ sem cobre, onde ela se localiza nos constituintes anódicos de $\mathrm{Zn}$ e $\mathrm{Mg}$ nos contornos de grão (Robinson e Hunter, 1972). Galvele e Micheli (1970) mostraram que a zona pobre em Cu ao longo do contorno de grão é responsável pela corrosão intergranular em uma liga Al-Cu.

Processos que envolvem mudanças microestruturais tais como tratamentos térmicos, termomecânicos ou de soldagem afetam as propriedades de corrosão dos materiais. Para liga de alumínio 5454, amostras soldadas por friç̧ão exibiram maior resistência à corrosão por pitting em solução salina de $\mathrm{NaCl}$ do que o metal base (Frankel e Xia, 1999).

Por outro lado, alguns estudos sobre corrosão na liga de alumínio 2024-T3 soldado por friç̧ão indicam que a zona da solda é mais susceptível à corrosão do que o material de base. Investigações iniciais feitas por Biallas et al. (1999) propuseram que o ataque preferencial se dava sobre a zona termomecanicamente afetada (ZTMA), porém Hannour et al. (2000) 
verificaram que a corrosão intergranular se dá predominantemente na região da zona termicamente afetada (ZTA) adjacente à ZTMA. Além disto, a área de corrosão apresenta a maior atividade eletroquímica (maior densidade de corrente e menor potencial de pitting), sendo que o ataque corrosivo nestas ligas é intergranular (Hannour et al., 2000). Estudos feitos por Lumsden et al. (1999) e Hannour et al. (2000), em ligas da série 7xxxx soldadas por fricção mostraram um ataque corrosivo intergranular preferencial na ZTA; este resultado foi justificado em função do empobrecimento de cobre ao longo do contorno de grão, aumento do tamanho de partículas de segunda fase e aumento da largura da zona livre de precipitados nos contornos de grão.

Alguns pesquisadores concentraram seus estudos em tratamentos superficiais visando aumentar a resistência à corrosão das ligas de alumínio. Experimentos usando feixe de íons demonstraram que este tratamento também pode melhorar significativamente as propriedades de corrosão de várias ligas de alumínio, entre elas 7075-T6 e 2024-T3 (Bystritskii et al., 1999). Hannour et al. (2001), demonstraram que, para as ligas 2024-T351 e 7010-T7651 soldadas por friç̧ão, um tratamento superficial a laser resultou em uma microestrutura refinada na região de solda. As altas taxas de resfriamento mantêm os elementos em solução sólida diminuindo consideravelmente a susceptibilidade ao ataque corrosivo. Além disto, as soldas tratadas a laser demonstraram resistência superior ao ataque anódico, menor densidade de corrente catódica e maior potencial de pitting quando comparadas às soldas não-tratadas.

Outro problema que pode acontecer em ligas de Al na presença de meios de íons cloreto é o fenômeno de corrosão sob tensão. Este é um fenômeno que ocorre pela conjunção simultânea de três fatores: suscetibilidade do material, tensões de tração acima de um determinado valor e meio ambiente propício. Sendo assim, a composição da liga e sua microestrutura tem um grande efeito na susceptibilidade do material.

Alguns fatores relativos ao meio devem ser considerados, tais como: $\mathrm{pH}$, temperatura, potencial eletroquímico, elementos em solução bem como a sua concentração e a concentração de oxigênio, sendo que a em ligas de Al pode ocorrer em diferentes meios, variando desde água condensada até soluções salinas. Concluindo que a corrosão sob tensão ocorre somente às 
ligas de Al que são possíveis de serem envelhecidas e que contenham elementos solubilizáveis tais como: $\mathrm{Cu}, \mathrm{Zn}, \mathrm{Mg}$ e $\mathrm{Si}$, sendo assim este fenômeno fortemente dependente da composição química.

\subsection{Microestrutura das ligas de alumínio trabalháveis}

A partir de lingotes fundidos as ligas de alumínio trabalháveis são convencionalmente produzidas, e todos os processos mecânicos e térmicos subseqüentes representam graus variados de mudança na estrutura bruta de fundição (Braga, 2010).

Cada classe de ligas de alumínio representa um tipo diferente de microestrutura por causa das diferenças dos elementos de liga. Nas ligas 7xxx (alumínio-zinco), o zinco, sozinho, é altamente solúvel no alumínio e não exerce influência apreciável na microestrutura de uma liga simples. No entanto, a classe de ligas encontrada mais freqüentemente contém magnésio e cobre, assim como aditivos como o cromo, manganês ou zircônio, e os sempre presentes ferro e silício. Na forma de lingotes, a liga 7075 forma um ou mais variantes do $(\mathrm{Fe}, \mathrm{Cr})_{3} \mathrm{SiAl}_{12}, \mathrm{Mg}_{2} \mathrm{Si}$, e um eutético pseudobinário constituído de alumínio e $\mathrm{MgZn}_{2}$. Esta última fase contém alumínio somado ao cobre como um substituto para o zinco e pode ser escrita como $\mathrm{Mg}(\mathrm{Zn}, \mathrm{Cu}, \mathrm{Al})_{2}$. Aquecimento subseqüente causa a transformação das fases ricas em ferro em $\mathrm{Al}_{7} \mathrm{Cu}_{2} \mathrm{Fe}$. O $\mathrm{Mg}_{2} \mathrm{Si}$ é relativamente insolúvel e tende um pouco a esferoidizar; o $\mathrm{Mg}(\mathrm{Zn}, \mathrm{Cu}, \mathrm{Al})_{2}$ rapidamente começa a dissolver-se, e ao mesmo tempo há precipitação de $\mathrm{Al}_{2} \mathrm{CuMg}$, o que requer altas temperaturas e encharque lento para dissolverse completamente. $\mathrm{O}$ cromo é precipitado da solução supersaturada como um dispersóide $\mathrm{Cr}_{2} \mathrm{Mg}_{3} \mathrm{Al}_{18}$, bastante concentrado nas regiões dendríticas primárias. Uma liga trabalhada bem solubilizada contém apenas $\mathrm{Al}_{7} \mathrm{Cu}_{2} \mathrm{Fe}$, ( $\mathrm{Fe} \mathrm{Cr})_{3} \mathrm{SiAl}_{12}$ e $\mathrm{Mg}_{2} \mathrm{Si}$ junto com o dispersóide (Braga, 2010).

Grãos recristalizados são extremamente alongados ou achatados devido ao bandeamento do dispersóide, e não raro se encontram regiões não recristalizadas, mesmo em chapas finas. As regiões não recristalizadas são constituídas de subgrãos muito finos, nos quais os contornos são 
decorados por precipitados endurecedores. Isto é mais óbvio em estruturas trabalhadas a quente, especialmente nas regiões mais trabalhadas próximas à superfície, onde a deformação acima da deformação crítica pode ter causado formação de grãos recristalizados grosseiros. Os dispersóides inibem a recristalização e a formação rápida de estruturas finas de subgrãos. $\mathrm{O} \mathrm{ZrAl}_{3}$ é coerente com a matriz, e tem efeitos similares. O recozimento em ligas tratáveis termicamente tem um propósito duplo: primeiro, a remoção do trabalho a frio residual equivalente e segundo a precipitação de soluto da solução sólida. Este último é conseguido por um esfriamento lento controlado e resulta em uma distribuição aleatória de precipitados. A presença dessa precipitação densa torna a estrutura de grãos de ligas com têmpera $O$ difícil de revelar. Outras ligas $7 x x x$ de alta e moderada resistência representam variantes da liga 7075 (Davis, 1993).

\subsection{Composição e propriedades da liga AA7050-T7451}

Definição da liga AA7050-T7451 pela SAE International-MAS:

Composição: $\mathrm{AlZn}{ }_{6} \mathrm{CuMgZr}$ sendo:

\%Wt: $\mathrm{Al}-87,3$ a $90,3 \%$.

$$
\begin{aligned}
& \text { Zn - 5,7 a } 6,7 \% . \\
& \text { Cu - } 2 \text { a } 2,6 \% . \\
& \text { Fe - máximo de } 0,15 \% . \\
& \text { Si - máximo de } 0,12 \% . \\
& \text { Zr - 0,08 a } 0,15 \% . \\
& \text { Mn - máximo de } 0,1 \% . \\
& \text { Ti - máximo de } 0,06 \% \text {. } \\
& \text { Cr no máximo de } 0,04 \% \text {. }
\end{aligned}
$$

Densidade: $2,83 \mathrm{~g} / \mathrm{cm}^{3}$.

Dureza Brinell: 132 em carga de $500 \mathrm{~kg}$ e esfera de $10 \mathrm{~mm}$.

Limite de resistência à tração: $524 \mathrm{MPa}$.

Módulo de elasticidade: 71,7 GPa.

Limite de resistência ao cisalhamento: $303 \mathrm{MPa}$.

Limite de escoamento: $454 \mathrm{MPa}$ 


\subsection{Laminação}

A laminação é um processo de produção de chapas e folhas que, devido a necessidade de produtos com pequenas espessuras, as tolerâncias e os requerimentos de qualidade ficam mais exigentes, pois tais formas tem grande dificuldade de serem obtidas diretamente da fundição. Adicionalmente na produção das requeridas formas, a deformação por laminação assegura que a microestrutura do produto é ajustada pelo processamento utilizado. As dentritas típicas ou a microestrutura celular grosseira bruta de fundição é efetivamente modificada pela laminação a quente. $O$ processo de recristalização conduz a uma completa reorganização da estrutura. Esta melhoria da microestrutura e propriedades mecânicas é também importante para os produtos industriais tais como as chapas (Oliveira, 2009). As ligas de alumínio oferecem adaptáveis níveis de limite de resistência entre 60 e $350 \mathrm{MPa}$, boa fusibilidade e plasticidade, boa resistência química, versátil possibilidade de tratamentos superficiais e alta condutividade elétrica e térmica (Karhausen e Korhonen, 2003).

A laminação é um processo de transformação mecânica que consiste na redução da seção transversal por compressão do metal, por meio da passagem entre dois cilindros de aço ou ferro fundido com eixos paralelos que giram em torno de si mesmos. Esta seção transversal é retangular e refere-se a produtos laminados planos de alumínio e suas ligas, compreendendo desde chapas grossas com espessuras de $150 \mathrm{~mm}$, usadas em usinas atômicas, até folhas com espessura de 0,005 mm, usadas em condensadores (Oliveira, 2009). Existem dois processos tradicionais de laminação de alumínio: Laminação a quente e laminação a frio. Atualmente, a indústria também utiliza a laminação contínua. A figura 3 mostra os tipos de laminadores utilizados: 


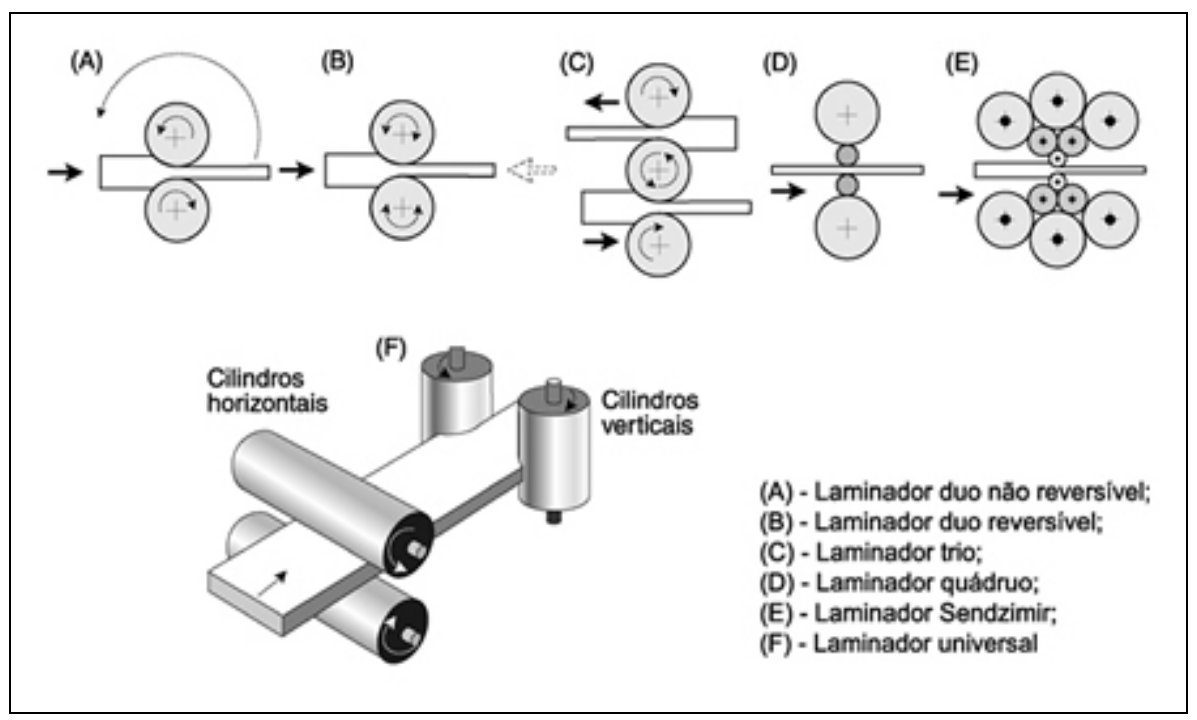

Figura 3: Tipos de laminadores utilizados para laminação (ABAL,2010).

Os principais tipos de produtos laminados são: chapas planas ou bobinadas, folhas e discos. Esses semimanufaturados têm diversas aplicações em setores como transportes (carrocerias para ônibus, equipamentos rodoviários, elementos estruturais, etc.), construção civil (telhas, fachadas, calhas, rufos, etc.), embalagens (latas, descartáveis e flexíveis) e bens de consumo (panelas, utensílios domésticos, etc.) (ABAL, 2010).

\subsection{Laminação a quente}

Neste processo se promove reduções da seção transversal com o metal a uma temperatura mínima de aproximadamente $350^{\circ} \mathrm{C}$ (igual à temperatura de recristalização do alumínio). A ductilidade do metal a temperaturas desta ordem é máxima $e$, nesse processo ocorre a recristalização dinâmica na deformação plástica. (ABAL, 2010). O processo transcorre da seguinte forma:

Uma placa (matéria-prima inicial), cujo peso varia de alguns quilos até 15 toneladas, é produzida na refusão, por meio de fundição semicontínua, em molde com seção transversal retangular. (Este tipo de fundição assegura a solidificação rápida e estrutura homogênea). A placa pode sofrer uma 
usinagem superficial (faceamento) para remoção da camada de óxido de alumínio, dos grãos colunares (primeiro material solidificado) e das impurezas provenientes da fundição.

Posteriormente, a placa é aquecida até tornar-se semiplástica.

A laminação a quente se processa em laminadores reversíveis duplos (dois cilindros) ou quádruplos (dois cilindros de trabalho e dois de apoio ou encosto).

O material laminado é deslocado, a cada passada, por entre os cilindros, sendo que a abertura dos mesmos define a espessura do passe. A redução da espessura por passe é de aproximadamente $50 \%$ e depende da dureza da liga que está sendo laminada. No último passe de laminação, o material apresenta-se com espessura ao redor de $6 \mathrm{~mm}$, sendo enrolado ou cortado em chapas planas, constituindo-se na matéria-prima para o processo de laminação a frio (ABAL, 2010).

A figura 4 mostra as etapas para a realização da laminação a quente.

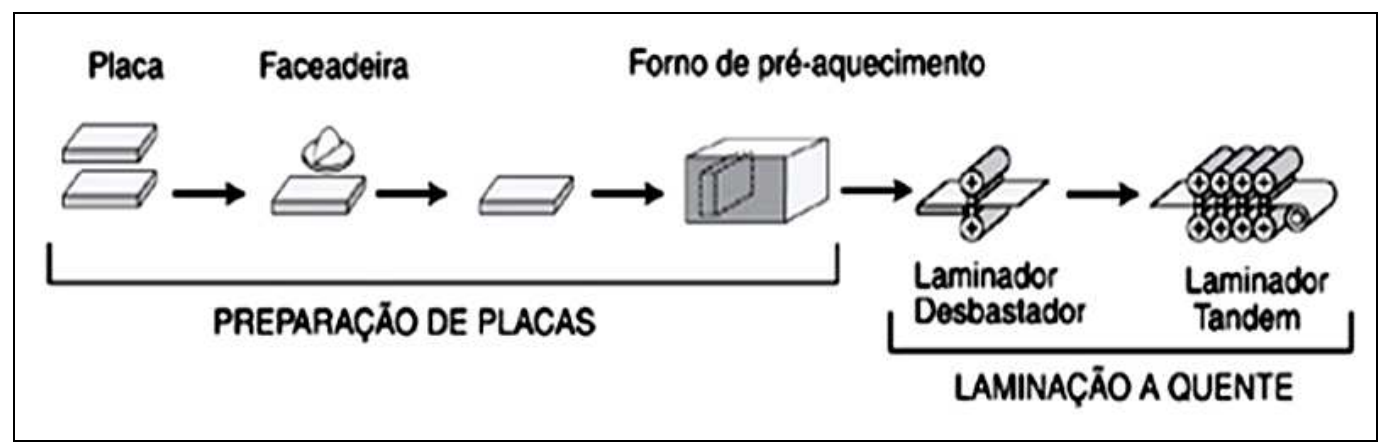

Figura 4: Etapas da laminação a quente (ABAL,2010).

Concepções mais modernas do processo de laminação a quente podem apresentar em linha, após o desbastamento, em um laminador reversível, uma cadeia de vários laminadores, denominada de "tandem", que reduz a espessura do material para cerca de $2 \mathrm{~mm}$.

Uma unidade de laminação a quente contém: laminador, refusão (unidade de fundição de placas), fornos de pré-aquecimento para placas, tratamentos térmicos de homogeneização (distribuição mais homogênea dos elementos microconstituintes químico-metalúrgicos), tesouras rotativas e 
guilhotinas para cortes laterais e longitudinais do material laminado, serras para cortes das extremidades e faceadeira para usinagem das superfícies (Oliveira, 2009).

Em alumínio de alta pureza, a mobilidade do contorno de grão é alta e o material além de se recuperar dinamicamente apresenta recristalização durante o processamento (Ponge et al.,1997). Em ligas industriais comumente utilizadas, a recristalização dinâmica pode ser observada em temperaturas extremamente altas, onde o efeito é causado principalmente pelo excesso local de contornos de grãos e não pela nucleação e crescimento. Para estes materiais, a recristalização ocorre tipicamente entre as caldeiras de laminação ou após a laminação em elevadas temperaturas (Oliveira, 2009). Na prática industrial, a estrutura recristalizada pode ser obtida separadamente num tratamento de recozimento, porém tecnologias mais sofisticadas utilizam o auto-recozimento durante o bobinamento na temperatura de laminação (Karhausen e Korhonen, 2003).

A laminação a quente é o processo dominante na cadeia de produção de tiras e chapas finas de alumínio induzindo heterogeneidades microestruturais no produto final. A laminação descontínua em um laminador reversível causa heterogeneidades ao longo da direção de laminação. $O$ tempo de demora entre a ponta e a cauda aumenta continuamente de modo que para alguns passes, a placa pode recristalizar parcialmente se nenhuma precaução for tomada. Especialmente, nos passes de desbaste, a deformação é caracterizada por grandes gradientes na taxa de deformação $\mathrm{e}$ as heterogeneidades na largura podem tornar-se severas quando operando em baixas velocidades (Oliveira, 2009). O layout e otimização de tais sistemas de interações complexas só podem ser executados se a microestrutura puder ser quantificada em todos os estágios de processamento. Assim, modelos que fazem tais previsões são essenciais para esta tarefa e é assunto principal dos esforços na indústria do alumínio. (Sellars, 1990; Riahifar e Serajzadeh, 2007) 


\subsection{Laminação a frio}

Realiza-se a temperaturas bem inferiores às de recristalização do alumínio. A matéria-prima é oriunda da laminação a quente. A laminação a frio é executada, geralmente, em laminadores quádruplos, reversíveis ou não, sendo este último mais empregado. O número de passes depende da espessura inicial da matéria-prima, da espessura final, da liga e da têmpera do produto desejado. Os laminadores estão dimensionados para reduções de seções entre $30 \%$ e $70 \%$ por passe, dependendo, também, das características do material em questão. Laminadores mais sofisticados possuem sistemas computadorizados de controle de espessura e de planicidade. Na laminação a frio utilizam-se dois recursos: tensões avante e tensões a ré (Oliveira, 2009).

Ambas aliviam o esforço de compressão exercido pelos cilindros ou aumentam a capacidade de redução por passe. Estes recursos são também responsáveis pela redução da espessura no caso de laminação de folhas finas, em que os cilindros de laminação estão em contato e praticamente sem abertura perceptível (ABAL, 2010).

A figura 5 mostra as etapas para a realização da laminação a frio.

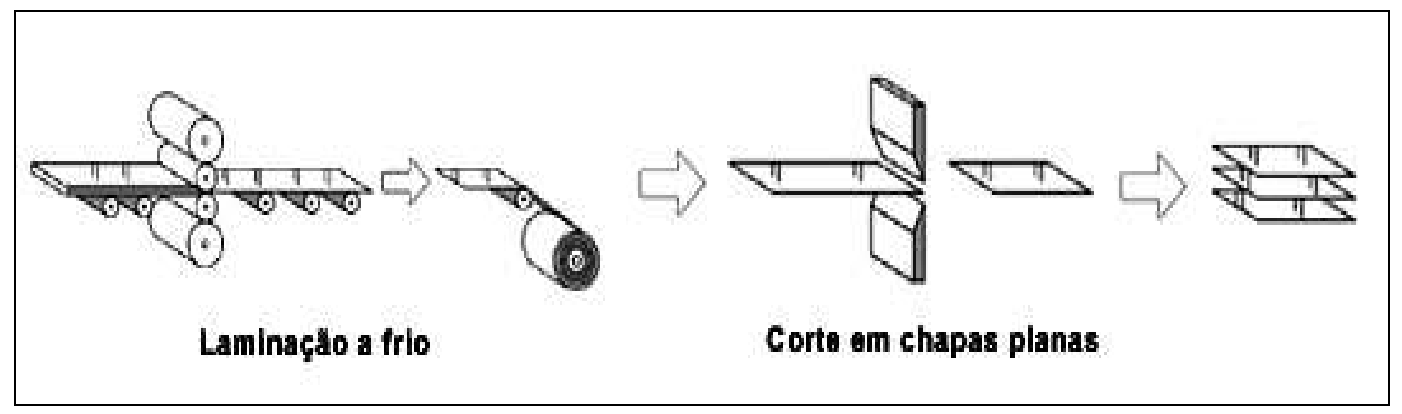

Figura 5: Etapas da laminação a frio (ABAL,2010).

A deformação a frio confere encruamento ao alumínio. Aumenta os limites de resistência à tração e ao escoamento, com diminuição do alongamento. Esse procedimento produz um metal com bom acabamento superficial e preciso controle dimensional. 
Os produtos laminados de alumínio são utilizados em todas as operações metalúrgicas usuais de chapas, incluindo aquelas que exigem do metal de excepcional ductilidade, como é o caso de processos como estampagem, extrusão por impacto, perfilação, etc. Recozimentos intermediários podem ser realizados para amolecimento (recristalização) e para facilitar posterior laminação ou determinar têmperas específicas (Oliveira, 2009).

Os produtos laminados a frio mais finos (folhas), com espessura de até $0,005 \mathrm{~mm}$, são produzidos em laminadores específicos, que concebem o processo de laminação de folhas duplas com lubrificação entre elas (ABAL, 2010).

Outro processo atualmente utilizado é o da laminação contínua que elimina a etapa de laminação a quente. O alumínio é solidificado entre dois cilindros refrigerados internamente por água, que giram em torno de seus eixos, produzindo uma chapa com seção retangular. Posteriormente, esta chapa é enrolada, obtendo-se assim um produto similar àquele obtido por laminação a quente. Porém, este produto apresentará uma estrutura bruta de fusão bastante refinada, dada a alta eficiência do refinador de grão utilizado no vazamento (ABAL, 2010).

A figura 6 mostra o processo de laminação contínua.

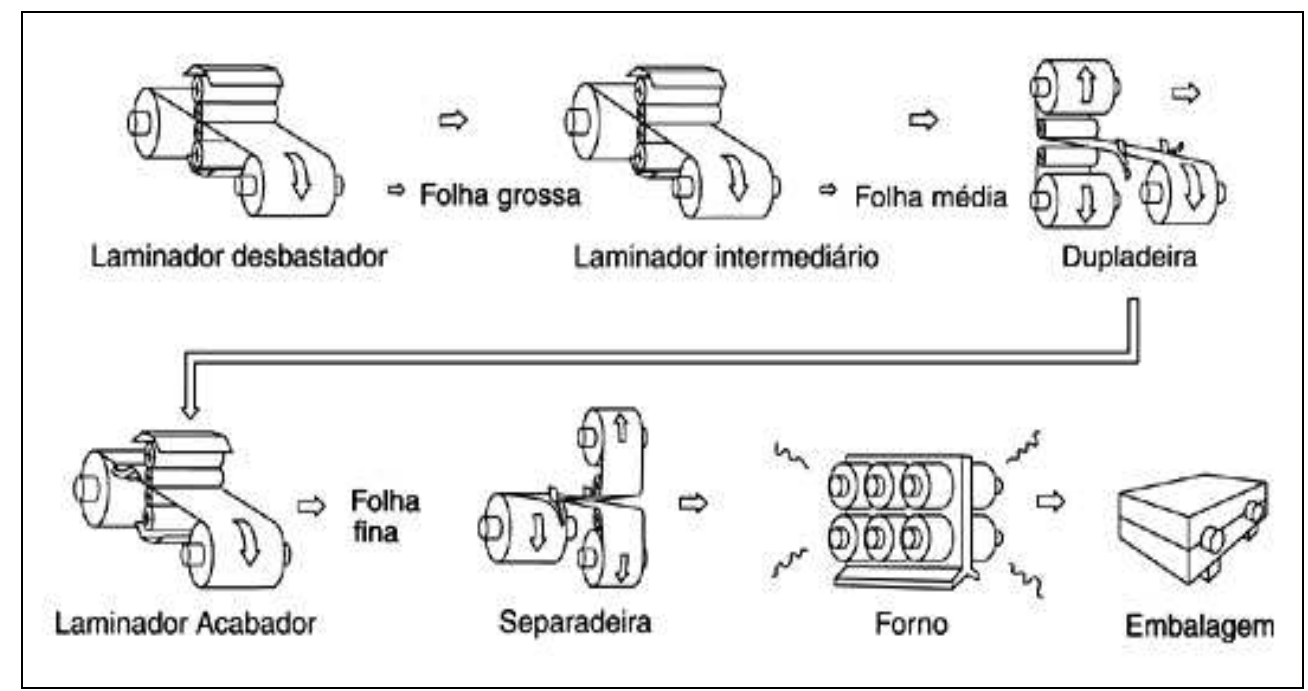

Figura 6: Laminação contínua (ABAL,2010). 


\subsection{Shot Peening}

Shot peening é um processo de trabalho a frio que consiste no jateamento repetitivo com esferas de aço, cerâmica ou vidro, na superfície das peças, e tem enorme importância na área industrial, ilustrado pela figura 7.

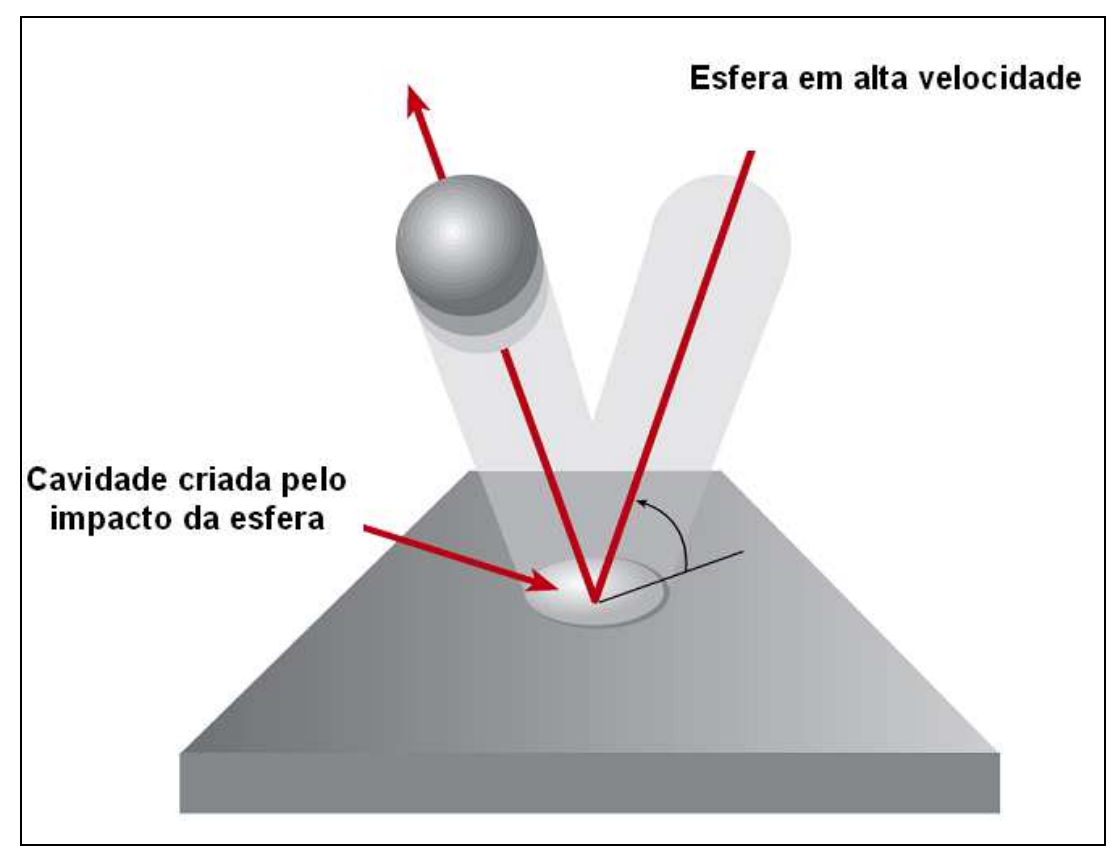

Figura 7: Demonstração do impacto da esfera sobre uma superfície (MIC, 2006)

A utilização do termo shot peening é universalmente aceito e decorre da intenção de caracterizar que não se trata de um simples jateamento, mas de uma ferramenta de precisão, decorrente de uma série de fatores, o que o torna rigorosamente controlável e repetível (Camargo, 2007).

O processo de shot peening é largamente empregado com uma série de objetivos: aumento da resistência à fadiga, uniformização de tensões nas camadas superficiais, compactação da estrutura cristalina para aumentar a resistência à oxidação, ao atrito e eliminar porosidades, obtenção de rugosidades controladas para reter lubrificação, fixar desmoldantes, etc. (Torres, 2002; Guagliano e Vergani, 2004; Wang e Wang, 1998).

Outro fator a ser estudado é o fenômeno do fechamento de trincas aplicado na maioria dos materiais de engenharia, tendo em vista o reconhecimento de que se trata de uma importante influência no comportamento de fadiga dos materiais. 
As modificações na superfície induzidas pelo processo de shot peening são a superfície rugosa; o aumento da dureza nas camadas superficiais e o perfil característico de tensão residual. Considerando os danos para a fadiga, a superfície rugosa acelera a nucleação e a propagação das trincas; porém, acontece um retardo no crescimento devido ao aumento da dureza e do perfil de tensão residual, que provoca uma tensão de fechamento da trinca (Curtis et al 2003).

A melhor condição do shot peening para aumentar a resistência à fadiga depende de variáveis como o aumento das tensões compressivas induzidas durante o processo; as condições de superfície criadas pelo shot peening e a possibilidade do campo de tensões residuais compressivas (CTRC) para deslocar a nucleação da trinca para baixo da superfície (Torres e Voorwald, 2002).

De maneira geral, as tensões residuais compressivas, localizadas na superfície, são benéficas, pois retardam ou impedem a abertura e o avanço de trincas de fadiga (Song e Wen,1999).

Após o impacto, o material é deformado plasticamente na região superficial, tendendo a alongar-se. Esta tendência ao alongamento é impedida pela parte inferior, que se deforma apenas elasticamente, gerando tensões de compressão nas camadas afetadas plasticamente (Diepart, 1994), conforme demonstrado na figura 8 :

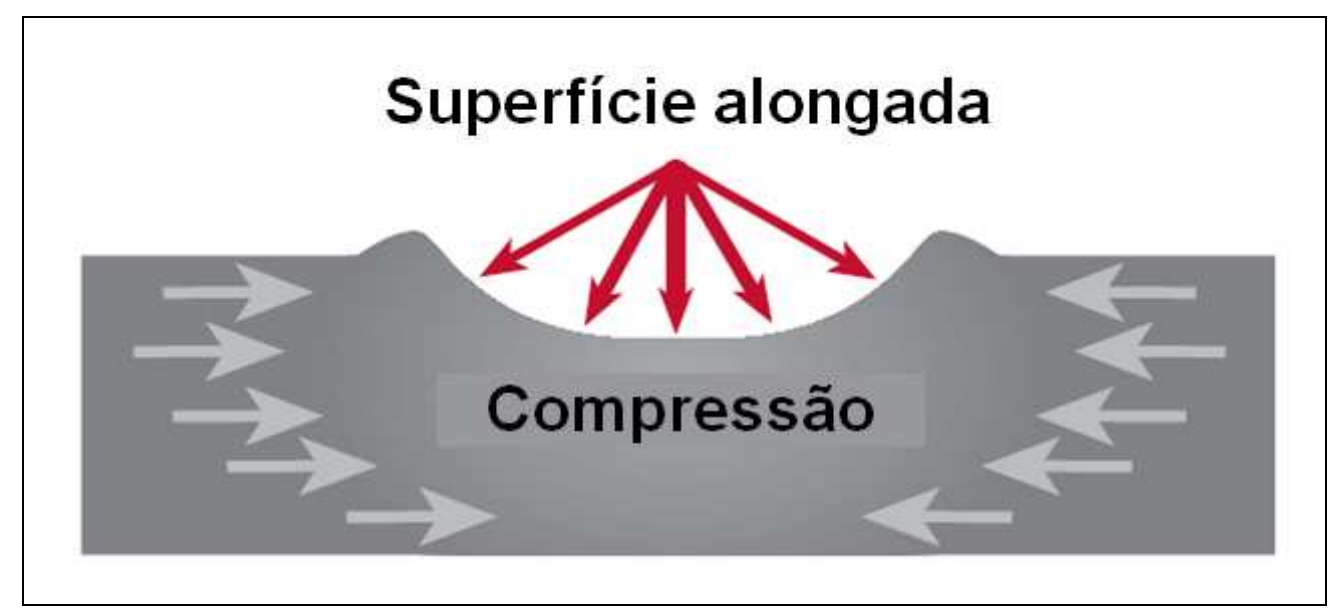

Figura 8: Distribuição de tensões após a aplicação do shot peening (MIC, 2006) 
Os impactos repetitivos das esferas produzem uma distribuição de tensões que variam com a profundidade da peça, além disso, o impacto a altas velocidades produz indentações na superfície do material, resultando no aumento da rugosidade superficial, o que proporciona a redução da resistência a fadiga dos componentes tratados (Sharp et al, 1994). Curtis (2003) concluiu que o desempenho do material após shot peening depende do compromisso entre os efeitos benéficos da tensão residual compressiva com os efeitos deletérios da rugosidade superficial. Isto proporciona um estudo relacionado aos pontos de concentração de tensão na superfície do material. O aumento destes pontos reflete na disposição do material a menor resistência corrosão sob tensão e conseqüentemente a redução a resistência a fadiga. A relação aplicada às medidas de fator de concentração de tensão (Kt), segundo Li et al (1992), é descrita por:

$$
k_{t}=1+2.1\left(\frac{R_{t}}{S}\right)
$$

onde:

$R_{t}$ é a medida pico-a-vale, sendo a rugosidade média dos 10 maiores valores obtidos pelo rugosímetro $\left(R_{z}\right)$ e $S$ é a medida entre os picos, que é o diâmetro de indentação da granalha sobre a amostra. A figura 9 apresenta um perfil típico de tensões induzidas pelo processo de shot peening (Torres, 2002). 


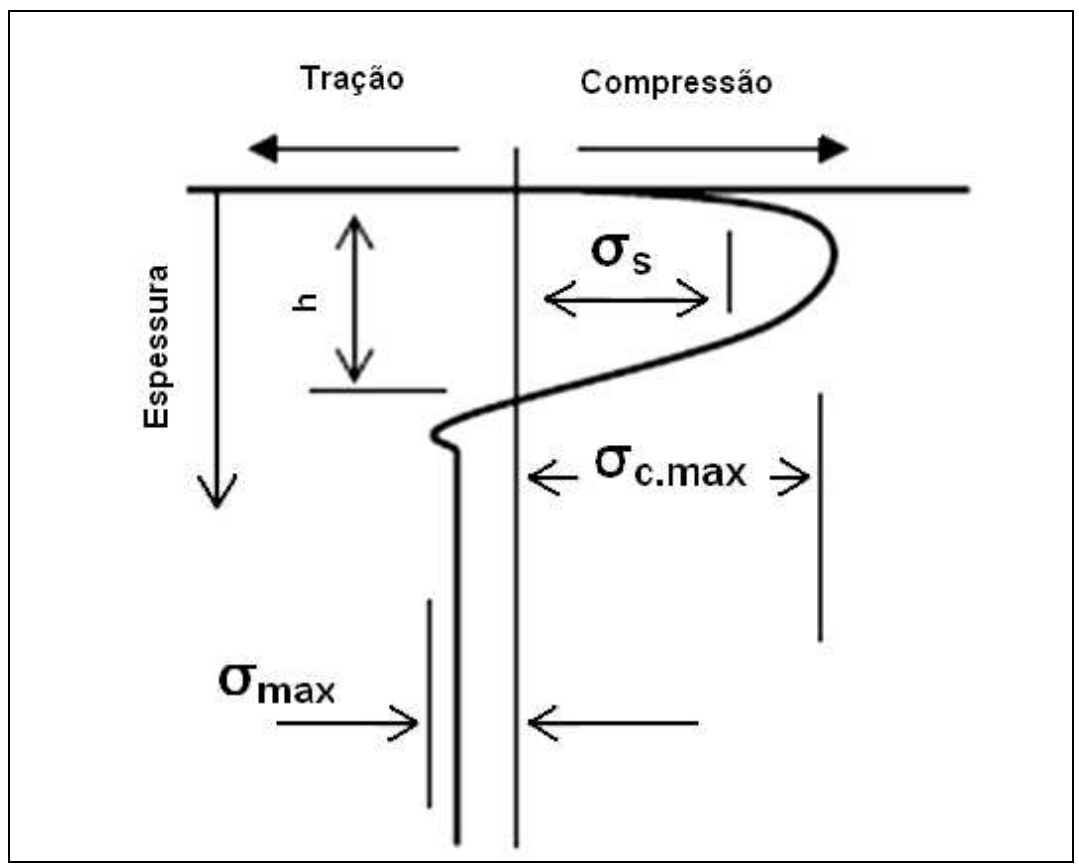

Figura 9: Perfil típico de tensões residuais (Torres, 2002).

onde:

$\sigma_{\mathbf{s}}$ é a tensão superficial; $\sigma_{\max }$ é a tensão máxima de tração; $\sigma_{\text {c.max }}$ é a tensão máxima de compressão e $\mathbf{h}$ a profundidade de inversão de tensão.

Os parâmetros que influenciam na eficiência do processo de shot peening podem ser divididos em três diferentes classes, cada uma delas associada às condições experimentais específicas:

Parâmetros do material: geometria e propriedades mecânicas;

Parâmetros de fluxo: propriedades da esfera (tipo, tamanho, material, massa específica, dureza, etc.), velocidade, ângulo de impacto, duração e distância do jateamento ao material tratado;

Parâmetros de contato: coeficiente de fricção e o coeficiente de restituição, que dependem da razão entre a dureza do material tratado e da esfera usada.

\subsection{Variáveis do processo de shot peening}

A superfície de cobertura é definida pela porcentagem de uma determinada área atingida pelas esferas. Uma relação entre cobertura e o 
número de ciclos de exposição pode ser expresso pela equação: (Torres, 2002);

$C_{n}=1-\left(1-C_{1}\right)^{n}$

onde:

$\mathrm{C}_{1}$ é a porcentagem de cobertura (decimal) após o $1^{\circ}$ ciclo (passe);

$\mathrm{C}_{\mathrm{n}}$ é a porcentagem de cobertura (decimal) após $\mathrm{n}$ ciclos, onde $\mathbf{n}$ é o número de ciclos do tratamento.

Embora o valor limite para a cobertura seja de 100\%, na prática, devido às dificuldades de mensuração, adota-se o valor de $98 \%$ como cobertura total.

O controle da intensidade do shot peening é realizado com a utilização das "placas de Almen", produzidas em aço SAE 1070, que são colocadas ao lado do material tratado, recebendo o mesmo tratamento da peça submetida ao processo (Camargo, 2007). O impacto das esferas induz tensões residuais nas placas, que se deformam, formando um pequeno arqueamento. $\mathrm{O}$ valor da medida da flecha produzida na placa de Almen é comparado com uma tabela na qual se obtém a intensidade Almen, que é uma referência utilizada no controle do processo e seu valor torna-se apropriado para ajustar diversos parâmetros envolvidos (Herzog, 1996).

Existem três padrões de placa Almen no uso corrente: "N", "A" e "C". A diferença de cada uma está na sua espessura. As relações das espessuras aproximadas entre elas são: $3 N=A=0,3 C$. A especificação da intensidade Almen deve incluir tanto a deformação ocorrida na placa (pol.), como o tipo de placa usada (Torres, 2002; Camargo, 2007).

O processo de shot peening atinge uma situação de saturação, quando, a partir de certo tempo, a intensidade do peening pouco ou nada afeta a deformação causada na placa Almen. Esse ponto de saturação praticamente coincide com uma cobertura de $98 \%$.

Em algumas operações são exigidas coberturas de $150 \%$ ou $200 \%$, o que nada mais é do que utilizar tempos iguais a $1,5 \mathrm{t}$ ou $2 \mathrm{t}$ respectivamente (Torres, 2002). 


\subsection{Esferas utilizadas no shot peening}

As esferas mais utilizadas no processo de jateamento são:

Ferro fundido, que são quebradiças e possuem uma dureza que varia de 58 a 68 HRC;

Aço fundido com dureza entre $40 \mathrm{HRC}$ a $50 \mathrm{HRC}$;

Esferas de vidro e cerâmica, que são normalmente utilizadas para materiais que podem ser contaminados pelo jateamento de partículas esféricas de aço e/ou ferro fundido, sua dureza está entre $46 \mathrm{HRC}$ a $50 \mathrm{HRC}$ e $58 \mathrm{HRC}$ a $63 \mathrm{HRC}$, respectivamente, podendo ser usadas em processos úmidos e secos.

O tamanho das esferas normalmente abrange um campo de $0.18 \mathrm{~mm}$ a 2,4 mm de diâmetro (Camargo, 2007).

As variações na dureza da esfera usada não afetam a intensidade do shot peening, desde que sejam mais duras do que o elemento que receba $o$ tratamento. Por outro lado, se a dureza do material a ser tratado for maior do que a da esfera, então pode haver uma diminuição na intensidade (Cao et al, 1995).

\subsection{Velocidade da esfera}

O aumento da velocidade das esferas faz com que aumente a intensidade do shot peening. Porém o controle da velocidade é um fator necessário a fim de evitar o desgaste e/ou a quebra das esferas usadas no processo (Torres, 2002), além de proporcionar efeitos indesejáveis no resultado final na superfície da amostra.

\subsection{6 Ângulo de impacto}

Por definição, o ângulo de impacto é um ângulo de $90^{\circ}$ ou menor entre a superfície da peça tratada e a direção da rajada. Quanto menor for o ângulo de impacto, menor será a intensidade de peening. Se o formato da 
peça não permitir um ângulo adequado de impacto, este deverá ser compensado, para a obtenção da intensidade de peening desejada, através da variação de outros fatores, como o tamanho da esfera ou sua velocidade. Além disso, a distância entre o bico ejetor e a superfície da peça também exerce influência na intensidade do shot peening. Quanto maior for à distância, menor serão a intensidade e a cobertura obtidas (Torres, 2002).

\subsection{Peen Forming}

O peen forming é um processo de conformação aplicado à temperatura ambiente por meio do shot peening, cuja combinação do estiramento elástico e da tensão compressiva gerada causa no material uma curvatura convexa na superfície onde ocorreu o shot peening (Kalpakdjian e Schmid, 2001), uma vez necessária o curvamento de uma placa metálica sem destruir sua resiliência provocada pelo uso da laminação convencional, quando ocorre a tentativa de produzir uma dobra em uma placa laminada (Hodges e McGuire, 1957).

O shot peening atuando na superfície de uma placa de metal proporciona energia cinética suficiente para conformar a especifica peça. Este processo é utilizado especificamente para a conformação de painéis de revestimentos das asas de aeronaves. É um processo geralmente de baixo custo, pois não necessita de acabamentos e subseqüentes tratamentos térmicos e uma vez que os parâmetros do processo estão determinados, este é facilmente reprodutível. Isto também é melhor adaptável a modernos designs em aeronaves, como por exemplo, a capacidade de ser aplicado em formas afiladas e partes estruturais, partes simples ou duplamente curvadas. Somando a isso, o peen forming provêm os benefícios do desempenho nos componentes pré formados, os resultados do processo de shot peening (Wang et al, 2006).

As condições que influenciam a tensão residual e a mudança de forma da chapa submetida ao peen forming estão diretamente relacionadas às propriedades do material, sendo que alguns parâmetros deverão ser utilizados para o desenvolvimento do trabalho, tendo em vista que os 
relacionados à intensidade do jateamento são os mais importantes, relativos ao tamanho, velocidade de arremesso, ângulo de impacto, massa e dureza das esferas, tempo de jateamento e fluxo do jato (Braga, 2010).

A massa das esferas será definida pelo tamanho e pela densidade do material empregado e os aspectos físico-metalúrgicos determinam a forma como o impacto entre as esferas e a chapa irá ocorrer.

O ângulo de impacto deverá ser o mais próximo a $90^{\circ}$, sendo que as esferas rebotadas não poderão interferir com o fluxo de esferas incidentes. A velocidade das esferas está em função do tamanho do bocal, pressão do ar e da distância do bocal até a chapa jateada. Deverá ser considerada como parâmetro a densidade de cobertura, sendo que a mesma se relaciona com o tempo de jateamento e o fluxo do jato de esferas, na relação entre a massa de esferas e o tempo transcorrido, devendo para isto, a constância e homogeneidade aplicada à superfície das amostras.

No processo peen forming há três métodos usados para criar curvaturas em painéis. Primeiramente, a curvatura pode ser atingida com o jateamento em apenas uma superfície. (figura 10a). Neste caso, a tensão de compressão na superfície jateada estica o metal, causando a mudança no formato. A limitação desse método de conformação é que ele está apenas no alcance elástico que o movimento pode realizar-se, e, portanto apenas pequenas curvaturas são alcançadas. Para obter maiores graus de curvatura, é usado o jateamento sob tensão (figura 10b), no qual o componente é mantido em uma condição pré-tensionada unidirecional e então é jateado na superfície tensionada. Isso significa que quando o componente é liberado dessa condição tensionada após o jateamento, a tensão compressiva é maior em uma direção que na outra, e é maior na direção da curvatura formada pelo processo de pré-tensão. O terceiro método de peen forming é por jateamento na periferia de ambos os lados de uma região de metal ao mesmo tempo (figura 10c) Isso fornece alongamento do componente causado pelo material esticado nas duas faces, superando a resistência do núcleo em deformação elástica (O’hara, 2002). 


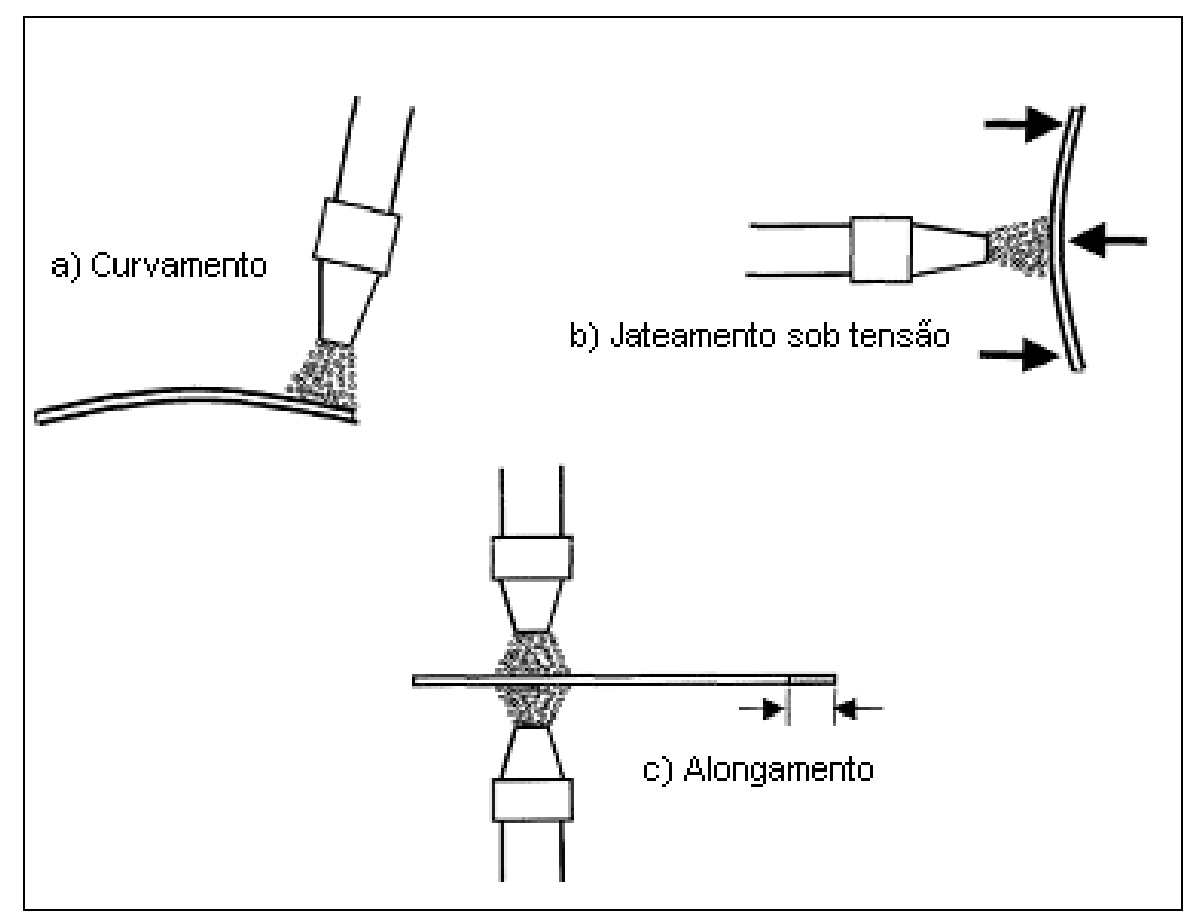

Figura 10: Três métodos para a aplicação do peen forming em uma placa metálica (O'hara, 2002).

\subsection{Tensão residual}

A tensão residual pode ser definida como qualquer tensão remanescente no volume de um material depois de cessada a aplicação de qualquer carga externa, (Almen e Back, 1963; Wulpi, 1985; James e Lu, 1996; Gurova at al., 2006). Diferentemente da tensão aplicada externamente ao corpo cujo efeito pode ser facilmente visualizado, medido e calculado, a tensão residual no material dificilmente pode ser visualizada. A sua medição exige o uso de técnicas especiais e o cálculo ainda tem grau relativo de precisão. Um grão individual ou cristal em um corpo metálico reage à tensão aplicada seja ela externa ou interna ao corpo e mesmo com toda dificuldade de medição da tensão residual, ela deveria ser considerada durante a fase de projeto de um componente ou em análise de falha (Perini, 2008). Existem inúmeros processos cujo único propósito é induzir tensões residuais compressivas e dentre os principais processos, destacam-se o roleteamento, o shot peening e o laser peening. No universo de processos que podem produzir tensões residuais de tração, os mais utilizados pela indústria são: a 
solda elétrica, processos de usinagem em geral, tratamentos térmicos e termoquímicos, a fundição e a conformação a frio e a quente, (Wulpi, 1985).

A tensão residual é descrita em termos de tensões de tração e de compressão. Por convenção, a tensão de tração recebe o sinal positivo $(+\sigma)$ e a de compressão recebe o sinal negativo $(-\sigma)$. Para que ocorra o aparecimento da tensão residual, é necessário que o componente sofra alguma deformação plástica. Por exemplo, supondo que a barra ilustrada na figura 11a está apoiada sobre dois pontos fixos, desprezando-se a ação da gravidade e assumindo que ela esteja livre de qualquer tensão $(\sigma=0)$, aplicase então uma força $(F)$ de igual valor em cada extremidade. Em qualquer ponto situado entre os apoios, a tensão nas fibras externas é constante, sendo de tração $(+\sigma)$ na parte superior e de compressão $(-\sigma)$ na parte inferior. No diagrama de tensão, à direita da figura 11a, é possível ver como a tensão varia ao longo da seção $A-A^{\prime}$, ela atinge seu valor máximo nas superfícies externas, decaindo a zero na linha neutra. Nessa situação, como a força aplicada à barra não foi suficiente para exceder o limite elástico do material, a barra retornara a sua condição inicial $(\sigma=0)$, assim que a força $(F)$ seja retirada. Imagine agora que o valor da força $(F)$ foi elevado até que a tensão na barra ultrapasse o limite de elasticidade do material, não somente nas fibras mais externas, mas a uma profundidade bem razoável. Então, ocorrerá o surgimento da deformação plástica, representado na figura $11 \mathrm{~b}$ pela região hachurada. Contudo, nas fibras, próximo ao centro da barra, o limite de elasticidade ainda não foi excedido e a deformação nesse ponto é apenas elástica. Toda tensão acima da linha neutra, tanto a elástica como a plástica, são de tração $(+\sigma)$ e todas abaixo são de compressão $(-\sigma)$. Quando a força $(F)$ é removida, figura 11c, a tensão elástica contida na barra tenta se liberar forçando a barra a se auto-endireitar (Perini, 2008). Devido à presença da deformação plástica, a ação dessas forças internas não é suficiente para reduzir as tensões à zero, mas são suficientes para inverter a direção das tensões nas regiões deformadas plasticamente. Desse modo, as regiões que durante a ação da força $(F)$ estavam tracionadas $(+\sigma)$, estão agora comprimidas $(-\sigma)$ e as que estavam comprimidas $(-\sigma)$, estão tracionadas $(+\sigma)$, (Cullity e Stock, 2001). Esse princípio da inversão das 
tensões é utilizado por todos os processos mecânicos para tratamento de superfícies que visam aumentar a resistência à fadiga.

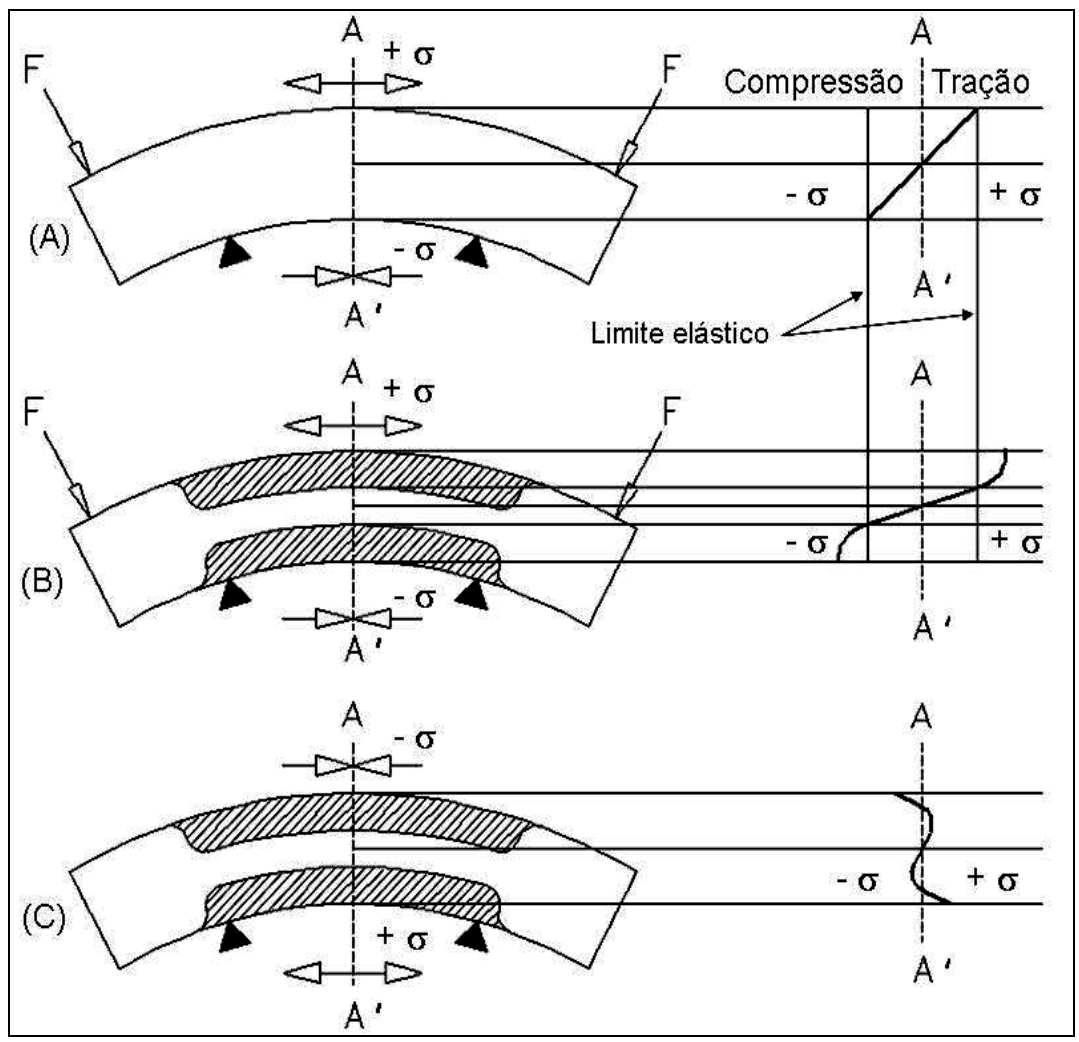

Figura11: Tensão residual induzida pela deformação plástica (Cullity e Stock, 2001).

A tensão residual atua em um sistema balanceado. Isso quer dizer, se uma parte do sistema sofre uma alteração, o resto do sistema se ajusta para manter o balanceamento. Esse ajuste resulta em distorções ou mudanças dimensionais no componente envolvido. A distorção é utilizada para estimar a sua magnitude e a sua direção. A tensão residual tem influência tridimensional nos corpos. Por exemplo, em um eixo, ela existe nas direções longitudinal, tangencial (também chamada de circunferencial) e radial (Perini, 2008). Em uma superfície plana, ela atua nas direções longitudinal, transversal e normal ao plano, (figura 12). Geralmente, as direções radiais e normais ao plano são desprezadas devido a sua baixa influência em causar danos ou benefícios, (Wulpi, 1985). 


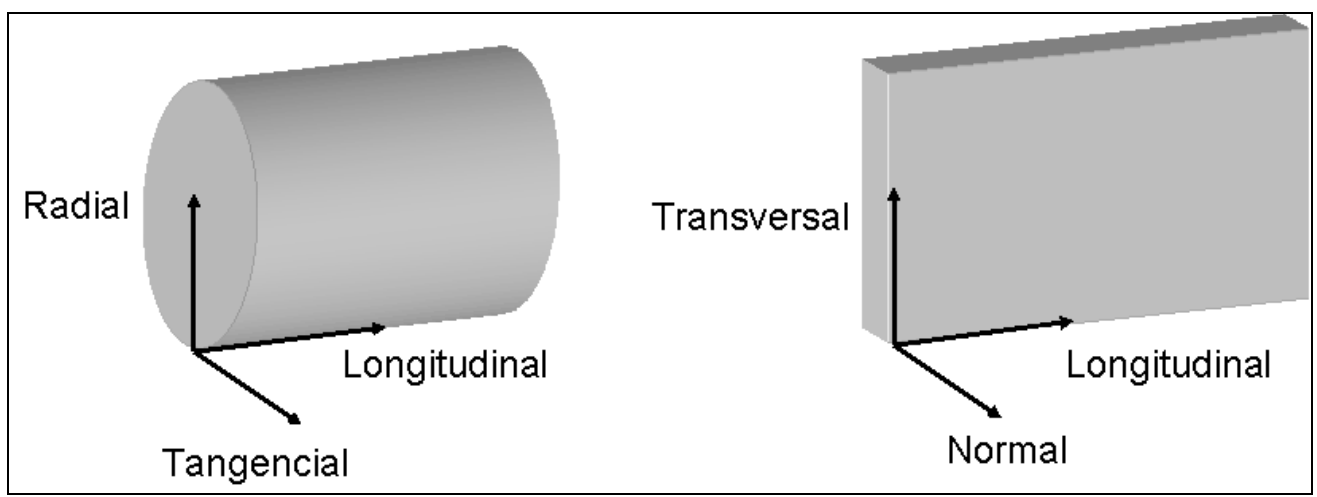

Figura 12: Nomenclatura das direções das tensões em eixos e chapas (Wulpi, 1985).

A tensão residual também pode ser classificada por três escalas de magnitude: macro, intergranular e atômica, (Wulpi, 1985).

Macro: nessa escala está compreendida toda seção transversal da peça. Por exemplo, se existir tensão residual compressiva em uma área próxima a superfície, então, a área próxima ao centro haverá tensão residual de tração, para que haja um balanceamento de forças, (Wulpi, 1985).

Intergranular: essa escala é utilizada para tratar da tensão residual em um grão individual ou grupo de grãos. Os grãos são afetados pelo campo de atuação da macro-tensão no qual estão localizados, mas cada grão está orientado aleatoriamente e seus micro-defeitos diferem dos grãos da vizinhança, (Wulpi, 1985).

Atômico: cada grão do material é composto por uma rede tridimensional de átomos, que é utilizada como um tensor para o cálculo da tensão residual. A distorção nessa rede não pode ser medida individualmente, então ela é tratada estatisticamente pela média, (Wulpi, 1985).

\subsection{Raios-x}

Em 8 de novembro de 1895, o físico alemão Wilhelm Conrad Röentgen acidentalmente descobriu este raio quando fazia experiências com raios catódios. Mais tarde ele os chamou de raios-x por causa de suas propriedades físicas desconhecidas e fez uma importante descoberta: os 
raios são ondas eletromagnéticas, como luz ou onda de rádio, porém se diferem dos raios de luz, porque possuem alta energia fazendo com que penetrem em material sólido. Röentgen apresentou as primeiras fotografias de raios-x: elas mostravam os ossos de uma mão, e causaram uma sensação mundial. A receptividade foi tão grande que foram instalados, por exemplo, equipamentos de raios-x em sapatarias para que os clientes pudessem examinar os seus pés dentro dos sapatos. Em março de 1896, o professor Henrique Morise da Escola Politécnica do Rio de Janeiro produziu as primeiras radiografias no Brasil (UFRGS, 2009).

Os raios-x também são produzidos quando uma substância é bombardeada por elétrons de alta velocidade. A radiação $\mathrm{x}$ é produzida pela conversão da energia cinética desses elétrons em fótons com energias apropriadas (Bottaro, 2007).

Quando um elétron em alta velocidade penetra a superfície de um material, ocorre uma série de interações, onde o elétron normalmente sofre perda de energia em ionizações.

O processo que contribui para a geração do maior número de fótons de radiação é o Bremsstrahlung. Neste processo, elétrons que penetram o material do alvo e passam perto de um núcleo de um átomo do alvo, são defletidos e freados pela força de atração do núcleo. A energia perdida pelo elétron durante esta interação aparece como um fóton de raios-x com freqüência $v$ e energia hv. Em algumas colisões mais raras, pode ocorrer o completo freamento do elétron, dando origem a um fóton de energia igual a energia inicial do elétron.(Johns, 1983). A figura 13 mostra a interação do elétron com um átomo do alvo gerando um fóton de raios- $x$ (Bremsstrahlung). 


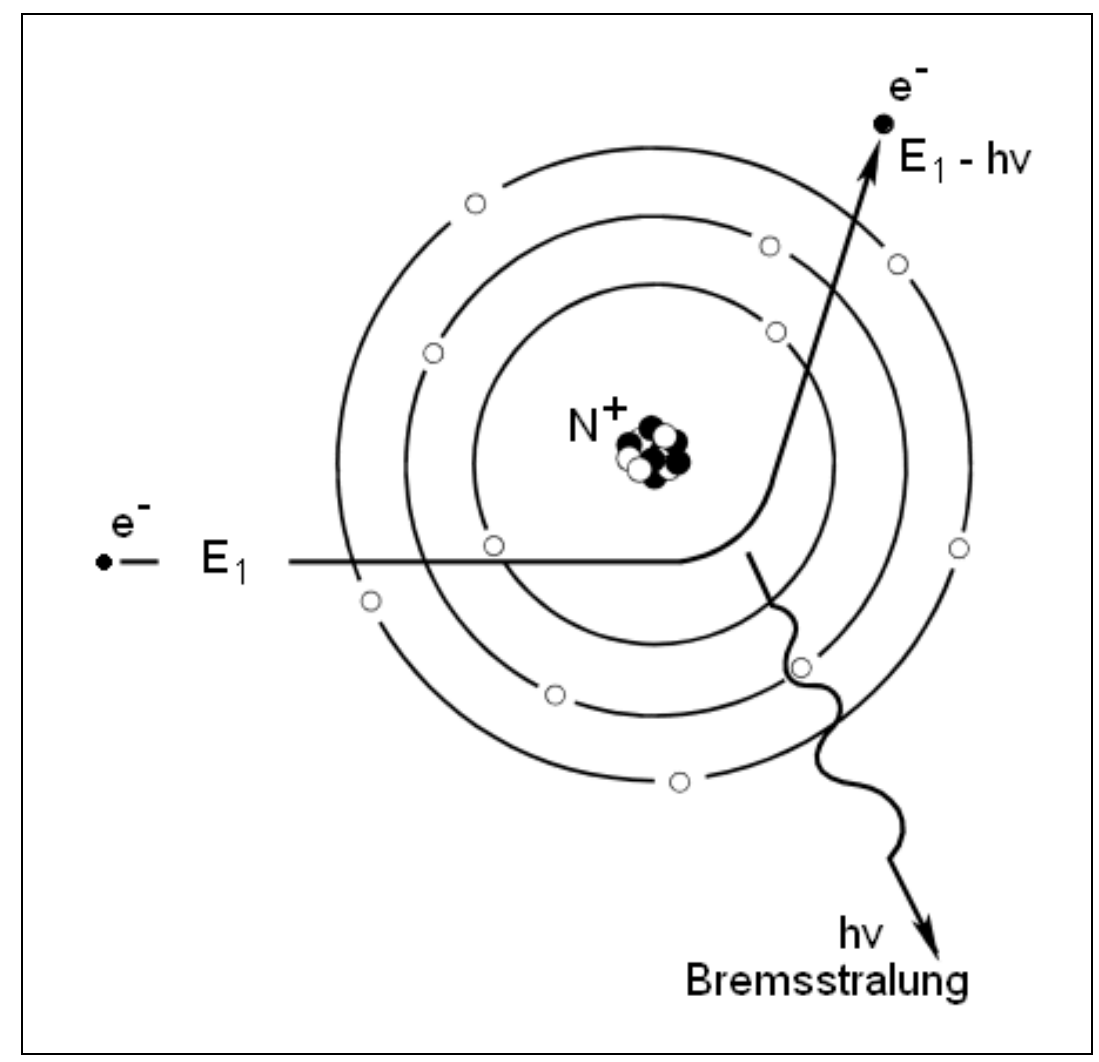

Figura 13: Colisão entre elétron de energia E1 e núcleo do átomo do alvo dando origem a um fóton de energia hv pelo processo Bremsstrahlung (University North Carolina, 2011).

Os elétrons produzem neste processo fótons de energias variadas, sendo a maior parte deles produzidos com energias inferiores à energia dos elétrons que os originou. De forma simplificada, pode-se dizer que os elétrons que atingem as zonas mais próximas do núcleo estão submetidos à maior força de atração, gerando assim fótons de maior energia. Analogamente, os elétrons que atingem as regiões mais externas sofrem interações mais fracas e conseqüentemente geram fótons de raios- $x$ de menor energia (Bottaro, 2007).

Dentro desta abordagem, pode-se verificar que o espectro de Bremsstrahlung (espectro continuo) é composto em maior parte por fótons de baixa energia e este número é reduzido à medida que a energia aumenta, até a energia máxima, que corresponde a energia dos elétrons acelerados. Este espectro apresenta, dependendo da energia inicial dos elétrons, picos superpostos de radiação característica (Johns, 1983). 


\subsection{Radiação Característica}

O processo de interação que produz a radiação característica envolve a colisão de elétrons em alta velocidade com elétrons orbitais dos átomos do alvo. A interação pode ocorrer somente quando os elétrons incidentes possuem energia cinética maior que a energia de ligação dos elétrons dos átomos do alvo. Nestas condições o elétron orbital é ejetado do átomo deixando uma vacância que é preenchida por um elétron de uma camada de maior energia. Nesta transferência de uma camada de maior energia para uma de energia menor, a energia perdida pelo elétron é emitida na forma de um fóton de raios-x (Johns, 1983; Sprawls, 1995; Wolbarst, 1993), mostrado na figura $14 a$, b e c.

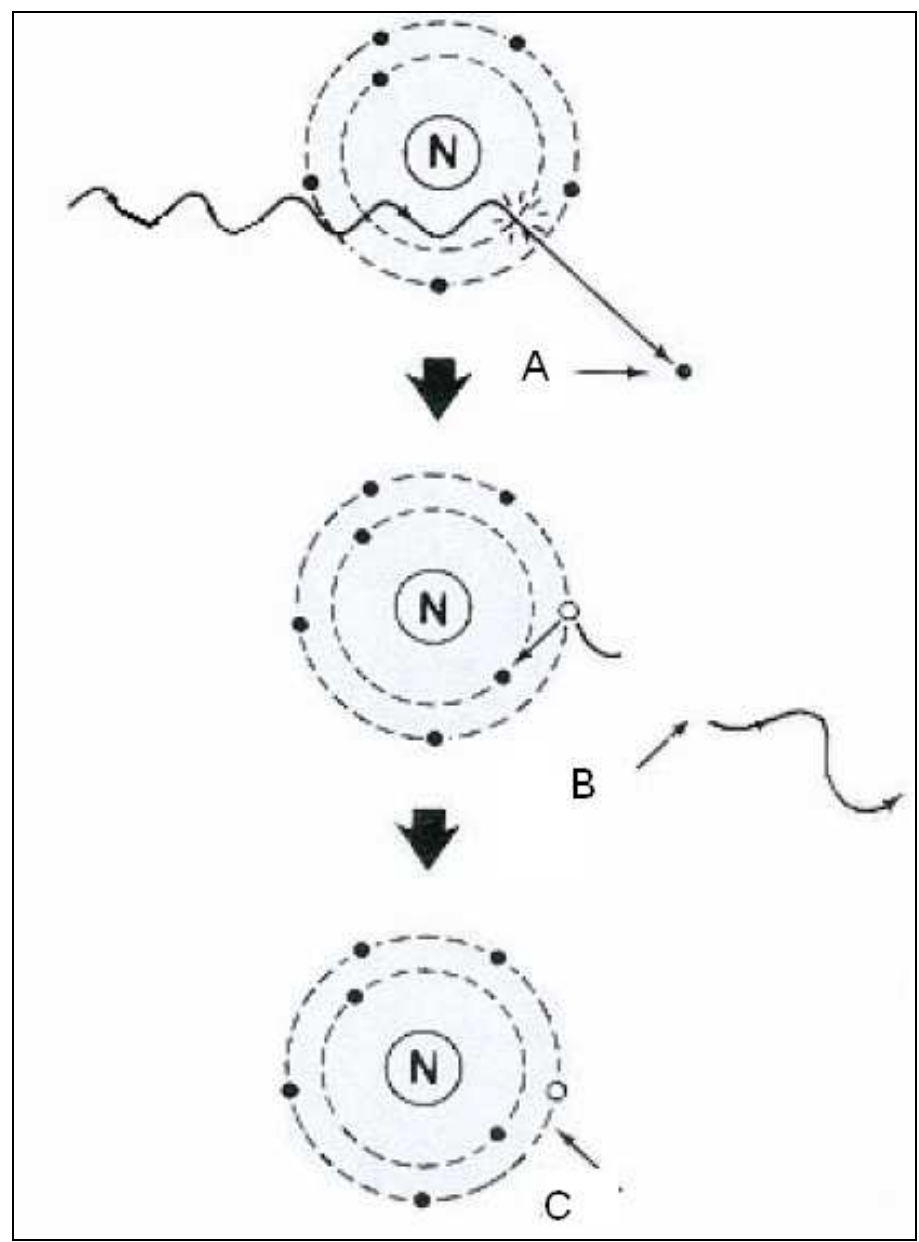

Figura14: O Elétron incidente ejeta o elétron orbital de um átomo do alvo (a). Um elétron de uma camada com maior energia preenche a lacuna dando origem à radiação característica (b). O átomo restabelece seu equilíbrio (c) (Bottaro, 2007). 
A energia do fóton de raios-x emitido neste processo é característica do elemento químico pertencente ao material do alvo, o que da o nome de radiação característica. Um determinado material alvo pode promover uma serie de energias de radiação características, dependendo do nível de energia em que as interações são originadas (Bottaro, 2007).

Para identificar todos os tipos de raios- $x$ que podem ser gerados, foi criado um código alfanumérico. Os raios-x são primeiramente nomeados com a letra que representa a camada de onde o elétron foi ejetado. Assim, os raios-x criados a partir de uma vacância na camada $\mathrm{K}$ são denominados como raios- $x \mathrm{~K}$, uma vacância na camada $\mathrm{L}$ origina um raios- $x \mathrm{~L}$. Depois, ele é identificado pela distância do salto do elétron. Uma vacância preenchida por elétron pertencente a uma camada adjacente é identificada pelo termo $\alpha$. Se a distância do salto do elétron for de duas camadas, o termo usado é $\beta$, e se forem três camadas, o termo é $\gamma$. Então, um elétron saltando da cama $L$ para a $K$, criará raios- $x K_{\alpha}$; se for da camada $N$ to $L$, criará raios- $x L_{\beta}$ (Postek et al, 2001), conforme mostra a figura 15:

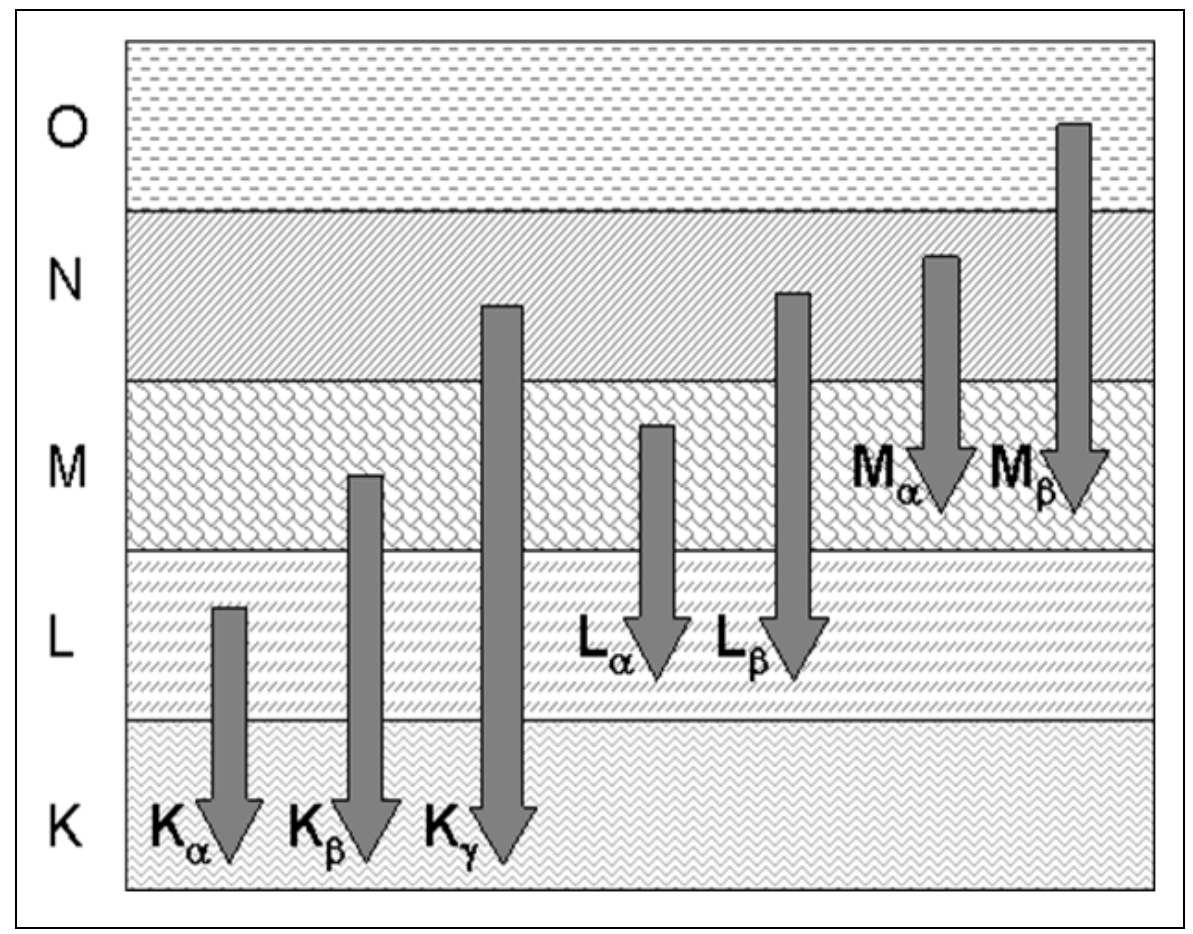

Figura 15: Tipos de radiação em função da mudança do elétron, de camada energética, (Cienfuegos e Vaitsman, 2000). 
Os comprimentos de onda das linhas dos raios-x diminuem, ou seja, aumentam sua freqüência e energia, quando o número atômico dos elementos aumenta. Os elementos chamados leves, de número atômico pequeno, possuem energias menores que correspondem a maiores comprimentos de onda. Radiações de elementos de número atômico maiores são chamadas pesadas ou duras. Os elementos, de número atômico maiores são chamados pesados porque eles têm mais níveis eletrônicos e maior série de limites de absorção $K, L, M$, etc. Os raios-X característicos de cada elemento são expressos, geralmente, em termos de energia, em KeV, (Cienfuegos e Vaitsman, 2000). A energia das linhas $\mathrm{K}$ aumenta com o número atômico segundo a relação:

$$
\begin{aligned}
& E(K e V)=h v \\
& v=\frac{c}{\lambda}
\end{aligned}
$$

onde:

$E=$ energia dos raios- $x$

$\lambda=$ comprimento de onda dos raios- $x$

$v=$ freqüência dos raios- $x$

$c=$ velocidade da luz $\approx 3,0 \times 10^{8} \mathrm{~m} / \mathrm{s}$

$\mathrm{h}=$ constante de Planck $=6,6262 \times 10^{-34}$ joule $\mathrm{x}$ seg. ou 4,135667 $\times 10^{-15} \mathrm{eV} \times$ seg.

Combinado as equações 1 e 2 e substituindo c e h pelos valores dados:

$$
\lambda=\frac{h c}{E}=\frac{12,396}{E}
$$

Por exemplo, $\mathrm{Cu}_{\mathrm{k} \alpha}$ tem energia de 8,047 KeV. Substituindo 8,047 na equação 18, tem-se o comprimento de onda em Angstroms do $\mathrm{Cu}_{\mathrm{k} \alpha}$ calculado. 
$\lambda=\frac{12,396}{8,047}=1,540 \AA$

Os relacionamentos descritos nas equações acima são utilizadas para identificar e caracterizar o raio $\mathrm{X}$ em análise de elementos, (Postek et al, 2001).

A figura 16 ilustra um espectro contínuo de raios-x (Bremsstrahlung) com pico característico superposto, evidenciando ainda a redução de fótons de baixa energia após a interposição de absorvedoras.

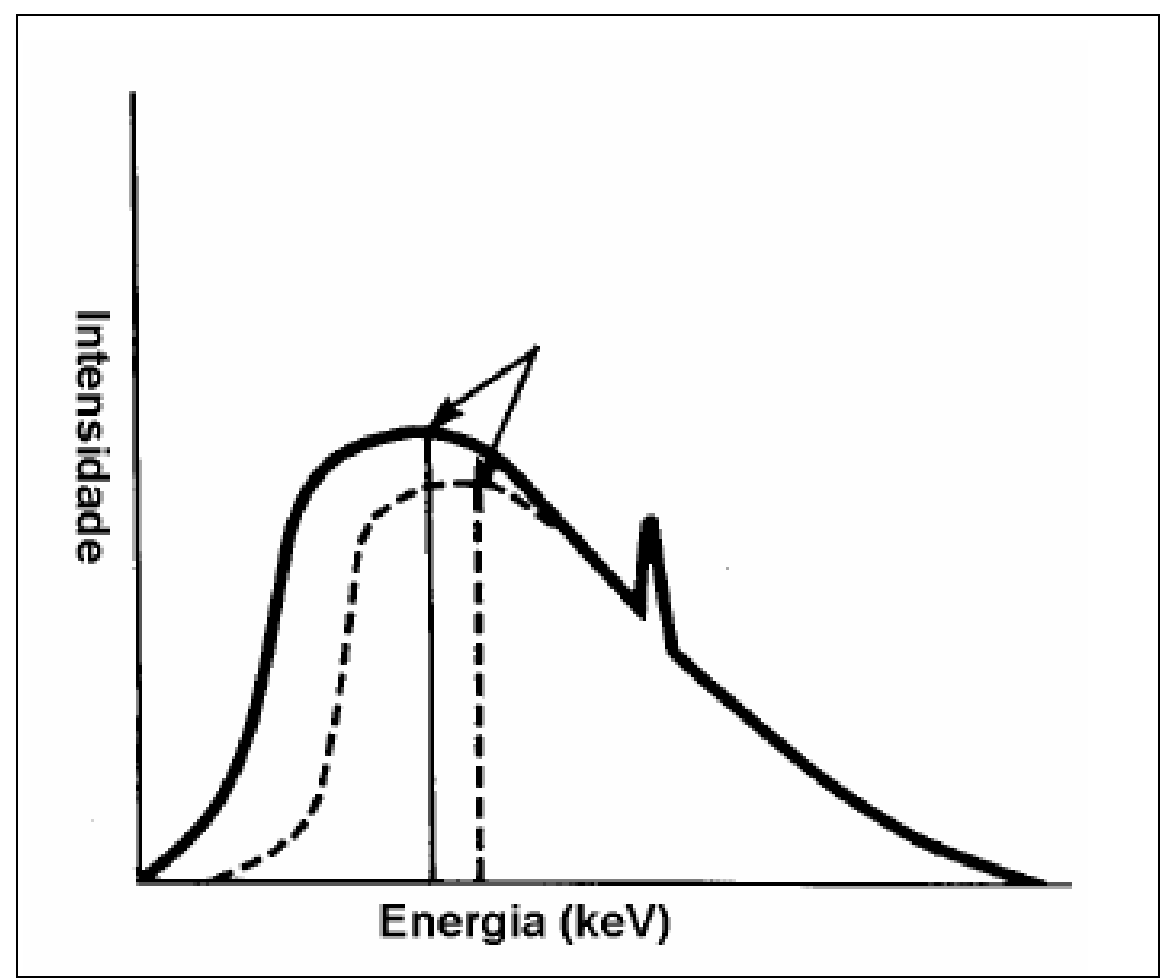

Figura 16: Espectro contínuo de raios-x. A figura mostra o aspecto emergente do alvo e o espectro filtrado (linhas tracejadas) (Bottaro, 2007).

\subsection{Gerador de raios-x}

Em um difratômetro, os raios-x são originados dentro do componente chamado tubo de raios-x. Nele, os elétrons são produzidos pelo filamento de tungstênio (catodo) e são acelerados contra o alvo metálico (ânodo). A aceleração dos elétrons ocorre devido a grande diferença de potencial 
existente entre o ânodo que é mantido aterrado (+) e o catodo (-), que é da ordem de 30.000 a 50.000 volts. A maior parte da energia cinética dos elétrons que atinge o alvo é dissipada em forma de calor, que é retirado pela água do sistema de arrefecimento. Ao redor do filamento de tungstênio existe a caneca de foco, por onde também está passando à mesma corrente elétrica do filamento, a sua função é repelir os elétrons e focalizá-los em uma pequena área no centro do alvo (Perini, 2008). Os raios-x são emitidos em todas as direções e escapam do tubo por quatro janelas. Como as janelas têm dupla função que é manter a integridade do vácuo e ainda ser transparente aos raios- $x$, elas são fabricadas de berílio, por possuir elevado ponto de fusão $\left(1287^{\circ} \mathrm{C}\right)$ e extremante permeável aos raios-X. A sua espessura é de apenas $0,25 \mathrm{~mm}$, contudo deve ser manuseado com muito cuidado por ser um material cancerígeno, figura 17, (Cullity e Stock, 2001).

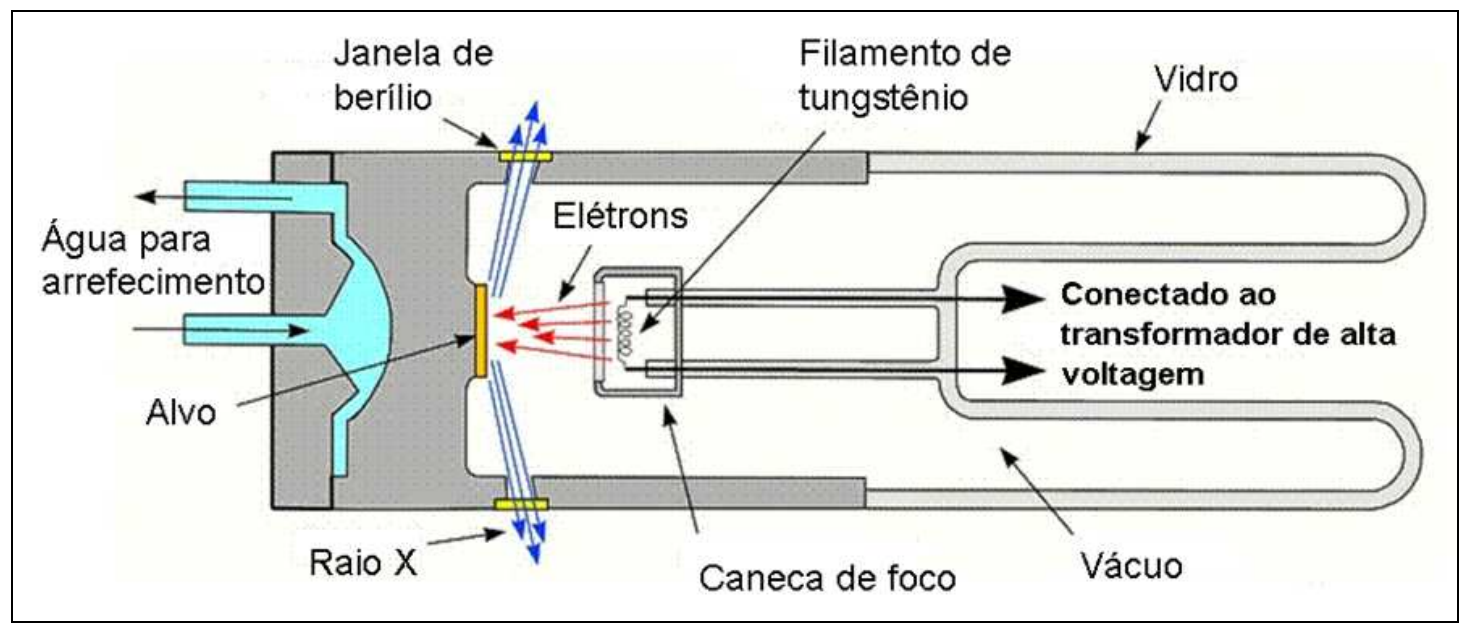

Figura 17: Esquema de uma seção de um tubo de raios-x selado a vácuo, (USGS, 2008).

Os raios- $x$ gerados pelo tubo tem o comprimento de onda característico do material utilizado como alvo. Dessa forma, o comprimento de onda pode ser alterado de acordo com a necessidade, apenas trocando o tubo de raios-x. Os materiais comumente utilizados como alvos são: molibdênio (Mo), cobre ( $\mathrm{Cu}$ ), cobalto (Co), ferro (Fe) e cromo ( $\mathrm{Cr}$ ). Os comprimentos de onda das radiações geradas por esses materiais estão descritos na tabela 1, (Cullity e Stock, 2001). 
Tabela 1: Comprimento de onda das radiações mais utilizadas em difração de raios- $x$ (em Angstrom), (Padilha e Ambrozio Filho, 2004).

\begin{tabular}{|c|c|c|c|c|}
\hline Elemento & $\begin{array}{c}\mathbf{K} \boldsymbol{\alpha}^{*} \\
(\mathbf{A})\end{array}$ & $\begin{array}{c}\mathbf{K} \boldsymbol{\alpha}_{\mathbf{2}} \\
(\mathbf{A})(\mathbf{f o r t e})\end{array}$ & $\begin{array}{c}\mathbf{K} \boldsymbol{\alpha}_{\mathbf{1}} \\
(\mathbf{A})(\text { muito } \\
\text { forte) }\end{array}$ & $\begin{array}{c}\mathbf{K} \boldsymbol{\beta}_{\mathbf{1}} \\
(\mathbf{A}) \text { (fraca) }\end{array}$ \\
\hline $\mathbf{C r}$ & 2,29100 & 2,293606 & 2,28970 & 2,08487 \\
\hline $\mathbf{F e}$ & 1,937355 & 1,939980 & 1,936042 & 1,75661 \\
\hline $\mathbf{C o}$ & 1,790260 & 1,792850 & 1,788965 & 1,62075 \\
\hline $\mathbf{C u}$ & 1,541838 & 1,544390 & 1,540562 & 1,392218 \\
\hline Mo & 0,710730 & 0,713590 & 0,709300 & 0,632288 \\
\hline
\end{tabular}

\subsection{Medidas da microdeformação por raios-x}

A difração de raios-x é um método muito propício para análise de tamanho de cristalito e microdeformação em materiais metálicos, e vale notar que a precisão da medição é crucial para o resultado da análise, que toma por base a alteração da largura dos perfis de difração. Para uma reflexão individual, a variação no valor da largura do pico deverá ser extremamente baixa, sendo aconselhável utilizar uma baixa velocidade de varredura, esta em torno de $0,1^{\circ}$ por minuto, a fim de garantir a precisão das medições (He e Schoenung, 2002).

Diversas formulações foram desenvolvidas para o cálculo de tamanho de cristalito e microdeformação com base nos perfis de difração de raios-X, entre elas, a equação de Scherrer.

Se a origem física do alargamento das reflexões de difração de raios$x$ for associado com o tamanho de cristalito individual, a relação entre o tamanho de grão (D) e a largura do pico a meia altura (FWHM), representada por $\Delta(2 \Theta)$, a equação de Scherrer (Scherrer, 1918) será expressa por:

$$
D=\frac{0,9 \lambda}{\Delta(2 \theta) \cos \theta}
$$


onde:

$\lambda$ é o comprimento de onda do anodo utilizado para a geração de raios- $x$, e $\theta$ o ângulo de difração. $O$ alargamento real do pico, $\Delta(2 \theta)$, pode ser obtido utilizando a equação:

$$
\Delta(2 \theta)=\left[\left(\Delta(2 \theta)_{h}\right)^{2}-\left(\Delta(2 \theta)_{g}\right)^{2}\right]^{\frac{1}{2}}
$$

onde:

$\Delta(2 \theta)_{h}$ é a FWHM do perfil medido e $\Delta(2 \theta)_{g}$ é o FWHM a partir do perfil de uma amostra padrão para a mesma reflexão.

O tamanho do de grão obtido com a descrição da equação de Scherrer é, portanto, o volume médio em uma direção perpendicular ao plano de difração (He e Schoenung, 2001).

Entretanto, quanto a determinação do nível de deformação, uma outra abordagem deverá ser utilizada, designada de "linear fitting".

Assumindo que, em geral, o perfil das reflexões de difração de raios-x são compostas por dois componentes (tamanho de grão e microdeformação), estas devem ser estudadas separadamente, sendo assim, o alargamento do pico resultante da microdeformação, $\Delta(2 \theta)_{s}$, pode ser expressa como: (Jeffery, 1971; Suryanarayana e Norton,1998):

$$
\Delta(2 \theta)_{s}=2 \varepsilon \cdot \tan \theta
$$

onde:

$\varepsilon$ é a microdeformação.

O componente de alargamento do pico resultante dos cristalitos, $\Delta(2 \theta)_{c}$, pode ser expresso pela equação de Scherrer, isto é:

$$
\Delta(2 \theta)_{c}=\frac{0,9 \lambda}{D \cos \theta}
$$


Sendo assim, o alargamento total do pico é dado por:

$\Delta(2 \theta)=\Delta(2 \theta)_{s}+\Delta(2 \theta)_{c}$

Portanto:

$\Delta(2 \theta) \cos \theta=2 \varepsilon \cdot \operatorname{sen} \theta+\frac{0,9 \lambda}{D}$

Sendo assim, se $\Delta(2 \theta) \cos \theta$ for plotado versus $\operatorname{sen} \theta$ para um certo número de reflexões de difração de raios-x em diferentes ângulos os dados devem produzir uma linha reta, com inclinação $2 \varepsilon$ e um intercepto de $\frac{0,9 \lambda}{D}$, permitindo, portanto a avaliação da microdeformação $(\varepsilon)$ e do tamanho do cristalito (D) (He e Schoenung, 2001).

\subsection{Medidas de tensão residual por raios-x}

As medidas de tensão residual por raios-x são baseadas na alteração das distâncias interplanares do material cristalino, medidas pela posição angular dos feixes de raios-x difratados, sendo que a mudança fracional distância interplanar é relacionada à deformação a partir da qual a tensão pode ser calculada (Regone, 2000).

$\mathrm{Na}$ análise bidimensional, a tensão pode ser medida em qualquer direção escolhida. Para realizar as medidas de tensão residual do material, o método da difração de raios- $x$ apresenta a vantagem de ser um método rápido e não destrutivo (Cullity,1978)

A primeira medida de tensão residual utilizando a difração de raios- $x$ foi realizada em 1925, sendo os resultados gravados em películas fotográficas. Em 1953 foi feito um grande avanço quando se mostrou que a tensão interna poderia ser medida rapidamente por um difratômetro de raiosx onde as medidas são gravadas eletronicamente (Cullity,1978). 
Existem dois métodos de análise de tensão interna de materiais por difração de raio-x: Análise Unidimensional e Análise Bidimensional.

\subsubsection{Análise unidimensional}

O método de análise unidimensional é mais simples de ser utilizado, pois o cálculo de tensão pode ser feito com um difratômetro comum, sendo que a tensão uniaxial do material em estudo é determinada em apenas uma direção.

Este método tem suas limitações, pois ele se aplica com resultados confiáveis apenas para monocristais, devido ao fato do material apresentar homogeneidade, para que em seguida as medidas possam ser comparadas a um material padrão do sistema JCPDS (Joint Committee for Powder Diffraction Standards) (Regone, 2000).

No método unidimensional analisa-se a tensão em uma única direção, considerando-se uma barra cilíndrica de seção A tensionada elasticamente por uma força $\mathrm{F}$, conforme a figura 18 :

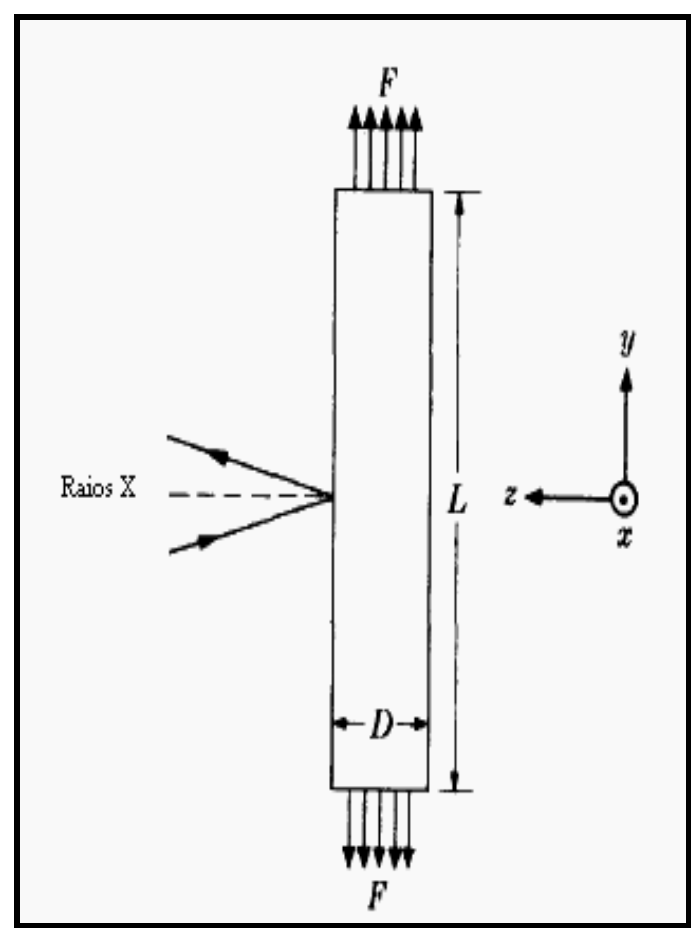

Figura 18: Barra cilíndrica tensionada por uma força (F) (Regone, 2000). 
Proporciona uma tensão:

$$
\sigma_{y}=\frac{F}{A}
$$

na direção y, porém não tensionada nas direções $x$ ou z. (estas tensões estão somente na normal, mesmo presentes as tensões de cisalhamento, as mesmas não são medidas por este método).

A tensão $\sigma_{y}$ produz deformação $\varepsilon_{y}$ na direção y dada por:

$\varepsilon_{y}=\frac{\Delta L}{L}=\frac{L_{f}-L_{o}}{L_{o}}$

Onde:

$L_{o}$ é o comprimento inicial da barra cilíndrica e $L_{f}$ é o comprimento final da barra cilíndrica.

Esta deformação é relacionada com a tensão por:

$\sigma_{y}=E \varepsilon_{y}$

onde:

$E$ é o modulo de Young e o alongamento da barra é acompanhado pela diminuição do diâmetro $D$.

Portanto, as deformações em x e z são dadas por:

$\varepsilon_{x}=\varepsilon_{z}=\frac{D_{f}-D_{o}}{D_{o}}$

onde:

$D_{0}$ e $D_{f}$ são os diâmetros inicial e final da barra. Se o material for isotrópico, as deformações são relacionadas pela equação: 
$\varepsilon_{x}=\varepsilon_{z}=-v \varepsilon_{y}$

onde:

$v$ é a razão de Poisson do material. Os valores de $v$ variam de 0.25 a 0.45 para a maioria dos metais e ligas.

Para medir a deformação $\varepsilon_{y}$ por raios-x são necessários os planos perpendiculares ao eixo da barra. Para isso utilizam-se as reflexões dos planos que são paralelos ao eixo da barra, sendo assim, será possível medir a deformação na direção z, dado por:

$\varepsilon_{z}=\frac{d_{n}-d_{o}}{d_{o}}$

onde:

$d_{n}$ é o espaçamento interplanar dos planos paralelos da barra sob tensão, e $d_{0}$ é o espaçamento do mesmo plano sem tensão.

Combinando as equações (14, 16 e 17), obtem-se requerida tensão:

$$
\sigma_{y}=-\frac{E}{v}\left(\frac{d_{n}-d_{o}}{d_{o}}\right)
$$

Nota-se que somente uma quantidade particular de grãos contribui para a reflexão hkl, que são os grãos cujos planos hkl estão paralelos a superfície da barra, conforme indicada na figura 19 e das quais estão comprimidas pela tensão aplicada. A distância interplanar $\left(d_{\mathrm{hkl}}\right)$ varia com a orientação do cristal e não é possível usar qualquer procedimento de extrapolação numérica para medi-la precisamente. Assim determina-se esta distância interplanar a partir da posição de uma linha de difração (Regone 2000). 


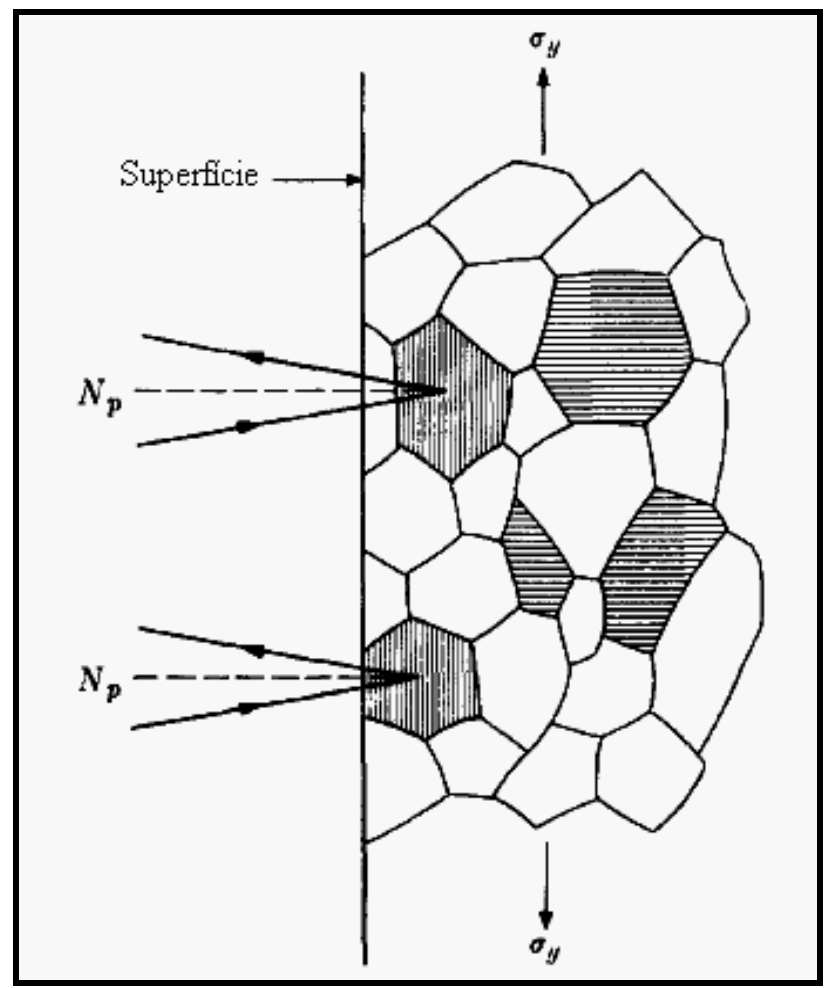

Figura 19: Difração dos grãos tensionados no eixo vertical. $N_{p}$ é o plano normal refletido (Regone, 2000).

Existem dois tipos de tensão: Tensão aplicada por uma força e tensão interna inerente ao material.

A primeira é dada simplesmente por uma força aplicada por uma unidade de área em uma seção e quando a força externa é removida, a tensão desaparece e o material recupera seu estado inicial (sem tensões).

As tensões internas surgem quando certas operações são realizadas em uma parte do material, ficando sob tensão após a remoção de todas as forças. Por outro lado, se a tensão interna estiver presente no material, $d_{0}$ deve ser medido em uma amostra livre de tensões extraídas do material (Cullity, 1978). 


\subsubsection{Análise Bidimensional}

As macrotensões são calculadas quando a deformação elástica gera uma mudança na distância interplanar. Se o limite elástico exceder, a rede do cristal irá modificar-se formando as microtensões, mas não será um aumento adicional na tensão macroscópica. Ainda que as tensões internas resultem de uma deformação plástica não uniforme, todas as macrotensões internas permanecem quando o material atinge a deformação plástica (Regone, 2000).

Em um material policristalino (metal ou cerâmico) livre de tensão, o espaçamento interplanar $\mathrm{d}_{0}$ para uma determinada família de planos não varia com a orientação desses planos, (figura 20). Se o material é submetido a uma tensão, durante a deformação elástica, o espaçamento interplanar varia de acordo com a orientação dos planos, relativa à direção da tensão. A distância interplanar aumentará para os planos perpendiculares à direção da tensão aplicada e diminuirá para os planos paralelos a essa tensão, (figura 21). A tensão em um cristal pode ser definida pela variação do espaçamento interplanar $d-d_{0}$, medida pela posição dos picos de difração (lei de Bragg) (François at al., 1996).

$$
\varepsilon=\frac{d-d_{0}}{d_{0}}=\frac{\Delta d}{d_{0}}=-\left(\theta-\theta_{0}\right) \cot g \theta_{0}=-\Delta \theta \cot g \theta_{0}
$$

onde:

$\theta$ é a posição do pico de difração para o espaçamento interplanar d (material sobre tensão) e $\theta_{0}$ é a posição correspondente para $d_{0}$ (material livre de tensão).

A rede cristalina (os planos cristalográficos) é utilizada como extensômetro que pode ser lido através de experimentos de difração. Como em qualquer método de extensometria a tensão pode ser calculada a partir da medição da deformação em varias direções mais a constante elástica do material, (François at al., 1996). 


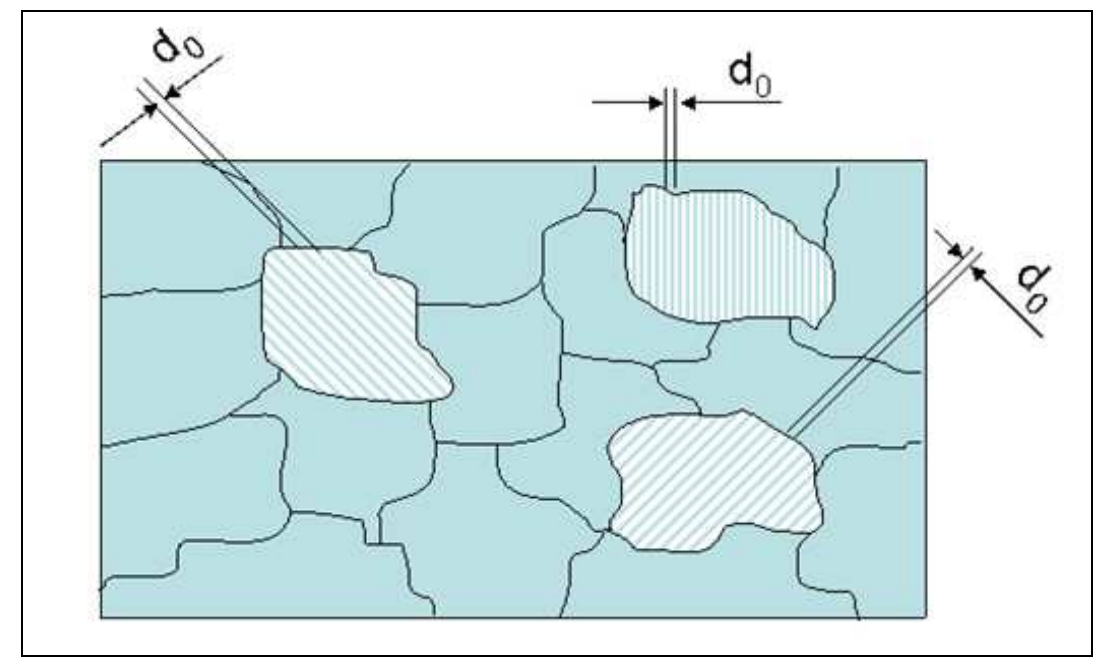

Figura 20: O espaçamento interplanar $d_{0}$ é o mesmo para todas as famílias de planos, em qualquer direção, quando o material está livre de tensões, (François at al., 1996).

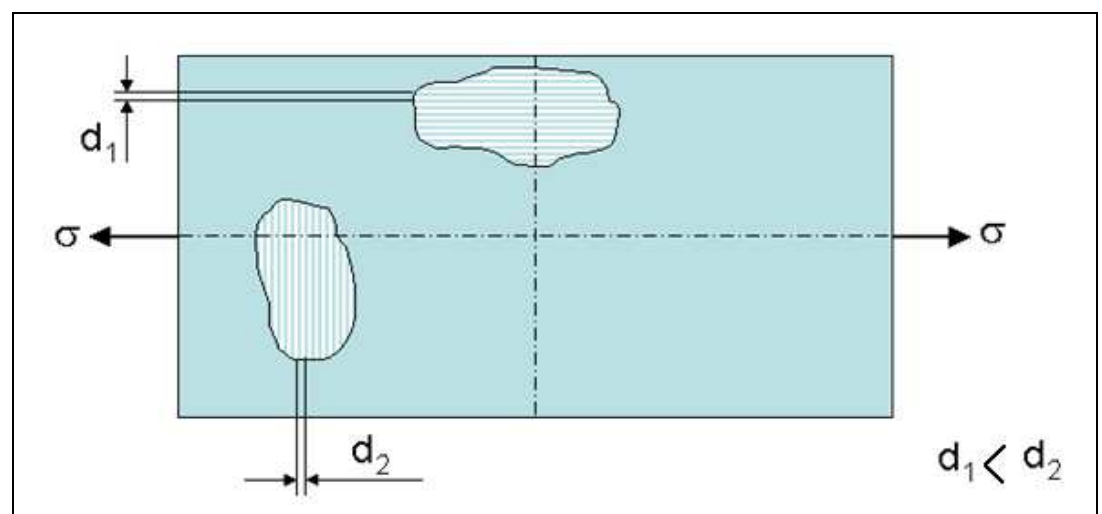

Figura 21: O espaçamento interplanar varia em todas as direções na presença de uma tensão, (François at al., 1996).

O cálculo da tensão residual utilizando difratometria de raios- $x$ baseiase na determinação de duas componentes de deformação $\varepsilon_{\phi \psi 1}$ e $\varepsilon_{\phi \psi 2}$ nas direções determinadas pelos ângulos $\phi$ e $\Psi$ de um sistema de coordenadas esféricas, (Assis at al, 2008). Definindo a relação entre o plano da tensão e a distorção da superfície da amostra, pode-se calcular a relação da tensão para um dado grau de inclinação da superfície da amostra. A inclinação do plano de difração e o plano da amostra são definidos como $\Psi$ (psi). Tomando um ponto qualquer na superfície da amostra como foco da medição, pode-se definir $\sigma_{1}, \sigma_{2}$ e $\sigma_{3}$ como as tensões principais e $\varepsilon_{1}, \varepsilon_{2}$ e $\varepsilon_{3}$ como as 
deformações principais. Devido ao plano de tensão, o valor de $\sigma_{3}$ para o eixo Z é 0, (figura 22), (Rigaku, 2003).

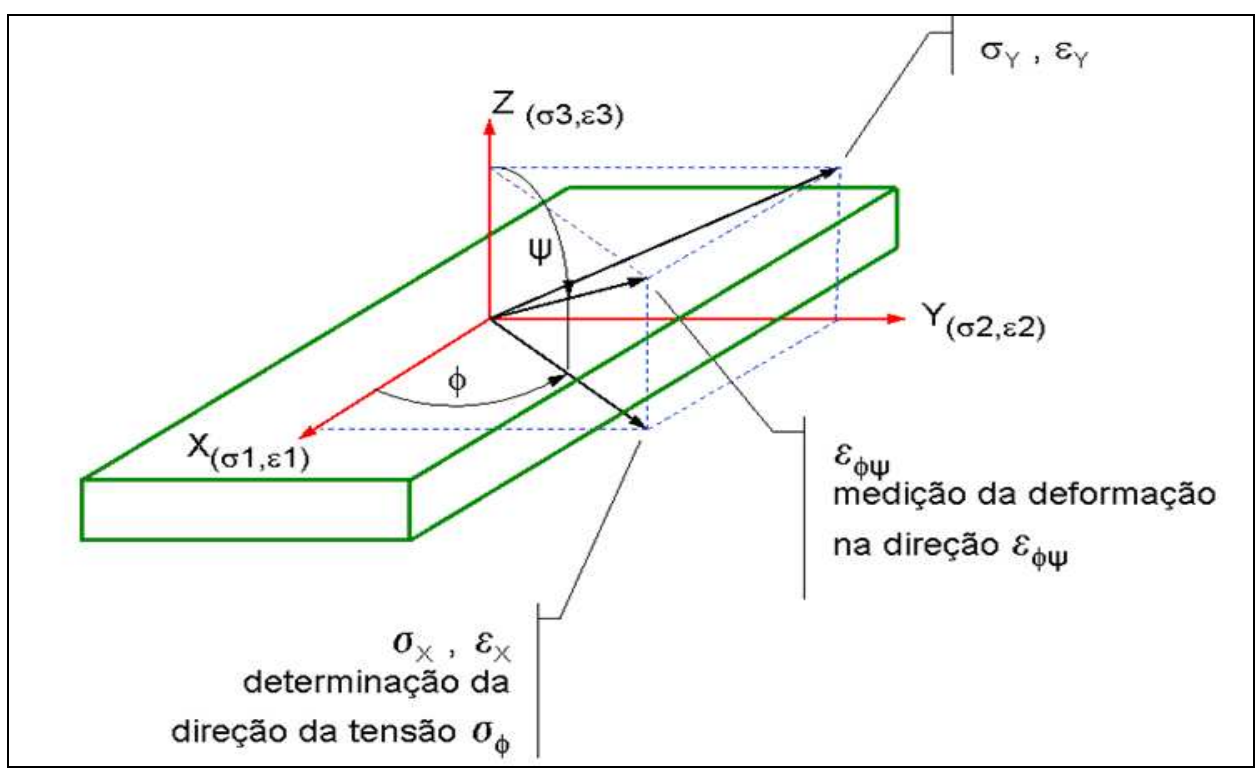

Figura 22: Direções da tensão e deformação principais, (Rigaku, 2003).

A deformação $\varepsilon_{\phi \psi}$ pode ser determinada através da equação (20) da teoria da elasticidade para o estado biaxial de tensões, (Assis at al, 2008):

$\varepsilon_{\phi \psi}=\left(\frac{1+v}{E}\right) \sigma_{\phi} \cdot \operatorname{sen}^{2} \psi-\frac{v}{E}\left(\sigma_{1}+\sigma_{2}\right)$

Neste caso a diferença entre as duas componentes da deformação será:

$\varepsilon_{\phi \psi 2}-\varepsilon_{\phi \psi 1}=\frac{1+v}{E} \sigma_{\phi}\left(\operatorname{sen}^{2} \psi_{2}-\operatorname{sen}^{2} \psi_{1}\right)$

onde:

E (módulo de elasticidade) e $v$ (Poisson) são as constantes elásticas do material, $\Psi$ e $\phi$ são os ângulos polares e azimutais, $\sigma_{\phi}$ a componente média 
da tensão, $\sigma_{1}$ e $\sigma_{2}$ as tensões principais. A componente $\sigma_{\phi}$ da equação (22) pode ser descrita como:

$\sigma_{\phi}=\left(\frac{E}{1+v}\right) \frac{\varepsilon_{\phi \psi 2}-\varepsilon_{\phi \psi 1}}{\operatorname{sen}^{2} \psi_{2}-\operatorname{sen}^{2} \psi_{1}}$

Usando a lei de Bragg, a deformação $\varepsilon_{\phi \psi}$ pode ser determinada como:

$\varepsilon_{\phi \psi}=\frac{d_{\phi \psi}-d_{0}}{d_{0}}=-\cot \theta_{0}\left(\theta_{\phi \psi}-\theta_{0}\right)$

onde:

$d_{\phi \psi}, d_{0}$ e $\theta_{\phi \psi}, \theta_{0}$ são as distâncias interplanares e os ângulos de difração para materiais com e sem tensão respectivamente. A equação final para o cálculo da componente de tensão $\sigma_{\phi}$ na direção escolhida é:

$\sigma_{\phi}=-\frac{E}{2(1+v)} \frac{\pi}{180} \cot \theta \frac{\delta(2 \theta)}{\delta\left(\operatorname{sen}^{2} \psi\right)}$

Para se obter resultados com maior precisão, é necessário que a medição do ângulo $\theta$ seja realizada em mais que duas posições $\psi\left(\psi_{1}, \psi_{2}\right.$, $\left.\Psi_{3}, \Psi_{n}\right)$. Os valores angulares de $\theta_{\mathrm{n}}\left(\theta_{1}, \theta_{2}, \theta_{3}, \theta_{\mathrm{n}}\right)$, correspondentes a cada ângulo $\Psi_{\mathrm{n}}$, são plotados em função de $\operatorname{sen}^{2} \Psi$. O coeficiente angular de ajuste da função, $y=a x+b$.

Visto que $E$, v e $\theta$ são valores conhecidos, formam uma constante $(k)$ :

$\sigma_{\phi}=-k \frac{\delta(2 \theta)}{\delta\left(\operatorname{sen}^{2} \psi\right)}$ 


\section{4..MATERIAIS E MÉTODOS}

\subsection{O material}

O material utilizado neste experimento foi a liga de alumínio identificado pelo sistema de classificação da Aluminum Association (AA) como da série 7050, cujo elemento de liga principal é o zinco. O material foi extraído de um bloco cedido pela EMBRAER laminado e usinado em placas de dimensões de $50 \mathrm{~mm}$ de largura, $400 \mathrm{~mm}$ de comprimento e variáveis de $2 \mathrm{~mm}, 5 \mathrm{~mm}, 10 \mathrm{~mm}$ e $15 \mathrm{~mm}$, cujos valores definidos pelas dimensões mais aplicadas em painéis, conforme a figura 23 :

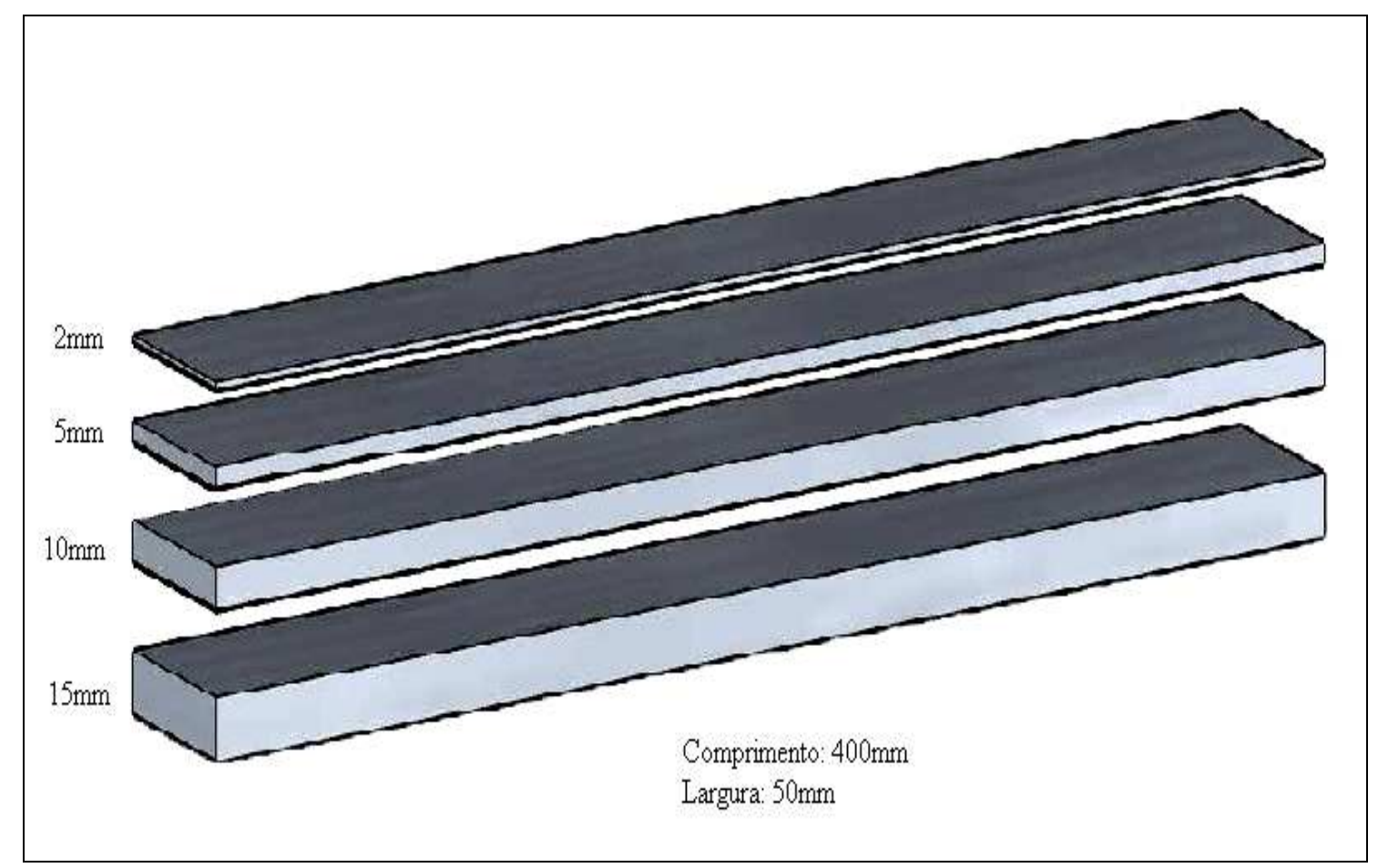

Figura 23: Dimensões dos corpos de prova para testes 


\subsection{Análise química do material recebido}

A análise elementar foi realizada por espectrometria de fluorescência de raios-x por dispersão de comprimento de onda por meio de um espectrômetro Rigaku Co., modelo RIX 3000.

\subsection{Aplicação do peen forming}

Os materiais dimensionados foram encaminhados ao Instituto de Pesquisas Tecnológicas para a aplicação do peen forming. Tal procedimento foi realizado em um equipamento produzido pela Brasibrás Tratamento de Metais Ltda, mostrado na figura 24, seguindo as características:

Gabinete em chapa de aço carbono, cujo interior se localiza uma base rotativa acionada manualmente dando suporte a uma mesa XY de curso em $700 \mathrm{~mm}$ para ambas as direções acionada por dois servomotores; Sistema contínuo de reciclagem do abrasivo; Sistema pneumático de emissão do jato de granalhas; Compressor volumétrico de parafusos, conectado a uma câmara reguladora de pressão; Vaso pressurizado com reservatório de 100 litros; Driver programável para controle de servomotor; Controlador multieixo, composto por hub para comunicação com até 4 drivers controladores dos servomotores e software para comando simultâneo desses drivers. 


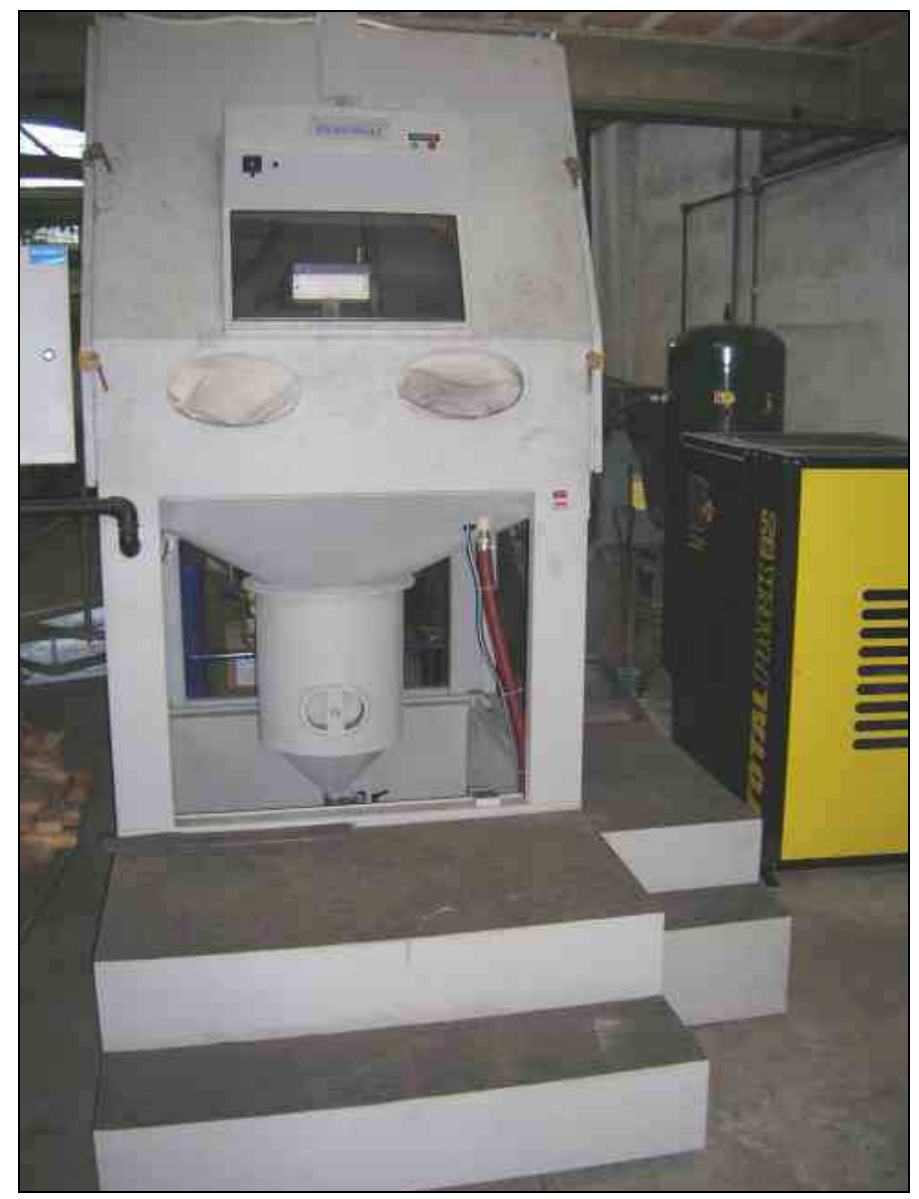

Figura 24: Equipamento para jateamento de granalhas (IPT-SP).

O interior do equipamento é mostrado na figura 25:

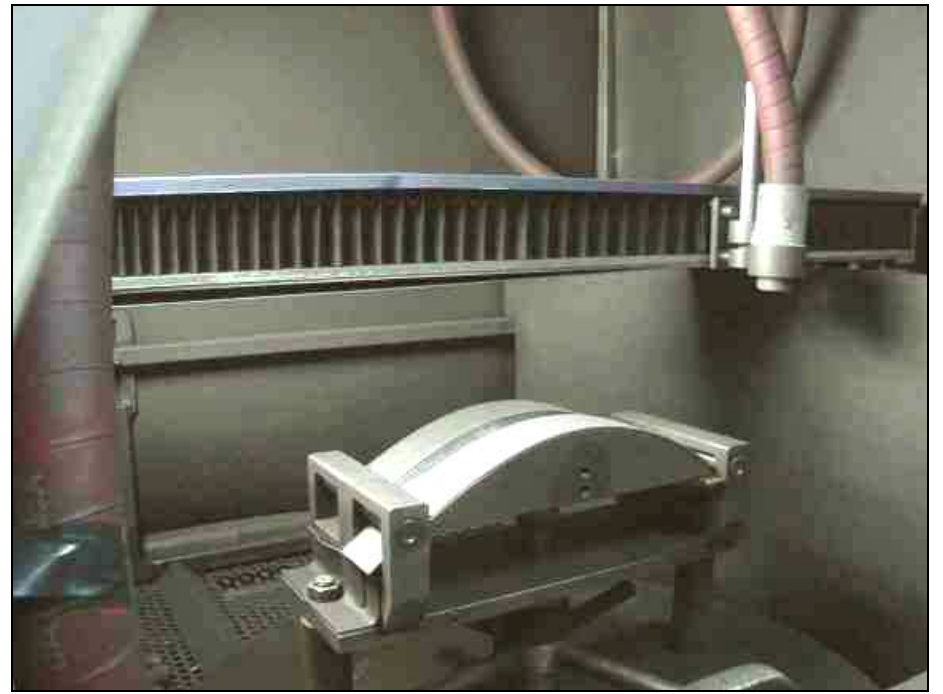

Figura 25: Área interna do equipamento para jateamento de granalhas (IPT-SP) 
A preparação das amostras para peen forming teve como base dois agentes principais: $O$ processo e o corpo de prova.

As variáveis do processo se relacionam às características do jato aplicado pelo equipamento que englobam a pressão do jato, a estratégia de aplicação espaço-temporal em relação à superfície da amostra, obtendo assim a cobertura desejada, que neste experimento foi de $200 \%$ e por fim os tipos de granalhas.

A vazão em massa de granalhas é proporcional à pressão na seção de entrada do bocal no equipamento e as pressões aplicadas foram classificadas de acordo com o tamanho das granalhas.

Os tipos de granalhas utilizados tem dureza média em torno de 43 $\mathrm{HR}_{\mathrm{c}}$ com especificações $\mathrm{S} 230$ ( $\varnothing \approx 0.023$ in), $\mathrm{S} 550(\varnothing \approx 0.055$ in) e $1 / 8$ "(0.125 in). Sendo assim, a pressão de ar, controlada por meio de uma válvula reguladora foram definidas da seguinte forma: 20, 40 e 60 psi para as esferas menores (S230), 10,20 e 30 psi para as esferas médias (S550) e 10, 20 e 25 psi para as esferas maiores (1/8"). A distância entre o bocal e o corpo de prova foi fixada em $90 \mathrm{~mm}$ e a cobertura em $200 \%$.

Outra variável aplicada associa-se ao corpo de prova ( $2^{\circ}$ agente). Foram utilizadas chapas de alumínio da liga AA7050 com $400 \mathrm{~mm}$ de comprimento e $50 \mathrm{~mm}$ de largura, variando-se as espessuras (2, 5, 10 e 15 $\mathrm{mm}$ ) e aplicação de pré tensão elástica ao corpo de prova em 2 condições de pré carregamento estático: Livre (carga estática externa nula) e prétensionada em flexão, cuja carga distribuída externa induziu tensões elásticas na ordem de $90 \%$ do valor da tensão de escoamento do material. A tabela 2 apresenta as combinações de variáveis aplicadas. 
Tabela 2: Variáveis aplicadas ao processo peen forming

\begin{tabular}{|c|c|c|c|c|}
\hline $\begin{array}{c}\text { Espessura } \\
\text { CDP }\end{array}$ & Granalha & $\begin{array}{c}\text { Pressão } \\
\text { (psi) }\end{array}$ & $\begin{array}{c}\text { Carregamento } \\
\text { (Pré-tensão) } \\
\mathrm{P}=\text { pré tensionado } \\
\mathrm{N}=\text { não tensionado }\end{array}$ & $\begin{array}{c}\text { Número } \\
\text { de } \\
\text { condições }\end{array}$ \\
\hline $2 \mathrm{~mm}$ & $\mathrm{~S} 230$ & $\begin{array}{l}20 \\
40 \\
60\end{array}$ & $\begin{array}{l}\mathrm{P} \\
\mathrm{N}\end{array}$ & 6 \\
\hline \multirow[t]{2}{*}{$5 \mathrm{~mm}$} & $\mathrm{~S} 230$ & $\begin{array}{l}20 \\
40 \\
60\end{array}$ & $\begin{array}{l}\mathrm{P} \\
\mathrm{N}\end{array}$ & \multirow{2}{*}{12} \\
\hline & S550 & $\begin{array}{l}10 \\
20 \\
30\end{array}$ & $\begin{array}{l}\mathrm{P} \\
\mathrm{N}\end{array}$ & \\
\hline \multirow[t]{2}{*}{$10 \mathrm{~mm}$} & S550 & $\begin{array}{l}10 \\
20 \\
30\end{array}$ & $\begin{array}{l}\mathrm{P} \\
\mathrm{N}\end{array}$ & \multirow{2}{*}{12} \\
\hline & $1 / 8^{\prime \prime}$ & $\begin{array}{l}10 \\
20 \\
25\end{array}$ & $\begin{array}{l}\mathrm{P} \\
\mathrm{N}\end{array}$ & \\
\hline $15 \mathrm{~mm}$ & $1 / 8^{\prime \prime}$ & $\begin{array}{l}10 \\
20 \\
25\end{array}$ & $\begin{array}{l}\mathrm{P} \\
\mathrm{N}\end{array}$ & 6 \\
\hline \multicolumn{4}{|c|}{ Total de combinações } & 36 \\
\hline
\end{tabular}

\subsection{Análise de tensão residual em profundidade ao longo da espessura}

O ponto básico deste trabalho se encontra na avaliação da distribuição da tensão residual do material após aplicação do peen forming em função dos parâmetros e condições relacionadas à tabela 2, aplicadas às amostras.

A preparação das amostras para a análise de tensão residual iniciouse com o corte, adequando às dimensões dos porta-amostras do difratômetro. $\mathrm{O}$ procedimento de corte foi realizado em cortadeira Isomet 2000.

Em seguida, a amostra foi atacada por $\mathrm{HCl}$ concentrado observando os parâmetros de tempo e volume de ácido. 
Para cada $10 \mu \mathrm{m}$ removidos de material são aplicados:

Ácido: $5 \mathrm{ml}$ de $\mathrm{HCl}$ concentrado.

Tempo: 30 segundos.

A medição da camada removida foi realizada com auxilio de um micrômetro.

Para a realização das análises de tensão residual foi utilizado um equipamento da marca Rigaku, modelo Rint 2000 com tubo de anodo de Cromo em tensão de $40 \mathrm{kV}$ e corrente de $20 \mathrm{~mA}$, mostrado na figura 26. Para aplicação do método sen $\psi^{2}$ foi utilizada a variação em $\psi$ de $-50^{\circ}$ a $+50^{\circ}$ com intervalos de $10^{\circ}$. A varredura em ângulo $2 \theta$ foi de $136,5^{\circ}$ a $141,9^{\circ}$, em referência ao plano (311), passo de $0,1^{\circ}$ em tempo fixo de 6 segundos

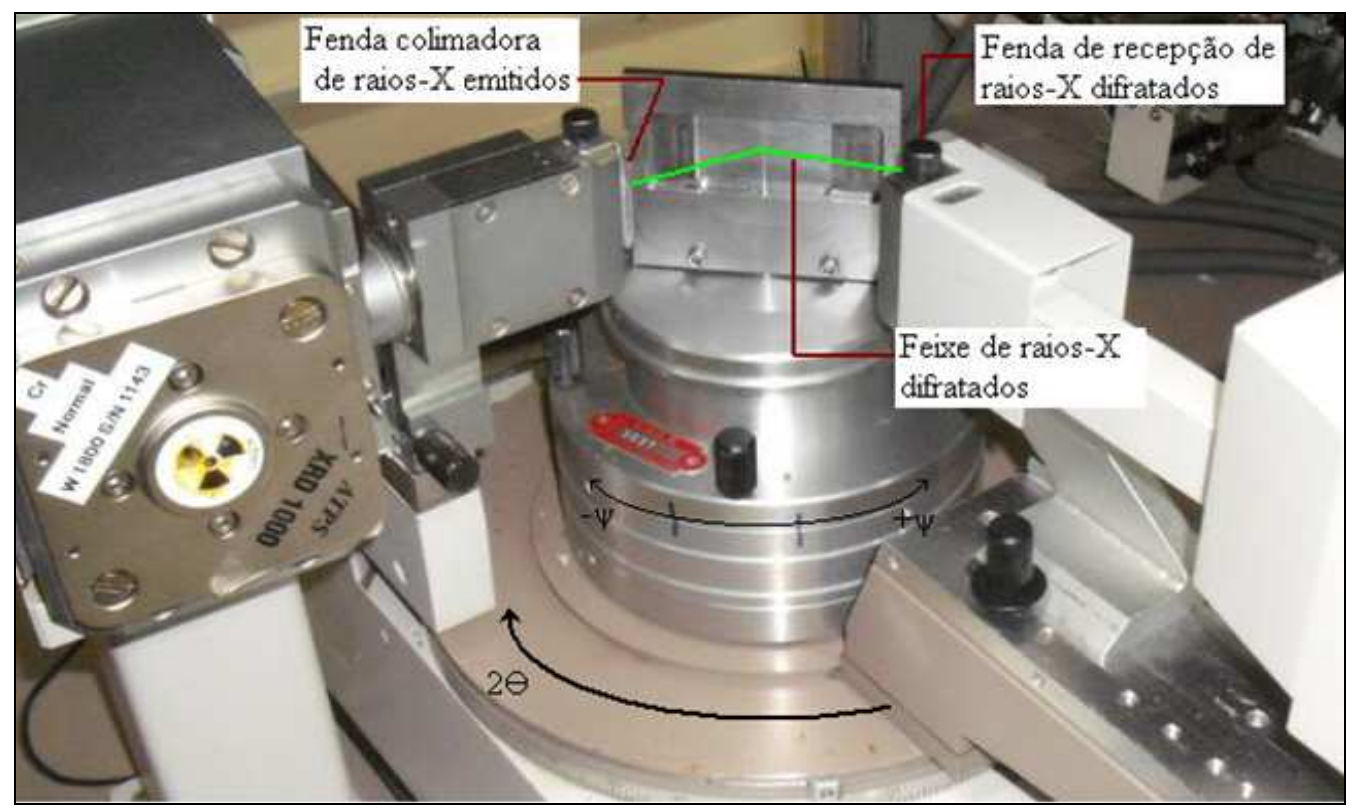

Figura 26: Montagem da amostra no difratômetro de raios-x para análise de tensão residual (IPEN/CNEN-SP)

\subsection{Caracterização da seção transversal}

Esta caracterização teve por objetivo a avaliação da camada deformada pela aplicação do peen forming na superfície e a realização de comparações do aspecto morfológico com os resultados das medições de tensão. 
As etapas para a preparação da amostra foram o corte, embutimento, lixamento e polimento da superfície analisada.

A condição para visualizar os contornos dos grãos foi obtida por ataque eletrolítico de anodização por condições de ataque Barker:

Catodo: Placa de aço inox 304.

Anodo: Amostra.

Eletrólito: $15 \mathrm{ml}$ de Ácido Fluorbórico $50 \% \mathrm{em} 300 \mathrm{ml}$ de $\mathrm{H}_{2} \mathrm{O}$ destilada.

Tensão: $20 \mathrm{~V}$.

Tempo: 30 segundos.

Para obtenção das imagens em microscopia óptica com luz polarizada realizada em microscópio Carl Zeiss, com câmera digital Moticam 1000 acoplada. O processamento das imagens foi obtido com o uso do software Motic Image Plus 2.0.

\subsection{Determinação da altura do arco de curvatura}

Para realizar o levantamento das deflexões das placas conformadas adotou-se o equipamento QM353 acompanhado do software QM Data 200, ambos fornecidos pela Mitutoyo Sul Americana Ltda. cujas características são apresentadas na figura 27 , procedendo -se por meio de medições com movimentação manual, com uma ponta de toque de alta sensibilidade, o que permite a determinação de coordenadas tridimensionais de alta precisão, com tolerância de $+/-5 \mu \mathrm{m}$.

Com a utilização deste equipamento determina-se o raio de curvatura. Para que as curvas medidas sejam melhores visualizadas nos gráficos, foi adotada como valores a altura do arco formado em relação ao comprimento do material em $400 \mathrm{~mm}$. 


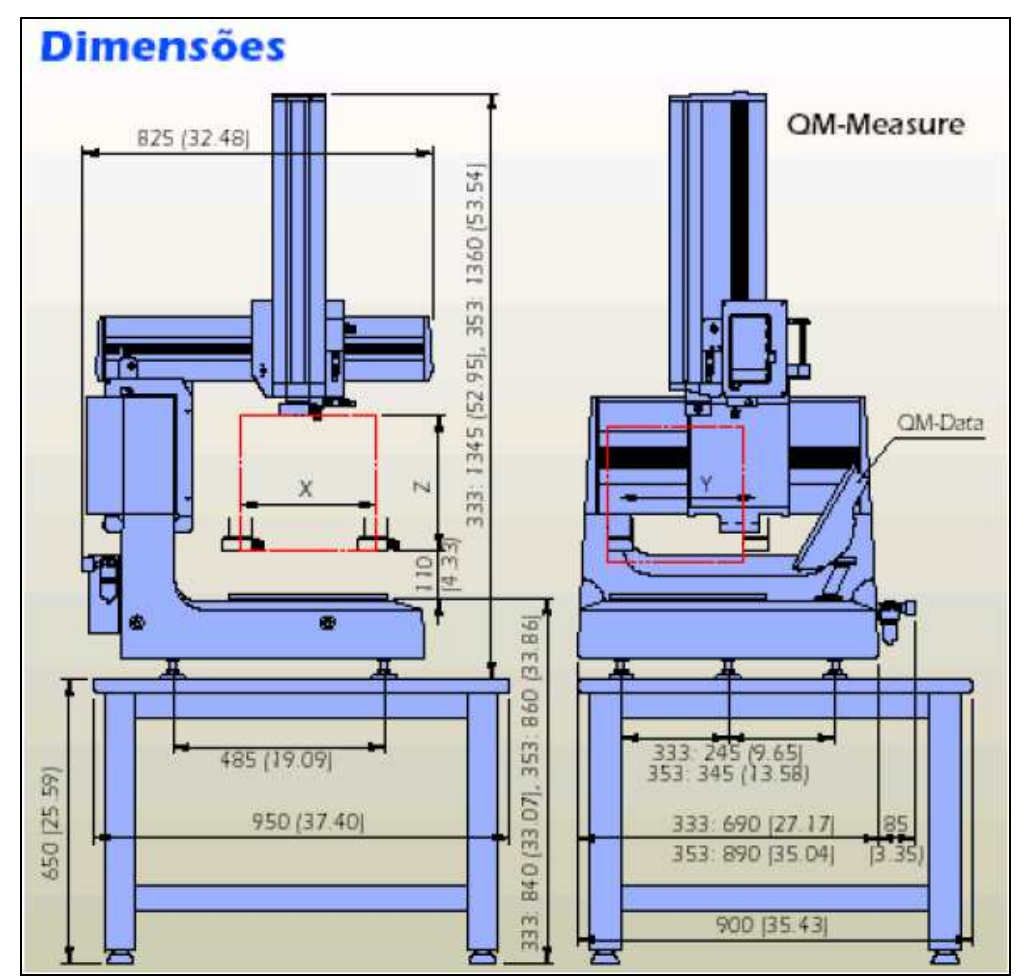

Figura 27: Características do equipamento para a realização de medição do raio de curvatura (Mitutoyo Sul Americana Ltda.)

\subsection{Determinação do fator de concentração de tensão}

Os valores do fator de concentração de tensão foram determinados por meio da medição do diâmetro provocado pela indentação da granalha sobre a superfície da amostra em relação à profundidade média de penetração das granalhas. As medidas dos diâmetros foram obtidas por microscopia eletrônica de varredura em aproximadamente 300 medições por amostra, com a utilização do equipamento Phillips, modelo XL30. A profundidade média foi obtida com a utilização do rugosímetro da Mitutoyo Sul Americana Ltda., modelo SJ301 pela norma ISO 1997.

O método para medição do fator de concentração de tensão (Kt) proposto por Li et al (1992) é descrito pela equação 1 na página 42: 


\subsection{Determinação da dureza}

A análise da dureza Vickers na seção transversal foi realizada no laboratório de caracterização da Politécnica-USP, por meio do equipamento da Buehler, modelo Micromet, série 2100. Os pontos de indentação foram aplicados nas profundidades onda a tensão residual é compressiva.

\subsection{Determinação da velocidade média das granalhas}

A medição da velocidade média das granalhas foi realizada no Instituto de Pesquisas Tecnológicas por meio de um dispositivo eletromecânico baseado no "Método dos Dois Discos" proposto por Clausen e Stangenberg (2002), mostrado na figura 28:

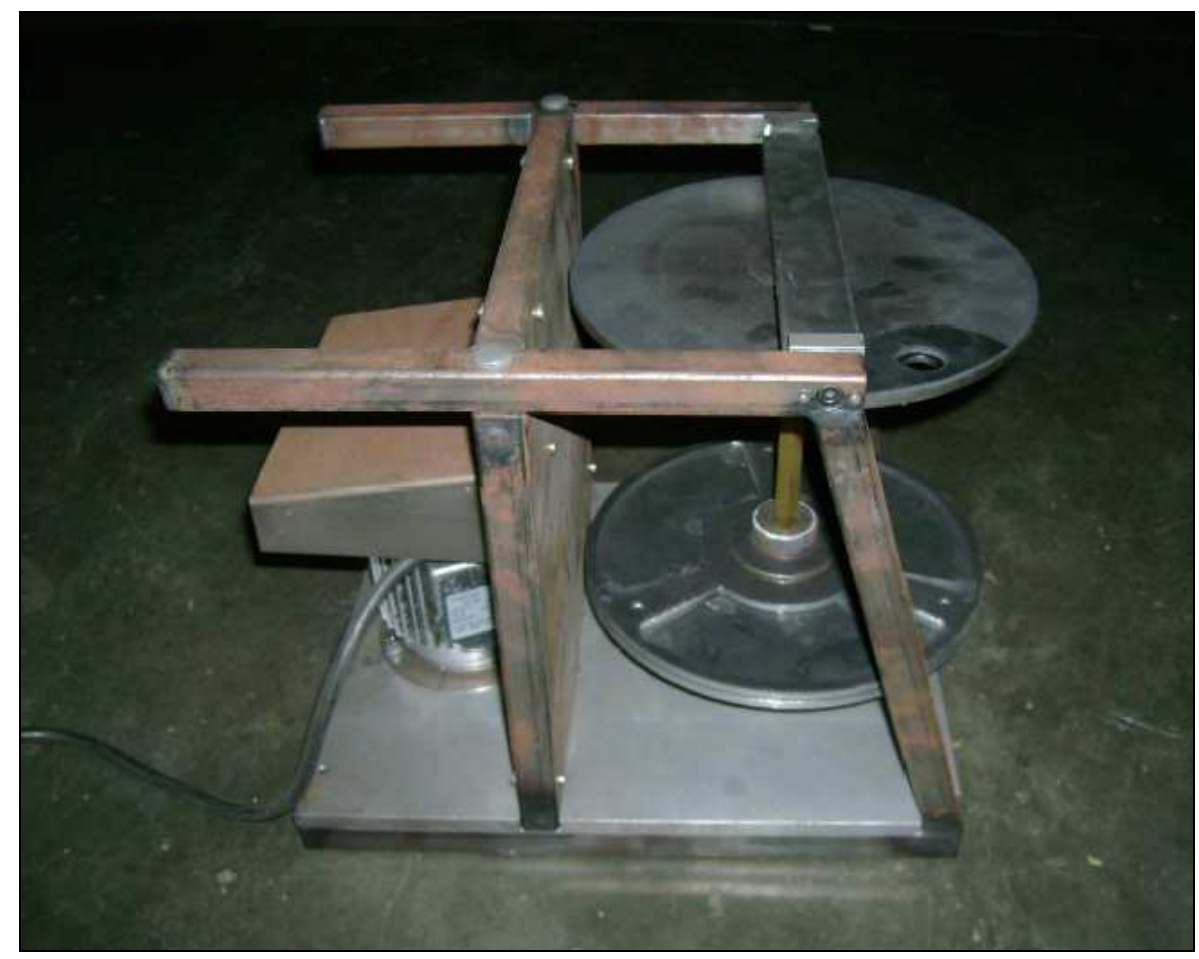

Figura 28: Dispositivo de medição da velocidade média das granalhas (IPT-SP).

Com o objetivo de melhor esclarecer este método, é representado pela figura 29 um diagrama do funcionamento do dispositivo, onde, 
conhecida a velocidade de rotação, o diâmetro de localização do orifício por onde passará a granalha, a distância entre os discos e a distância entre o bico ejetor e o primeiro disco, basta calcular a distância angular entre a reta do orifício do disco inferior e a indentação causada pelo impacto de uma esfera passante.

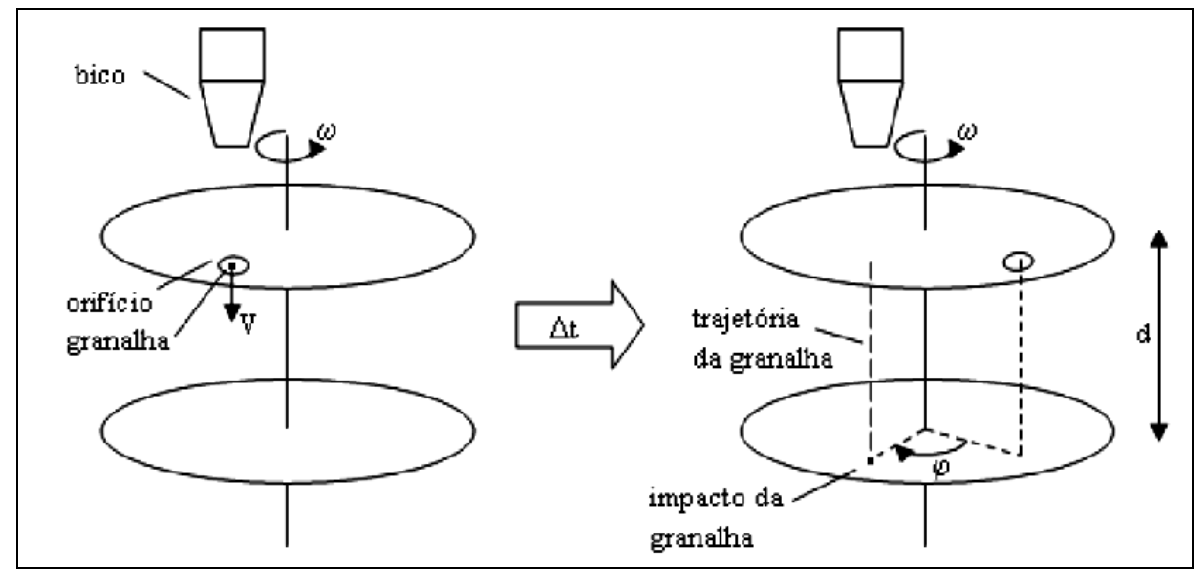

Figura 29: Diagrama do dispositivo de medição da velocidade média das granalhas

\subsection{Medidas de microdeformação e tamanho médio de cristalito}

A determinação da porcentagem da microdeformação na rede cristalina e do tamanho médio de cristalito teve por base a análise do alargamento dos picos proporcionado pela difração de raios-x nas seguintes amostras de alumínio 7050 .

Amostras de $5 \mathrm{~mm}$ espessura jateadas com granalhas S230, com regime de pressão de 20, 40 e 60 psi sem carregamento de pré tensão.

Amostras de $15 \mathrm{~mm}$ de espessura, jateadas com granalhas 1/8", com pressão de 20 psi, analisadas por difração de raios-x na superfície jateada $\left(\mu \sigma_{\text {sup }}\right)$ e na superfície onde a tensão residual é nula $\left(\mu \sigma_{\text {tot }}\right)$.

Amostra de $15 \mathrm{~mm}$ de espessura sem a aplicação de peen forming, no estado "como recebido".

As medidas de difração de raios- $x$ foram realizadas por um difratômetro de raios-x da Rigaku, modelo Multiflex em condições de 40 kV 
de tensão, $20 \mathrm{~mA}$ de corrente, passo de $0,02^{\circ}$ em tempo de contagem de 6 segundos.

Os resultados foram analisados pelo software GSAS (Larson \& VonDreele, 2004), sendo que o refinamento dos picos obtidos por difração proporcionaram as informações:

GU: alargamento relacionado a microdeformação.

LX: alargamento relacionado ao tamanho do cristalito.

As equações necessárias para a determinação da microdeformação e do tamanho do cristalito respectivamente são (Larson \& Dreele, 2004):

$S=\frac{\pi}{18000} \sqrt{(8 \ln 2)(G U)} * 100$

e:

$$
P=\frac{18000}{\pi \cdot L X} k \cdot \lambda
$$

onde

$k=0.9$ 


\section{RESULTADOS E DISCUSSÃO}

\subsection{Alumínio no estado como recebido}

A tabela 3 mostra a composição química em porcentagem em peso do material utilizado. A análise foi realizada na superfície da amostra sem a aplicação de jateamento.

Tabela 3: Resultado da análise química quantitativa da material obtida por fluorescência de raios $\mathrm{x}$

\begin{tabular}{|c|c|}
\hline Elem./Comp. & \% wt \\
\hline $\mathbf{A l}$ & $88,6 \pm 0,1$ \\
\hline $\mathbf{Z n}$ & $6,6 \pm 0,1$ \\
\hline $\mathbf{C u}$ & $2,4 \pm 0,1$ \\
\hline $\mathbf{M g}$ & $2,1 \pm 0,1$ \\
\hline $\mathbf{S i}$ & $0,15 \pm 0,05$ \\
\hline $\mathbf{F e}$ & $0,13 \pm 0,05$ \\
\hline $\mathbf{S}$ & $0,03 \pm 0,01$ \\
\hline $\mathbf{Z r}$ & $0,03 \pm 0,01$ \\
\hline $\mathbf{P}$ & $0,03 \pm 0,01$ \\
\hline $\mathbf{G a}$ & $0,012 \pm 0,005$ \\
\hline $\mathbf{M n}$ & $0,003 \pm 0,001$ \\
\hline
\end{tabular}

O resultado da análise mostra que o material de ensaio se encontra dentro das normas de especificação da Aluminum Association, como AA7050. 


\subsection{Resultados da determinação da velocidade média, energia cinética e momento das granalhas}

O encurvamento da amostra jateada está diretamente ligado as variáveis da velocidade média das esferas ao impactar com a placa, que por sua vez está relacionada com a energia cinética e o momento aplicado.

Os valores da velocidade média foram obtidos experimentalmente pelo método dos dois discos (Clausen e Stangenberg, 2002).

A energia cinética, sendo a energia que o sistema possui em virtude do movimento depende dos valores de velocidade da partícula e da massa, no caso, das granalhas de jateamento e é calculado:

$$
E_{c}=\frac{m v^{2}}{2}
$$

onde:

$m$ se refere a massa individual da granalha e $v$ é a velocidade de jateamento.

A quantidade de movimento linear, ou momento linear, definido pelo produto entre a massa e a velocidade de um corpo, no caso, as esferas de jateamento, permitindo o conhecimento da força resultante entre os dois sistemas (esferas e placa), calculado por:

$$
\vec{P}=m \vec{v}
$$

onde:

$m$ se refere a massa individual da granalha e $v$ é a velocidade de jateamento.

Os dados das granalhas estão descritos na tabela 4: 
Tabela 4: Dados das granalhas obtidos pelo fornecedor

\begin{tabular}{|c|c|c|c|}
\hline Granalha & $\begin{array}{c}\text { Diâmetro } \\
(\mathbf{m})\end{array}$ & $\begin{array}{c}\text { Massa } \\
\mathbf{( k g )}\end{array}$ & $\begin{array}{c}\text { Densidade } \\
\mathbf{( k g / \mathbf { m } ^ { 3 }}\end{array}$ \\
\hline S230 & 0,000584 & $7,88^{*} 10^{-7}$ & 7560 \\
\hline S550 & 0,001397 & $9,992^{*} 10^{-6}$ & 7000 \\
\hline $\mathbf{1 / 8} \boldsymbol{}$ & 0,003175 & $1,0491^{*} 10^{-4}$ & 6260 \\
\hline
\end{tabular}

A tabela 5 mostra os valores obtidos da velocidade média, energia cinética e momento linear para o regime de jateamento:

Tabela 5: Relação das granalhas e pressão de jateamento para cálculo de energia cinética e momento linear

\begin{tabular}{|c|c|c|c|c|}
\hline \multirow{3}{*}{ Granalhas } & $\begin{array}{c}\text { Pressão de } \\
\text { jateamento } \\
\text { (psi) }\end{array}$ & $\begin{array}{c}\text { Velocidade } \\
\mathbf{m e ́ d i a} \\
\mathbf{( m / s )}\end{array}$ & $\begin{array}{c}\text { Energia } \\
\text { cinética } \\
(\mathbf{J})\end{array}$ & $\begin{array}{c}\text { Momento } \\
\text { linear } \\
\mathbf{( k g} \cdot \mathbf{m} / \mathbf{s})\end{array}$ \\
\hline \multirow{3}{*}{$\mathbf{S 2 3 0}$} & 20 & 50,2 & $9,934^{*} 10^{-4}$ & $3,958^{*} 10^{-5}$ \\
\cline { 2 - 5 } & 40 & 61,2 & $1,477^{*} 10^{-3}$ & $4,746^{*} 10^{-5}$ \\
\cline { 2 - 5 } & 60 & 72,2 & $2,055^{*} 10^{-3}$ & $5,692^{*} 10^{-5}$ \\
\hline \multirow{3}{*}{$\mathbf{S 5 5 0}$} & 10 & 16,2 & $1,311^{*} 10^{-3}$ & $1,619^{*} 10^{-4}$ \\
\cline { 2 - 5 } & 20 & 22,4 & $2,507^{*} 10^{-3}$ & $2,238^{*} 10^{-4}$ \\
\hline \multirow{3}{*}{$\mathbf{1 / 8}}$, & 30 & 28,6 & $4,087^{*} 10^{-3}$ & $2,858^{*} 10^{-4}$ \\
\cline { 2 - 5 } & 10 & 12,5 & $8,196^{*} 10^{-3}$ & $1,311^{*} 10^{-3}$ \\
\cline { 2 - 5 } & 20 & 16,9 & $1,498^{*} 10^{-2}$ & $1,773^{*} 10^{-3}$ \\
\cline { 2 - 5 } & 25 & 18,5 & $1,795^{*} 10^{-2}$ & $1,941^{*} 10^{-3}$ \\
\hline
\end{tabular}

Os resultados da tabela 5 mostram que em geral a energia cinética e o momento linear aplicada a amostra é proporcional a pressão de jateamento e ao tamanho da granalha, sendo a única exceção, quando a granalha S550 é aplicada a 10 psi de pressão, sendo sua energia cinética menor do que a granalha S230 com pressão de jateamento de 60 psi. 


\subsection{Medição da altura do arco de curvatura}

O resultado da altura arco de curvatura foi obtido pela parábola de ajuste dos pontos de medição das coordenadas referentes ao material de análise. Os valores calculados estão apresentados na tabela 6:

Tabela 6: Resultados dos valores do raio de curvatura após o processo peen forming em parâmetros de regime de pressão e aplicação de pré tensão.

\begin{tabular}{|c|c|c|c|c|}
\hline $\begin{array}{l}\text { Espessura } \\
\text { Granalha }\end{array}$ & Pressão (psi) & $\begin{array}{c}\text { Carregamento } \\
\mathbf{S}=\text { Pré tensionado } \\
\mathbf{N}=\mathbf{N a ̃ o} \\
\text { tensionado }\end{array}$ & $\begin{array}{l}\text { Raio de } \\
\text { curvatura } \\
\quad(\mathbf{m m})\end{array}$ & $\begin{array}{c}\text { Altura do } \\
\operatorname{Arco}(\mathbf{m m})\end{array}$ \\
\hline \multirow[b]{2}{*}{$2 \mathrm{~mm}$} & \multirow[t]{2}{*}{20} & $\mathrm{~S}$ & 303,26 & 65,50 \\
\hline & & $\mathrm{N}$ & 727,27 & 27,50 \\
\hline \multirow{4}{*}{$\mathbf{S 2 3 0}$} & \multirow[t]{2}{*}{40} & $\mathrm{~S}$ & 256,87 & 77,60 \\
\hline & & $\mathrm{N}$ & 611,80 & 32,90 \\
\hline & \multirow[t]{2}{*}{60} & $\mathrm{~S}$ & 241,22 & 82,10 \\
\hline & & $\mathrm{N}$ & 595,77 & 33,70 \\
\hline \multirow{3}{*}{$5 \mathrm{~mm}$} & \multirow[t]{2}{*}{20} & $\mathrm{~S}$ & 1990,04 & 10,05 \\
\hline & & $\mathrm{N}$ & 4434,59 & 4,51 \\
\hline & \multirow[t]{2}{*}{40} & $\mathrm{~S}$ & 1583,53 & 12,63 \\
\hline \multirow[t]{3}{*}{$\mathbf{S 2 3 0}$} & & $\mathrm{N}$ & 3246,75 & 6,16 \\
\hline & \multirow[t]{2}{*}{60} & $\mathrm{~S}$ & 1494,77 & 13,38 \\
\hline & & $\mathrm{N}$ & 2894,36 & 6,91 \\
\hline \multirow{6}{*}{$5 \mathrm{~mm}$} & \multirow[t]{2}{*}{10} & $S$ & 1281,23 & 15,61 \\
\hline & & $\mathrm{N}$ & 3179,65 & 6,29 \\
\hline & \multirow[t]{2}{*}{20} & $S$ & 1010,10 & 19,80 \\
\hline & & $\mathrm{N}$ & 2317,50 & 8,63 \\
\hline & \multirow[t]{2}{*}{30} & $S$ & 884,96 & 22,60 \\
\hline & & $\mathrm{N}$ & 1901,14 & 10,52 \\
\hline \multirow{6}{*}{$10 \mathrm{~mm}$} & \multirow[t]{2}{*}{10} & S & 6920,41 & 2,89 \\
\hline & & $\mathrm{N}$ & 17241,38 & 1,16 \\
\hline & \multirow[t]{2}{*}{20} & $S$ & 5167,96 & 3,87 \\
\hline & & $\mathrm{N}$ & 11111,11 & 1,80 \\
\hline & \multirow[t]{2}{*}{30} & $S$ & 4761,90 & 4,20 \\
\hline & & $\mathrm{N}$ & 9756,10 & 2,05 \\
\hline \multirow{6}{*}{$10 \mathrm{~mm}$} & \multirow[t]{2}{*}{10} & $S$ & 3322,26 & 6,08 \\
\hline & & $\mathrm{N}$ & 8771,93 & 2,28 \\
\hline & \multirow[t]{2}{*}{20} & $S$ & 2132,20 & 9,38 \\
\hline & & $\mathrm{N}$ & 4819,28 & 4,15 \\
\hline & \multirow[t]{2}{*}{25} & $\mathrm{~S}$ & 1980,20 & 10,10 \\
\hline & & $\mathrm{N}$ & 4444,44 & 4,50 \\
\hline \multirow{6}{*}{$15 \mathrm{~mm}$} & \multirow[t]{2}{*}{10} & $S$ & 7604,56 & 2,63 \\
\hline & & $\mathrm{N}$ & 23255,81 & 0,86 \\
\hline & \multirow[t]{2}{*}{20} & $S$ & 5361,93 & 3,73 \\
\hline & & $\mathrm{N}$ & 14084,50 & 1,42 \\
\hline & \multirow[t]{2}{*}{25} & $\mathrm{~S}$ & 5333,33 & 3,75 \\
\hline & & $\mathrm{N}$ & 18888,89 & 1,44 \\
\hline
\end{tabular}


A discussão destes resultados será feita mais a frente para cada granalha em conjunto com os resultados de tensão residual e fator de concentração de tensão.

\subsection{Resultados obtidos em fator de concentração de tensão}

A avaliação do fator de concentração da tensão $\left(K_{t}\right)$ foi realizada por meio de informações obtidas pelo estudo da rugosidade, onde a profundidade média $\left(R_{z}\right)$ foi medida e pelos dados estatísticos obtidos por micrografias em MEV da superfície, obtendo o diâmetro médio resultante do impacto das granalhas com a superfície da amostra. Os resultados obtidos em $\left(K_{t}\right)$ para as amostras jateadas em granalhas S230, S550 e 1/8" estão descrit0s pela tabela 7 . 
Tabela 7: Resultados dos fatores de concentração de tensão obtidos em relação ao regime de pressão e carregamento das amostras de alumínio 7050 em espessura de 2, 5, 10 e $15 \mathrm{~mm}$.

\begin{tabular}{|c|c|c|c|}
\hline $\begin{array}{l}\text { Espessura } \\
\text { Granalha }\end{array}$ & Carregamento & $\begin{array}{l}\text { Pressão } \\
\text { (psi) }\end{array}$ & $\mathbf{K}_{\mathbf{t}}$ \\
\hline \multirow{3}{*}{$2 \mathrm{~mm}$} & \multirow{3}{*}{ Pré Tensionado } & 20 & 1,21 \\
\hline & & 40 & 1,22 \\
\hline & & 60 & 1,25 \\
\hline \multirow[t]{3}{*}{$\mathbf{S 2 3 0}$} & \multirow{3}{*}{ Não Tensionado } & 20 & 1,20 \\
\hline & & 40 & 1,24 \\
\hline & & 60 & 1,29 \\
\hline \multirow{3}{*}{$5 \mathrm{~mm}$} & \multirow{3}{*}{ Pré Tensionado } & 20 & 1,22 \\
\hline & & 40 & 1,24 \\
\hline & & 60 & 1,26 \\
\hline \multirow[t]{3}{*}{$\mathrm{S} 230$} & \multirow{3}{*}{ Não Tensionado } & 20 & 1,25 \\
\hline & & 40 & 1,26 \\
\hline & & 60 & 1,27 \\
\hline \multirow{6}{*}{$5 \mathrm{~mm}$} & \multirow{3}{*}{ Pré Tensionado } & 10 & 1,11 \\
\hline & & 20 & 1,12 \\
\hline & & 30 & 1,12 \\
\hline & \multirow{3}{*}{ Não Tensionado } & 10 & 1,12 \\
\hline & & 20 & 1,13 \\
\hline & & 30 & 1,16 \\
\hline \multirow{6}{*}{$10 \mathrm{~mm}$} & \multirow{3}{*}{ Pré Tensionado } & 10 & 1,11 \\
\hline & & 20 & 1,11 \\
\hline & & 30 & 1,11 \\
\hline & \multirow{3}{*}{ Não Tensionado } & 10 & 1,11 \\
\hline & & 20 & 1,14 \\
\hline & & 30 & 1,15 \\
\hline \multirow{6}{*}{$10 \mathrm{~mm}$} & \multirow{3}{*}{ Pré Tensionado } & 10 & 1,06 \\
\hline & & 20 & 1,07 \\
\hline & & 25 & 1,07 \\
\hline & \multirow{3}{*}{ Não Tensionado } & 10 & 1,06 \\
\hline & & 20 & 1,09 \\
\hline & & 25 & 1,09 \\
\hline \multirow{6}{*}{$15 \mathrm{~mm}$} & \multirow{3}{*}{ Pré Tensionado } & 10 & 1,06 \\
\hline & & 20 & 1,06 \\
\hline & & 25 & 1,07 \\
\hline & \multirow{3}{*}{ Não Tensionado } & 10 & 1,08 \\
\hline & & 20 & 1,07 \\
\hline & & 25 & 1,06 \\
\hline
\end{tabular}

As figuras 30,31 e 32 apresentam a amostragem da obtenção dos parâmetros para o cálculo do fator de concentração de tensão para amostras jateadas com granalhas S230, S550 e 1/8", com micrografias obtidas por microscopia eletrônica de varredura e dados de rugosidade, aplicando o método descrito na equação 1, página 42 (Li et al,1992): 


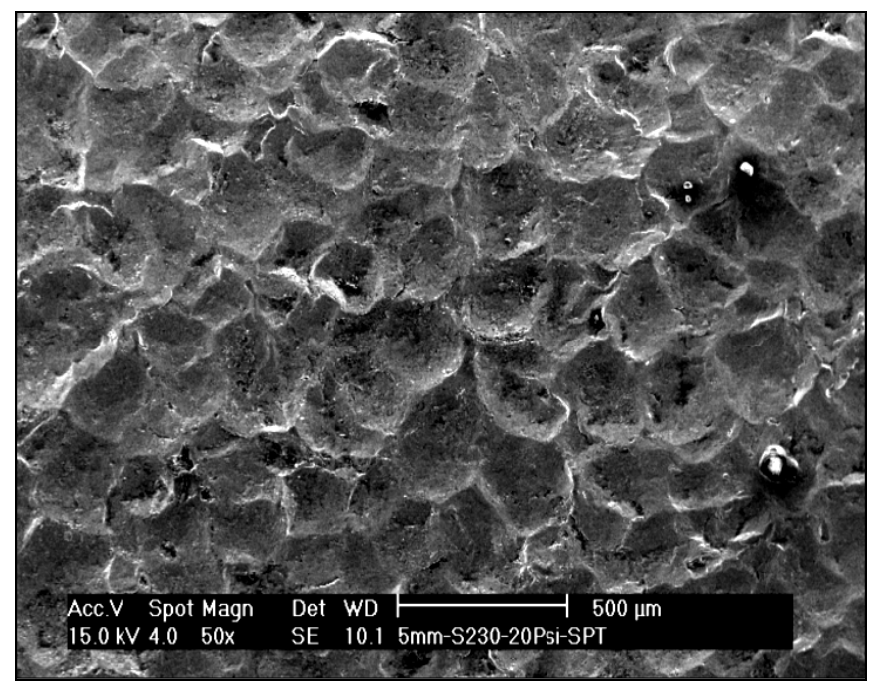

Figura 30: Micrografia em superfície jateada com granalha S230.

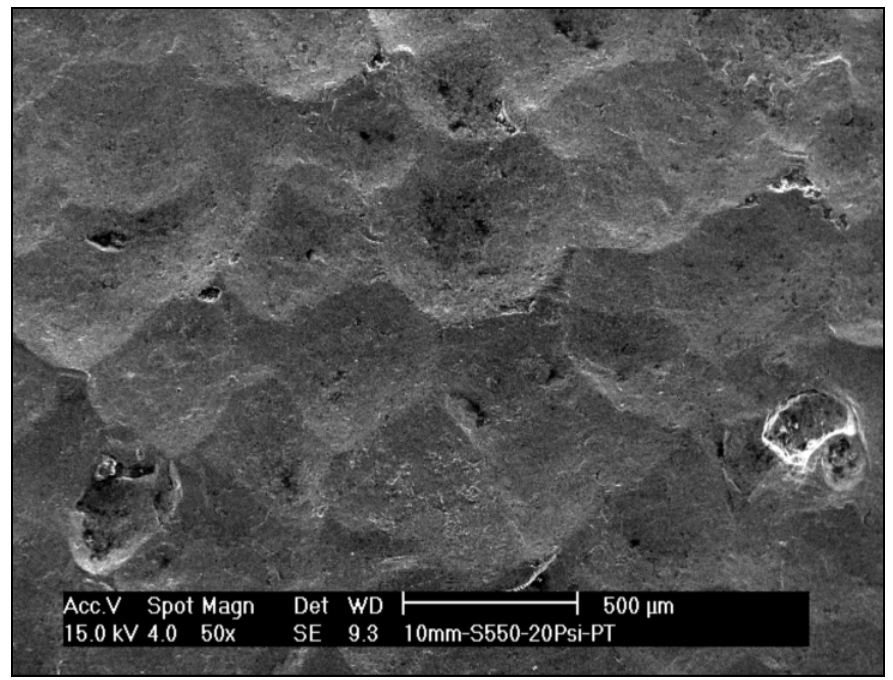

Figura 31: Micrografia em superfície jateada com granalha S550.

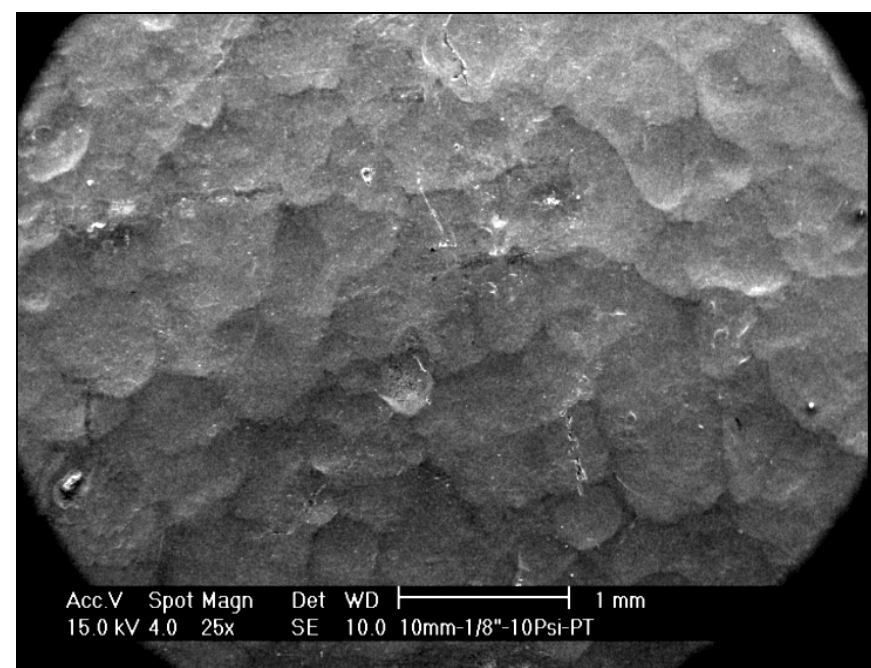

Figura 32: Micrografia em superfície jateada com granalha 1/8”. 
Conforme a relação referente a equação 26 , os dados de rugosidade estão apresentados nas figuras 33, 34 e 35, para amostras jateadas com as granalhas S230, S550 e 1/8".

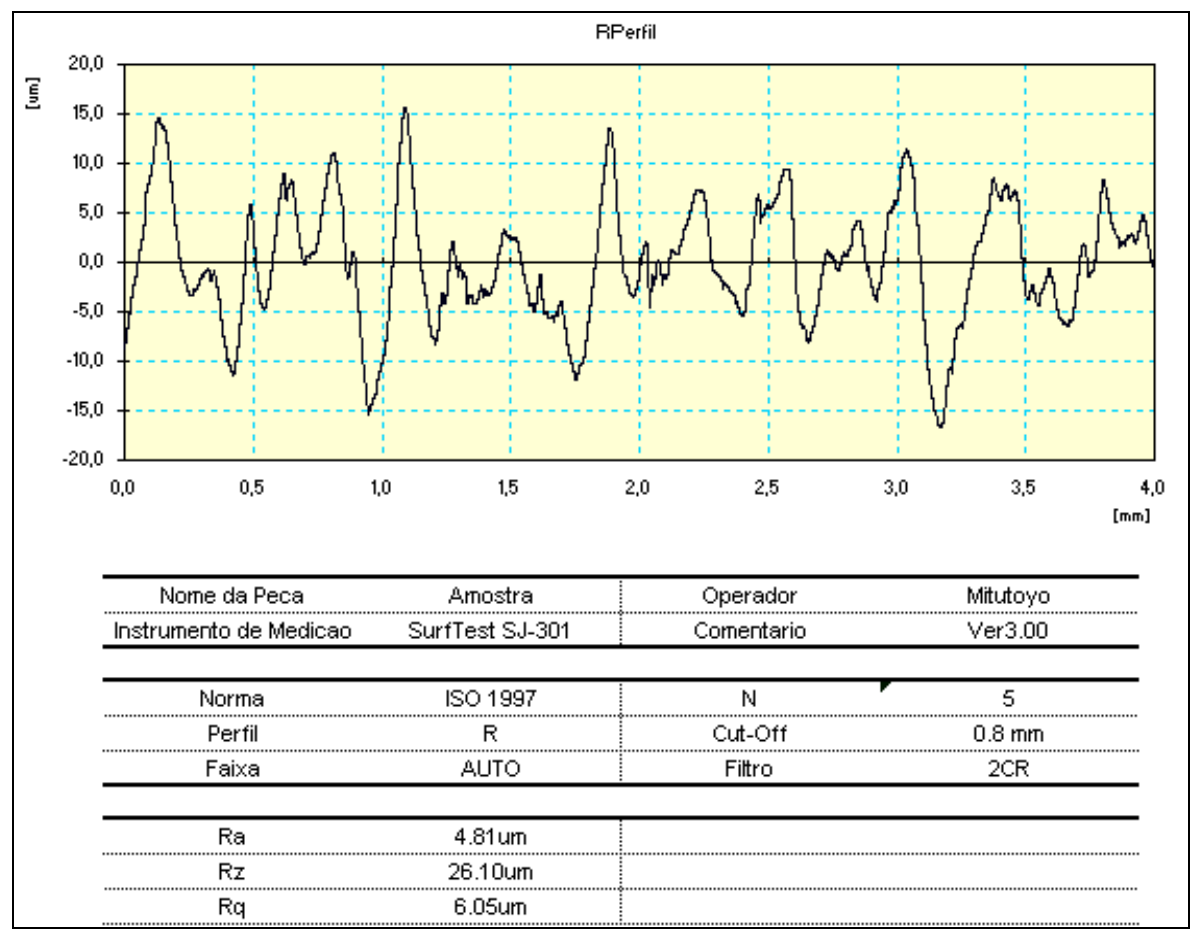

Figura 33: Resultado do ensaio de rugosidade para amostra jateatada com granalha S230.

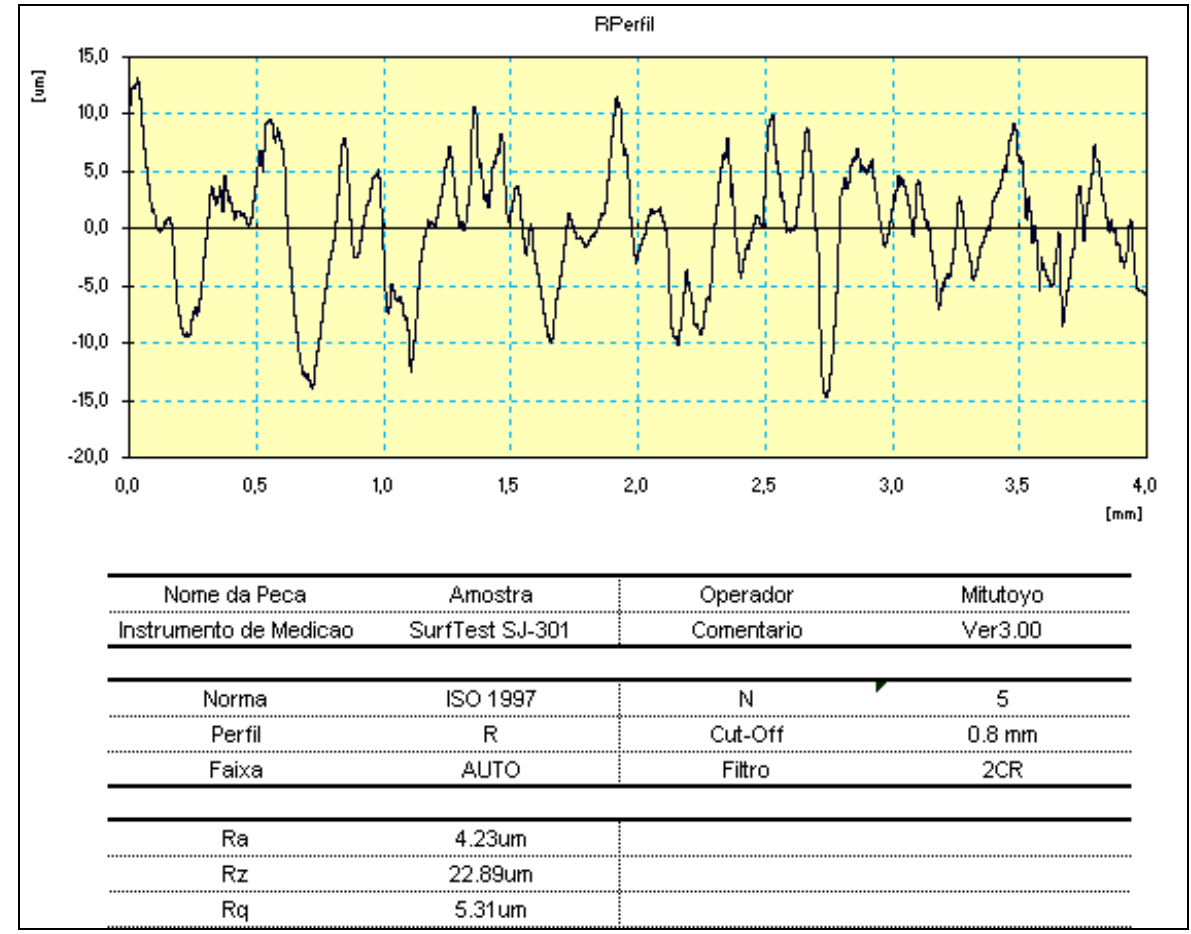

Figura 34: Resultado do ensaio de rugosidade para amostra jateatada com granalha S550. 


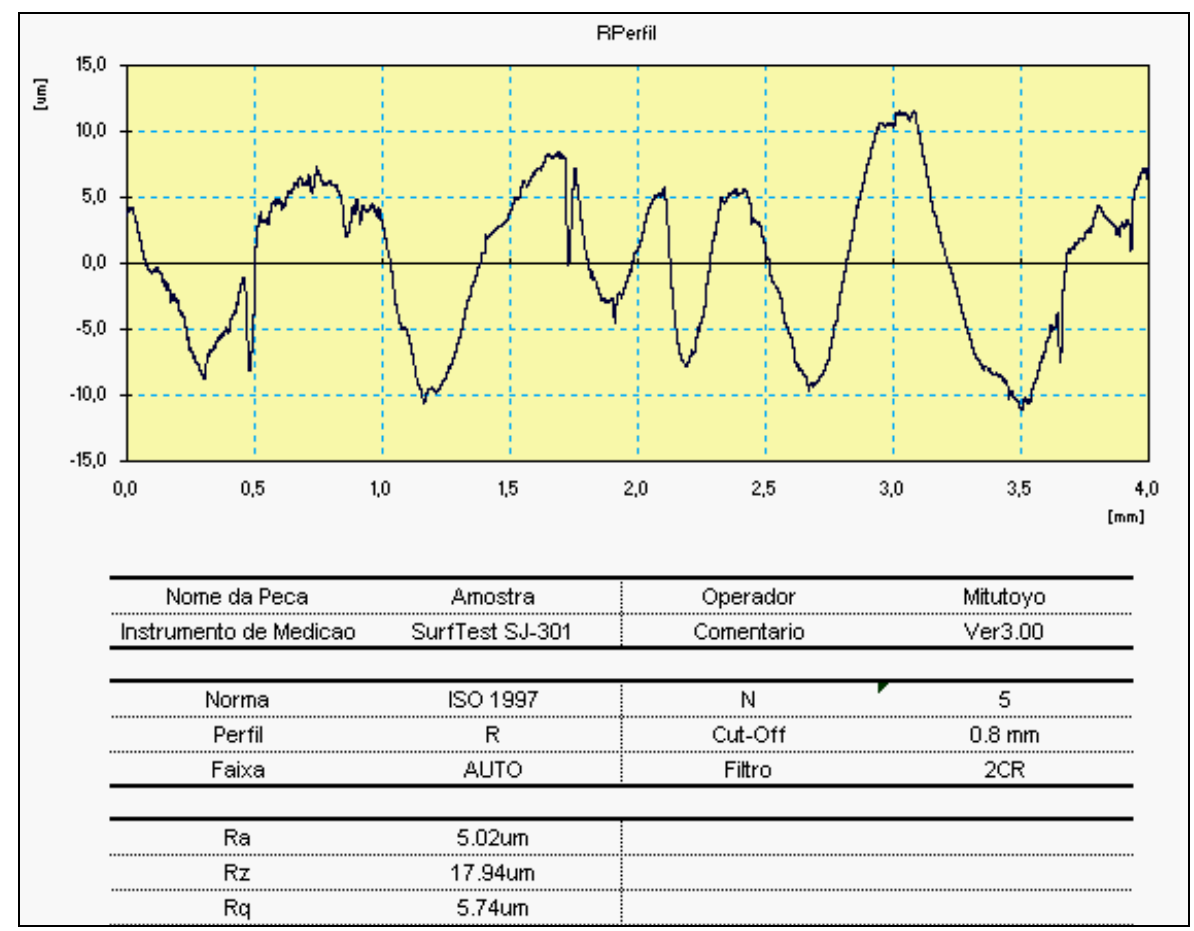

Figura 35: Resultado do ensaio de rugosidade para amostra jateatada com granalha 1/8".

\subsection{Resultados das medidas de microdureza}

O ensaio de microdureza foi realizado em amostras selecionadas para as granalhas S230, S550 e 1/8" e o objetivo inicial esta relacionado com os resultados de dureza em função da distribuição da tensão residual nas camadas adjacentes a superfície do material. Pelos resultados apresentados na figura 36 não foi possível estabelecer uma correspondência entre a evolução da dureza e a distância medida a partir da superfície submetida ao peen forming. O fato em não se obter uma relação direta dos efeitos causados pela deformação da rede cristalina ou por defeitos nos grãos, remete a diversas circunstâncias: A primeira circunstância leva em consideração a dificuldade encontrada em projetar 0 indentador do microdurômetro nas camadas próximas a superfície, pois o mesmo causa a deformação na geometria necessária para a medição ideal. Outro fator se encontra na dificuldade em se definir o ponto inicial (distância zero) em relação a superfície, pois a mesma possui irregularidades em demasia, de caráter ondulatório, chegando a valores aproximados de $50 \mu \mathrm{m}$ de pico a 
vale, estes maiores do que a média das medições de indentação do penetrador.

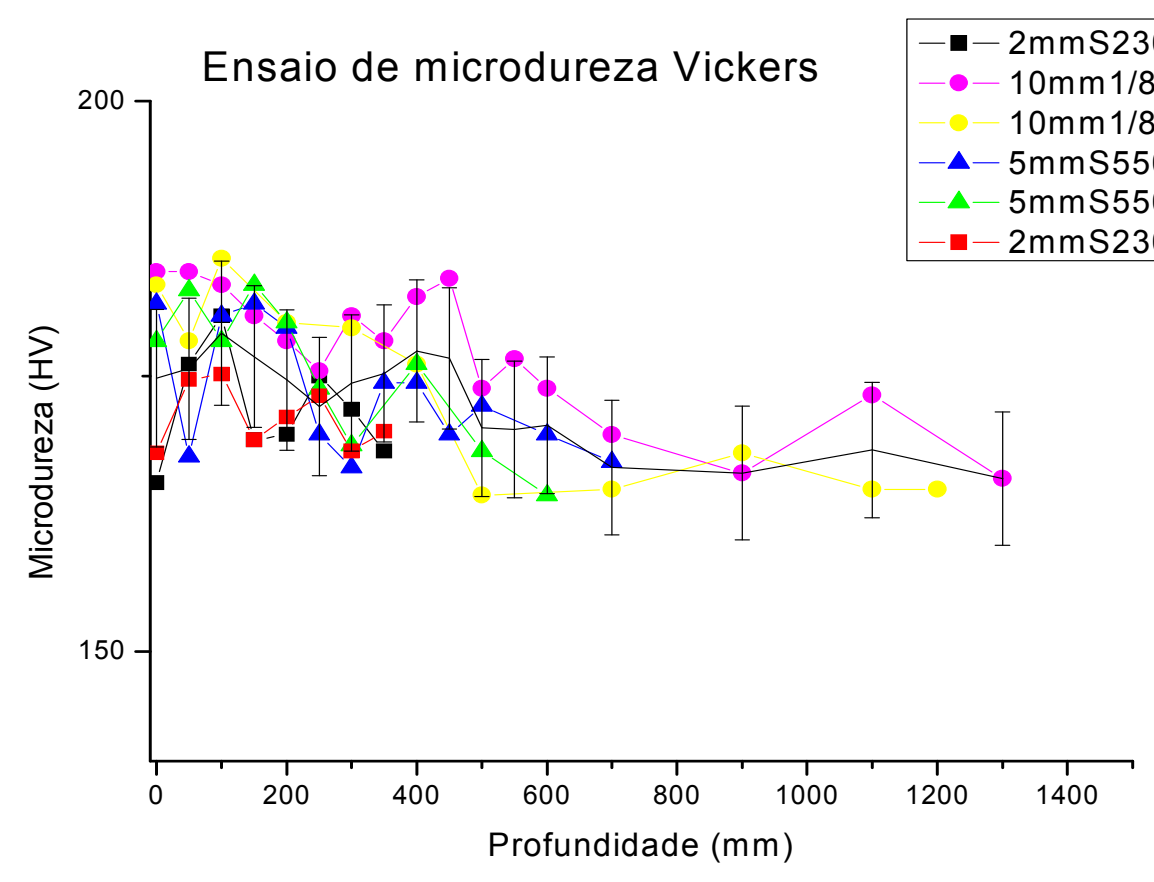

Figura 36: Distribuição de microdureza Vickers em amostras jateadas a 20 psi com granalhas S230, S550 e 1/8".

A observar na figura 36 , os valores de microdureza Vickers se encontram entre $164 \mathrm{HV}$ e $184 \mathrm{HV}$, esperados para o material tratado pelas condições T7451 (Davis, 1993).

\subsection{Resultados da distribuição da tensão residual}

\subsubsection{Granalha S230}

Os resultados das análises dos perfis de tensão residual das amostras estão apresentados nos gráficos a seguir. As figuras 37 e 38 relacionam o comportamento das curvas de tensão residual em amostras com espessura de $2 \mathrm{~mm}$, com a aplicação do peen forming em granalhas S230, variando a pressão em 20, 40 e 60 psi para amostras pré tensionadas (PT) e sem a aplicação da pré tensão (NT) respectivamente. Os dados de 
tensão residual em profundidade foram ajustados com função polinomial de grau 3.

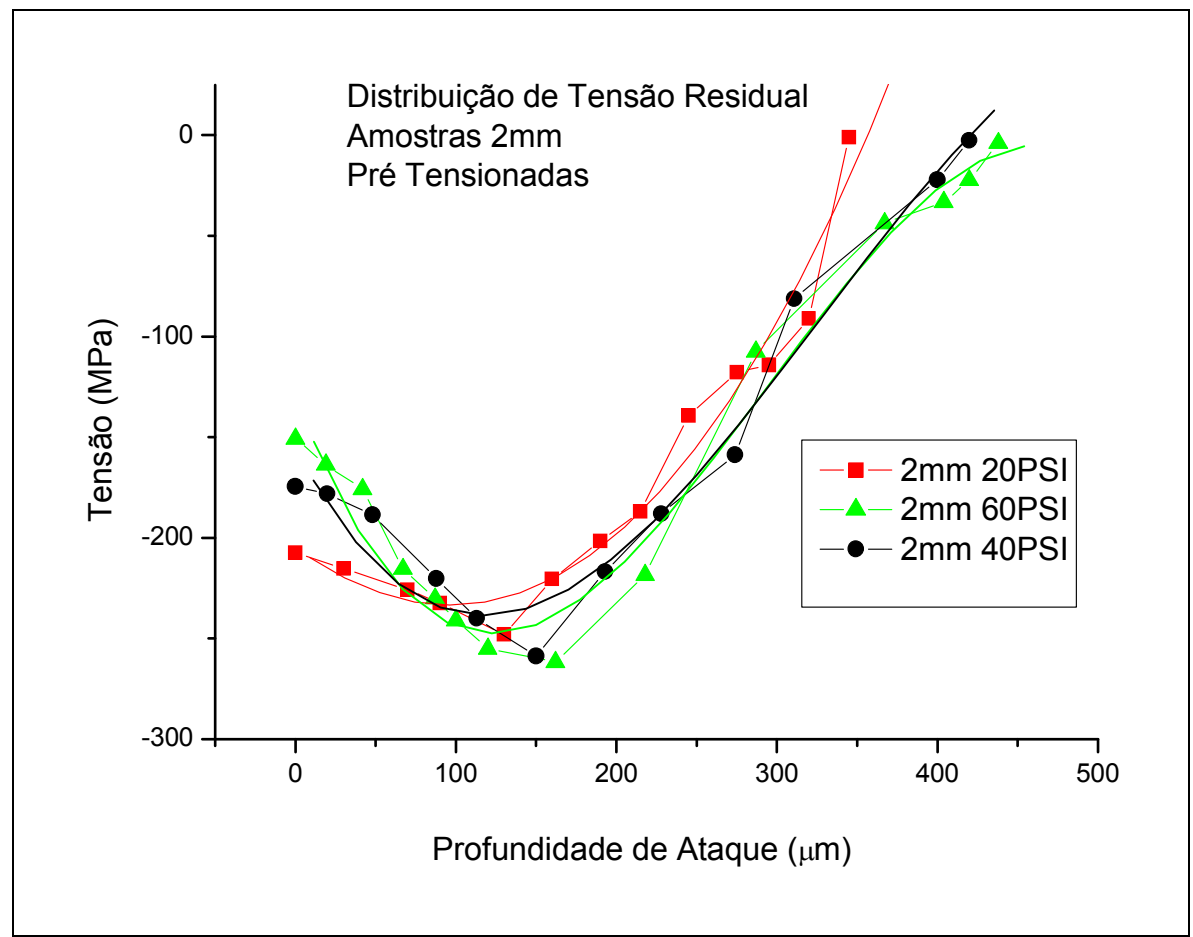

Figura 37: Distribuição de tensão residual em amostras de $2 \mathrm{~mm}$ de espessura com a aplicação do pré tensionamento.

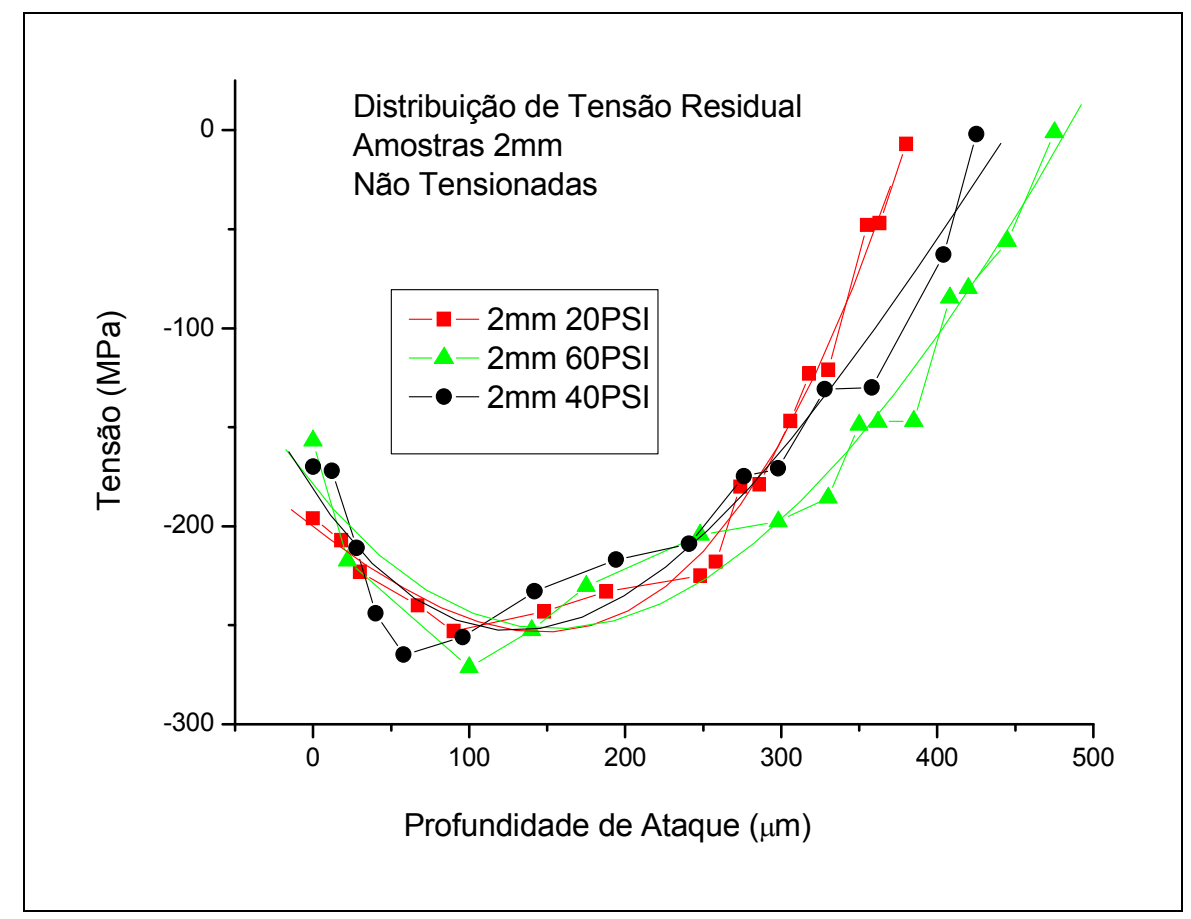

Figura 38: Distribuição de tensão residual em amostras de $2 \mathrm{~mm}$ de espessura sem a aplicação do pré tensionamento. 
Na tabela 8 estão tabulados os valores de profundidade em máxima tensão residual de compressão $\left(\mu \sigma_{M a x}\right)$, a máxima tensão residual de compressão ( $\left.\sigma_{\text {máx }}\right)$, a tensão residual na superfície da amostra ( $\left.\sigma_{\text {sup }}\right)$ e a profundidade máxima onde se mantém $\mathrm{p}$ estado de tensão residual de compressão $\left(\mu \sigma_{\text {tot }}\right)$, extraídos dos gráficos das figuras 37 e 38 .

Tabela 8: Relação entre pressão, tensão e profundidade para amostras $2 \mathrm{~mm}$ de espessura

\begin{tabular}{|c|c|c|c|c|c|}
\hline & Pressão(psi) & $\begin{array}{c}\mu \boldsymbol{\sigma}_{\text {máx }} \\
(\boldsymbol{\mu m})\end{array}$ & $\begin{array}{c}\boldsymbol{\sigma}_{\text {máx }} \\
(\mathbf{M P a})\end{array}$ & $\begin{array}{c}\boldsymbol{\sigma}_{\text {sup }} \\
(\mathbf{M P a})\end{array}$ & $\boldsymbol{\mu \sigma _ { \text { tot } } ( \boldsymbol { \mu m } )}$ \\
\hline \multirow{2}{*}{$\begin{array}{c}\mathbf{2} \mathbf{m m} \\
\text { Pré }\end{array}$} & 20 & 96 & -233 & -207 & 355 \\
\cline { 2 - 6 } & 40 & 117 & -238 & -174 & 420 \\
\cline { 2 - 6 } & 60 & 122 & -247 & -150 & 440 \\
\hline \multirow{2}{*}{$\begin{array}{c}\mathbf{2} \mathbf{N a ̃ o} \\
\text { tensionada }\end{array}$} & 20 & 154 & -253 & -196 & 383 \\
\cline { 2 - 6 } & 40 & 118 & -252 & -170 & 425 \\
\cline { 2 - 6 } & 60 & 154 & -253 & -156 & 475 \\
\hline
\end{tabular}

Analisando os gráficos apresentados pelas figuras 37 e 38 e pela tabela 8, afirma-se em linhas gerais que a profundidade $\left(\mu \sigma_{\text {tot }}\right)$ onde se mantém no estado de tensão residual de compressão está diretamente relacionada a pressão de jateamento, porém este não está relacionado com as variações nos valores de tensão residual máxima ( $\left.\sigma_{\text {máx }}\right)$, que varia de $233 \mathrm{MPa}$ a -247 MPa para as amostras pré tensionadas e de -252 a -253 MPa para as amostras sem a pré tensão. Observamos que os valores de tensão residual na superfície das amostras ( $\sigma_{\text {sup }}$ ) decrescem quanto maior for o regime de pressão de jateamento, mostrando que o aumento de pressão produz uma redução na tensão residual na superfície da amostra, devido ao relaxamento da rede proporcionado pelo alto impacto das esferas com o material.

As figuras 39a e 39b mostram as superfícies da seção transversal das amostras de espessura de $2 \mathrm{~mm}$ jateadas com granalha $\mathrm{S} 230$ a pressão de 20 psi e 60 psi, respectivamente condições de carregamento pré tensionado 
(a)

(b)
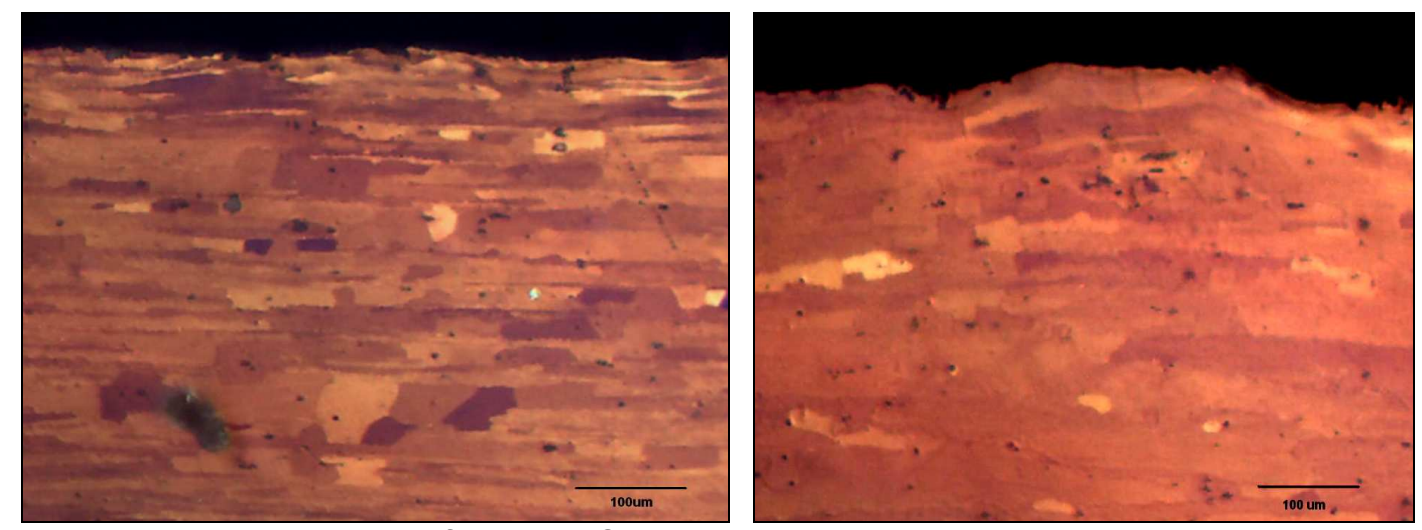

Figuras 39a e 39b: Micrografias em MO das amostras $2 \mathrm{~mm}$, jateadas a pressão de 20 e 60 psi em condição de carregamento pré tensionado em granalhas S230

Nota-se pela avaliação das imagens os efeitos causados na superfície das amostras, observando o aspecto ondulado e deformado nos relevos das amostras jateadas com 20 e 60 psi.

O efeito destrutivo que as granalhas proporcionam na superfície leva a considerar as vantagens ou desvantagens na aplicação de maiores pressões de jateamento, sendo que o mesmo pode resultar em efeitos deletérios, como a diminuição da resistência à fadiga pelo surgimento de micro trincas, além da formação de pontos de corrosão. Observando a tabela 9 percebe-se que o fator de concentração de tensão $(\mathrm{Kt})$, é maior para as amostras jateadas com pressões maiores, obtendo-se valores de 1,21 para pressões de 20 psi e 1,25 para pressões de 60 psi para amostras pré tensionadas e variações do tipo Kt igual a 1,20 para pressão de 20 psi e 1,29 para a pressão de $60 \mathrm{psi}$ em amostras não tensionadas.

A seguir serão demonstrados os estudos relacionados às amostras de $5 \mathrm{~mm}$ de espessura com aplicação de peen forming com granalha S230. As figuras 40 e 41 apresentam o comportamento das curvas de tensão residual nas amostras com espessura de $5 \mathrm{~mm}$, com variação de pressão em 20, 40 e 60 psi para amostras pré tensionadas e sem a aplicação da pré tensão respectivamente. Os dados de tensão foram ajustados com função polinomial de grau 3 . 


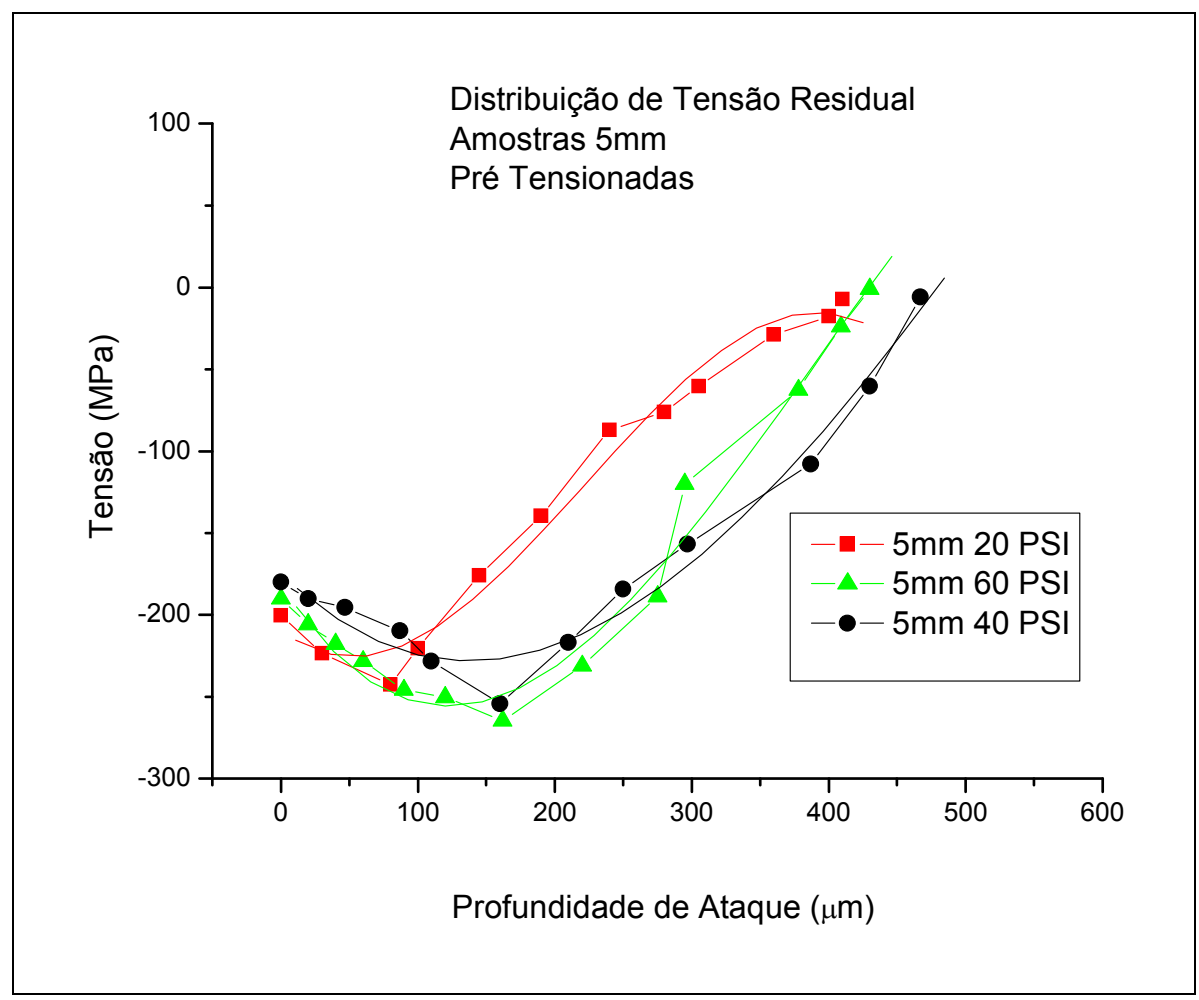

Figura 40: Distribuição de tensão residual em amostras de $5 \mathrm{~mm}$ de espessura com a aplicação do pré tensionamento em granalha S230.

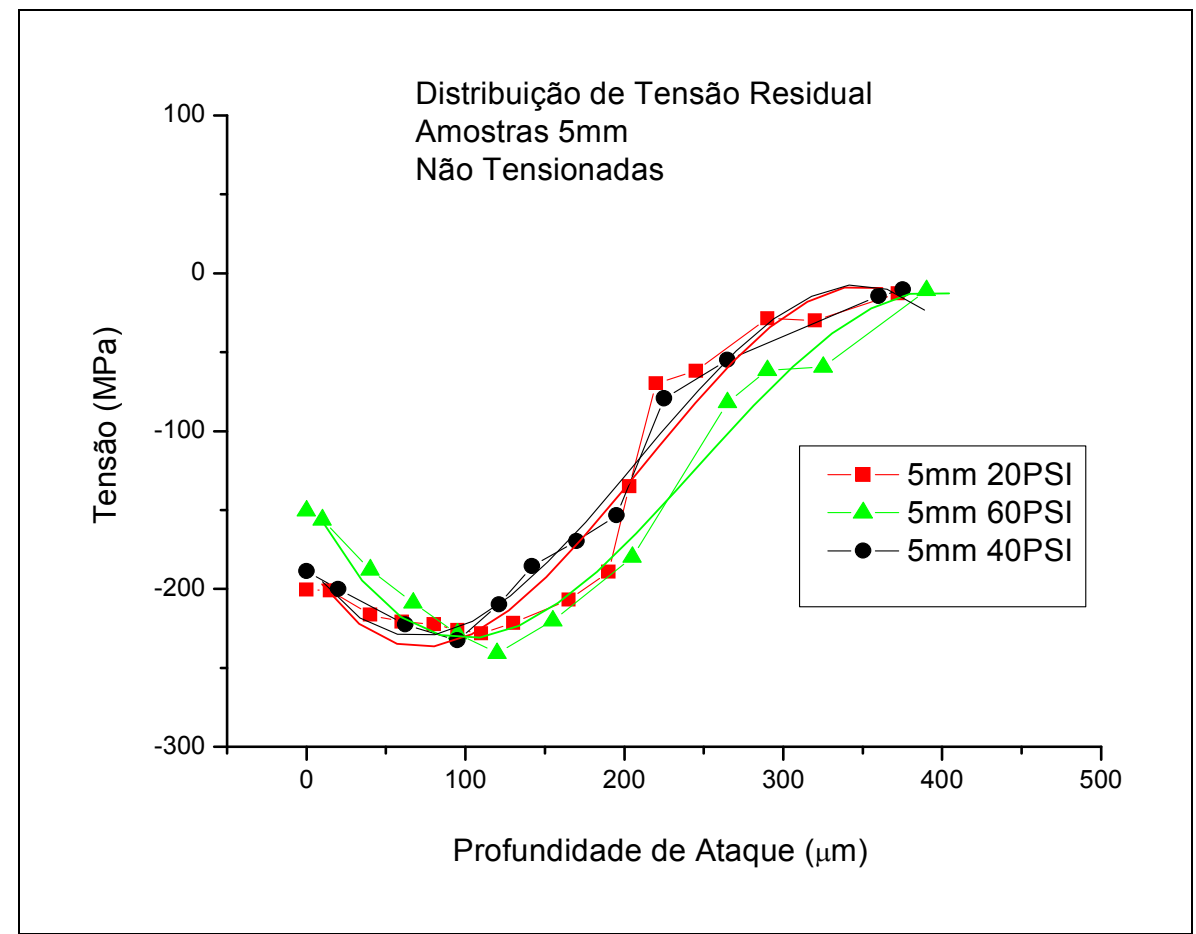

Figura 41: Distribuição de tensão residual em amostras de $5 \mathrm{~mm}$ de espessura sem a aplicação do pré tensionamento em granalha S230. 
A tabela 9 apresenta a relação dos gráficos acima (figuras 40 e 41) demonstrando os valores numericamente obtidos para os principais pontos de tensão residual e os pontos relativos à profundidade em função do regime de pressão.

Tabela 9: Relação entre pressão, tensão e profundidade para amostras $5 \mathrm{~mm}$ de espessura jateadas com $\mathrm{S} 230$

\begin{tabular}{|c|c|c|c|c|c|}
\hline & Pressão(psi) & $\begin{array}{c}\mu \boldsymbol{\sigma}_{\text {máx }} \\
(\boldsymbol{\mu m})\end{array}$ & $\begin{array}{c}\boldsymbol{\sigma}_{\text {máx }} \\
(\mathbf{M P a})\end{array}$ & $\begin{array}{c}\boldsymbol{\sigma}_{\text {sup }} \\
(\mathbf{M P a})\end{array}$ & $\boldsymbol{\mu \sigma _ { \text { tot } } ( \boldsymbol { \mu m } )}$ \\
\hline \multirow{2}{*}{$\begin{array}{c}\text { Pmm } \\
\text { Pré }\end{array}$} & 20 & 62 & -225 & -200 & 412 \\
\cline { 2 - 6 } & 40 & 130 & -227 & -180 & 470 \\
\cline { 2 - 6 } & 60 & 120 & -255 & -190 & 430 \\
\hline \multirow{2}{*}{$\begin{array}{c}\text { Não } \\
\text { tensionada }\end{array}$} & 20 & 80 & -236 & -200 & 410 \\
\cline { 2 - 6 } & 40 & 81 & -229 & -188 & 400 \\
\hline
\end{tabular}

De acordo com a tabela 9, observa-se a semelhança entre resultados obtidos em relação às amostras de $2 \mathrm{~mm}$, nas mesmas condições de regime de pressão e carregamento externo (tabela 8), sendo que os valores de tensão máxima $\left(\sigma_{\text {máx }}\right)$ não apresentaram variações significativas, com diferença de -30 MPa entre o maior e o menor valor. A tensão residual em superfície $\left(\sigma_{\text {sup }}\right)$ apresentou a tendência ao menor valor em regimes de maior pressão, considerando assim o mesmo comportamento para amostras de espessura de $2 \mathrm{~mm}$.

Não foi verificado variações significativas de profundidade máxima $\left(\mu \sigma_{\text {tot }}\right)$ até onde se mantém o estado de tensão residual de compressão

Observando as figuras $42 \mathrm{a}$ e $42 \mathrm{~b}$ o aspecto da superfície das amostras de $5 \mathrm{~mm}$ de espessura, jateadas em granalhas S230 com 20 psi e 60 psi respectivamente, com aplicação de tensionamento.

Pelas micrografias apresentadas não é possível notar pelo aspecto do relevo diferenças significativas em relação a aplicação de diferentes pressões de jateamento. Sendo assim se obtém a relação com os dados da tabela 9 onde se demonstra que a diferença entre as tensões residuais na superfície $\left(\sigma_{\text {sup }}\right)$ são insignificantes 
(a)

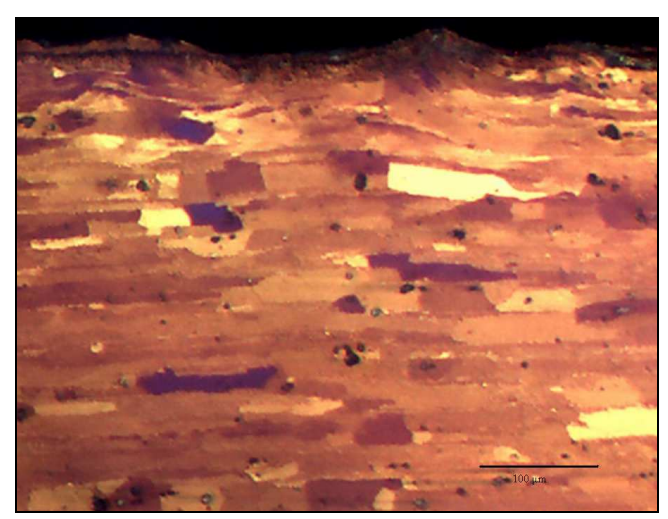

(b)

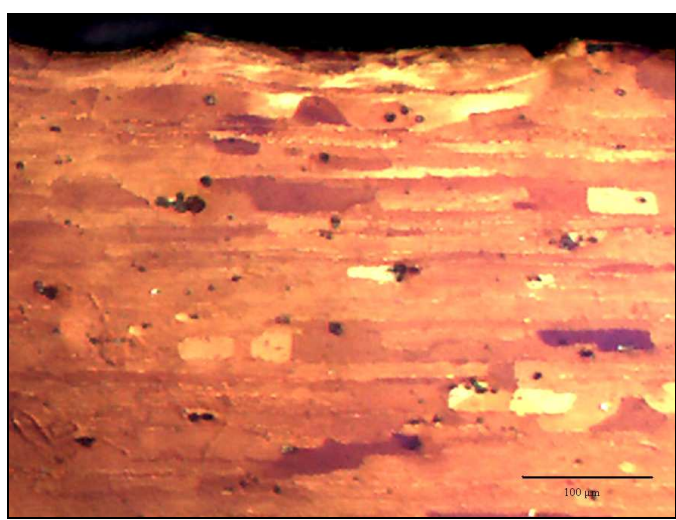

Figuras 42a e 42b: Micrografias em MO das amostras $5 \mathrm{~mm}$, jateadas a pressão de 20 e 60 psi em condição de carregamento pré tensionado em granalhas S230.

O impacto causado na superfície das amostras pelo peen forming induz um momento fletor correspondido pela resistência do material. $\mathrm{O}$ balanceamento de momentos fletores após o jateamento configuram a formação de uma curvatura na superfície relativa a região deformada plasticamente. As figuras 43 e 44 apresentam os valores dos arcos formados para as amostras de $2 \mathrm{~mm}$ e $5 \mathrm{~mm}$ respectivamente. A figura 43 apresenta um comparativo entre as amostras de $2 \mathrm{~mm}$ nas condições de pré tensionamento e sem a aplicação de tensão. Nota-se que, para ambas as amostras, o aumento de pressão de jateamento incrementa o valor da altura do arco formado e a taxa de aumento do tamanho do arco decresce com a taxa de aumento de pressão até o ponto no qual o aumento de pressão não implicaria no tamanho do aumento da altura do arco, ponto este denominado ponto de saturação. 0 mesmo comportamento é observado na figura 44 , onde o ponto de saturação é atingido na pressão de 60 psi 


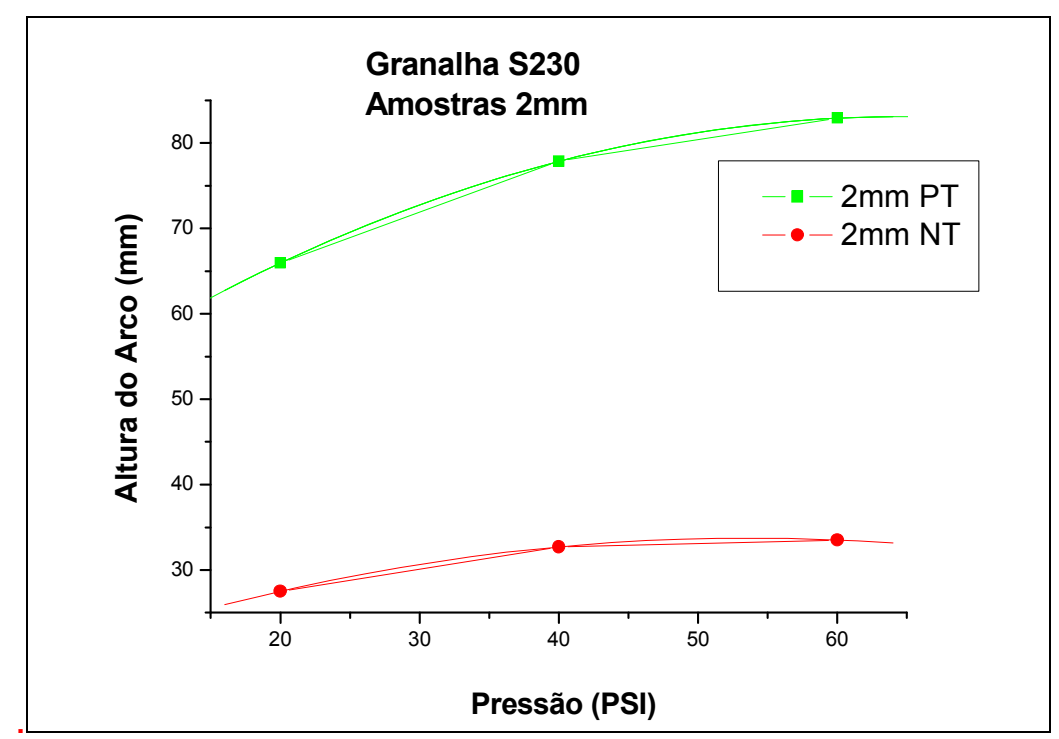

Figura 43: Formação da altura do arco pelo peen forming em amostras de $2 \mathrm{~mm}$ jateadas em S230..

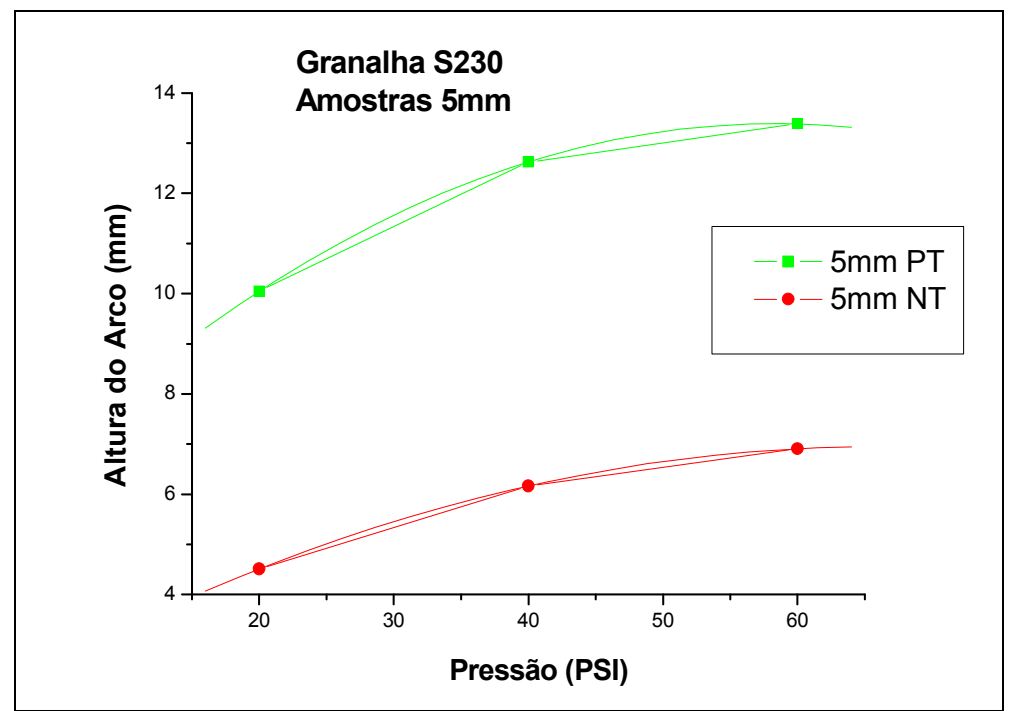

Figura 44: Formação da altura do arco pelo peen forming em amostras de $5 \mathrm{~mm}$ jateadas em S230.

Para ambas as amostras, o pré tensionamento favorece a conformação das chapas com arcos maiores. A tabela 10 apresenta os resultados numericamente expressos das figuras 43 e 44 . 
Tabela 10: Resultados dos valores do raio de curvatura após o processo peen forming em parâmetros de regime de pressão e aplicação de pré tensão em amostras jateadas em S230.

\begin{tabular}{|c|c|c|c|c|}
\hline $\begin{array}{l}\text { Espessura } \\
\text { Granalha }\end{array}$ & Pressão (psi) & $\begin{array}{c}\text { Carregamento } \\
\mathbf{S}=\text { Pré tensionado } \\
\mathrm{N}=\mathbf{N a ̃ o} \\
\text { tensionado }\end{array}$ & $\begin{array}{l}\text { Raio de } \\
\text { curvatura } \\
(\mathbf{m m})\end{array}$ & $\begin{array}{c}\text { Altura do } \\
\text { Arco (mm) }\end{array}$ \\
\hline \multirow[b]{2}{*}{$2 \mathrm{~mm}$} & \multirow[t]{2}{*}{20} & $\mathrm{~S}$ & 303,26 & 65,50 \\
\hline & & $\mathrm{N}$ & 727,27 & 27,50 \\
\hline \multirow{4}{*}{$\mathbf{S 2 3 0}$} & \multirow[t]{2}{*}{40} & $\mathrm{~S}$ & 256,87 & 77,60 \\
\hline & & $\mathrm{N}$ & 611,80 & 32,90 \\
\hline & \multirow[t]{2}{*}{60} & $\mathrm{~S}$ & 241,22 & 82,10 \\
\hline & & $\mathrm{N}$ & 595,77 & 33,70 \\
\hline \multirow{3}{*}{$5 \mathrm{~mm}$} & \multirow[t]{2}{*}{20} & $\mathrm{~S}$ & 1990,04 & 10,05 \\
\hline & & $\mathrm{N}$ & 4434,59 & 4,51 \\
\hline & \multirow[t]{2}{*}{40} & $\mathrm{~S}$ & 1583,53 & 12,63 \\
\hline \multirow[t]{3}{*}{$\mathbf{S} 230$} & & $\mathrm{~N}$ & 3246,75 & 6,16 \\
\hline & \multirow[t]{2}{*}{60} & $\mathrm{~S}$ & 1494,77 & 13,38 \\
\hline & & $\mathrm{N}$ & 2894,36 & 6,91 \\
\hline
\end{tabular}

A tabela 11 apresenta os valores dos fatores de concentração de tensão das amostras com 2 e $5 \mathrm{~mm}$ de espessura jateadas com granalhas S230.

Tabela 11: Resultados dos fatores de concentração obtidos em relação ao regime de pressão e carregamento das amostras de alumínio 7050 em espessura de 2 e 5mm, granalhas S230

\begin{tabular}{|c|c|c|c|}
\hline $\begin{array}{l}\text { Espessura } \\
\text { Granalha }\end{array}$ & Carregamento & $\begin{array}{c}\text { Pressão } \\
\text { (psi) }\end{array}$ & $\mathrm{K}_{\mathrm{t}}$ \\
\hline \multirow{3}{*}{$2 \mathrm{~mm}$} & \multirow{3}{*}{ Pré Tensionado } & 20 & 1,21 \\
\hline & & 40 & 1,22 \\
\hline & & 60 & 1,25 \\
\hline \multirow[t]{3}{*}{$\mathbf{S} 230$} & \multirow{3}{*}{ Não Tensionado } & 20 & 1,20 \\
\hline & & 40 & 1,24 \\
\hline & & 60 & 1,29 \\
\hline \multirow{3}{*}{$5 \mathrm{~mm}$} & \multirow{3}{*}{ Pré Tensionado } & 20 & 1,22 \\
\hline & & 40 & 1,24 \\
\hline & & 60 & 1,26 \\
\hline \multirow[t]{3}{*}{$\mathbf{S 2 3 0}$} & \multirow{3}{*}{ Não Tensionado } & 20 & 1,25 \\
\hline & & 40 & 1,26 \\
\hline & & 60 & 1,27 \\
\hline
\end{tabular}


O fator de concentração de tensão apresenta a mesma tendência observada para as amostras com $2 \mathrm{~mm}$ de espessura, isto é, quanto maior a pressão de jateamento, maior o fator de concentração de tensão. Além disso as amostras não tensionadas apresentam maior fator de concentração de tensão quando comparadas as amostras tensionadas.

Pode-se concluir que o desempenho do peen forming depende da pressão de jateamento, espessura da chapa, tipo de granalha e pré tensão aplicada e que o fato da amostra possuir diferentes espessuras ou se elas foram tensionadas ou não, pouco interfere nos resultados de fator de concentração de tensão $\left(\mathrm{K}_{\mathrm{t}}\right)$.. Este age como acelerador na nucleação e propagação de trincas o que leva à diminuição da resistência à fadiga do material. O acréscimo de pressão de jateamento não interfere na tensão residual máxima atingida ( $\sigma_{\text {máx }}$ ), embora o aumento de pressão de jateamento não induz o acréscimo da tensão residual na superfície do material

De um modo geral, quanto maior a pressão de jateamento, tamanho da granalha e menor espessura do material, maior é a altura do arco de curvatura. O fator de concentração de tensão é menor para pressões menores e menores granalhas nas duas situações com e sem a aplicação da pré tensão.

\subsubsection{Granalha S550}

A linha de trabalho com as granalhas S550 segue a mesma lógica dos trabalhos realizados com as granalhas $\$ 230$, ocorrendo uma significativa diferença nos parâmetros de regime de pressão, passando de 20,40 e 60 psi com granalhas S230 para 10, 20 e 30 psi com as granalhas S550, adequando às condições do processo de jateamento, pois pressões maiores com granalhas maiores causariam efeitos destrutivos na superfície do material.

As figuras 45 e 46 apresentam a distribuição de tensão residual nas amostras de $5 \mathrm{~mm}$ de espessura pré tensionadas e sem tensionamento. 


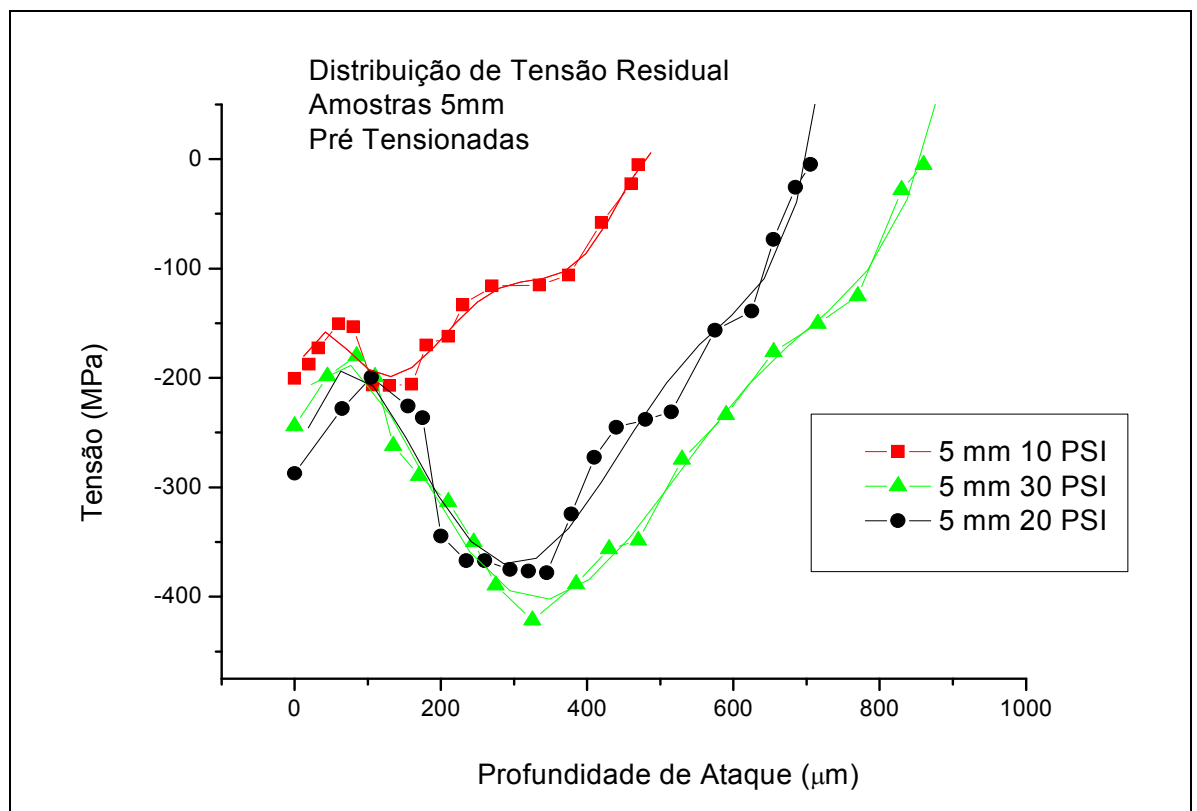

Figura 45: Distribuição de tensão residual em amostras de $5 \mathrm{~mm}$ de espessura com a aplicação do pré tensionamento em granalha S550.

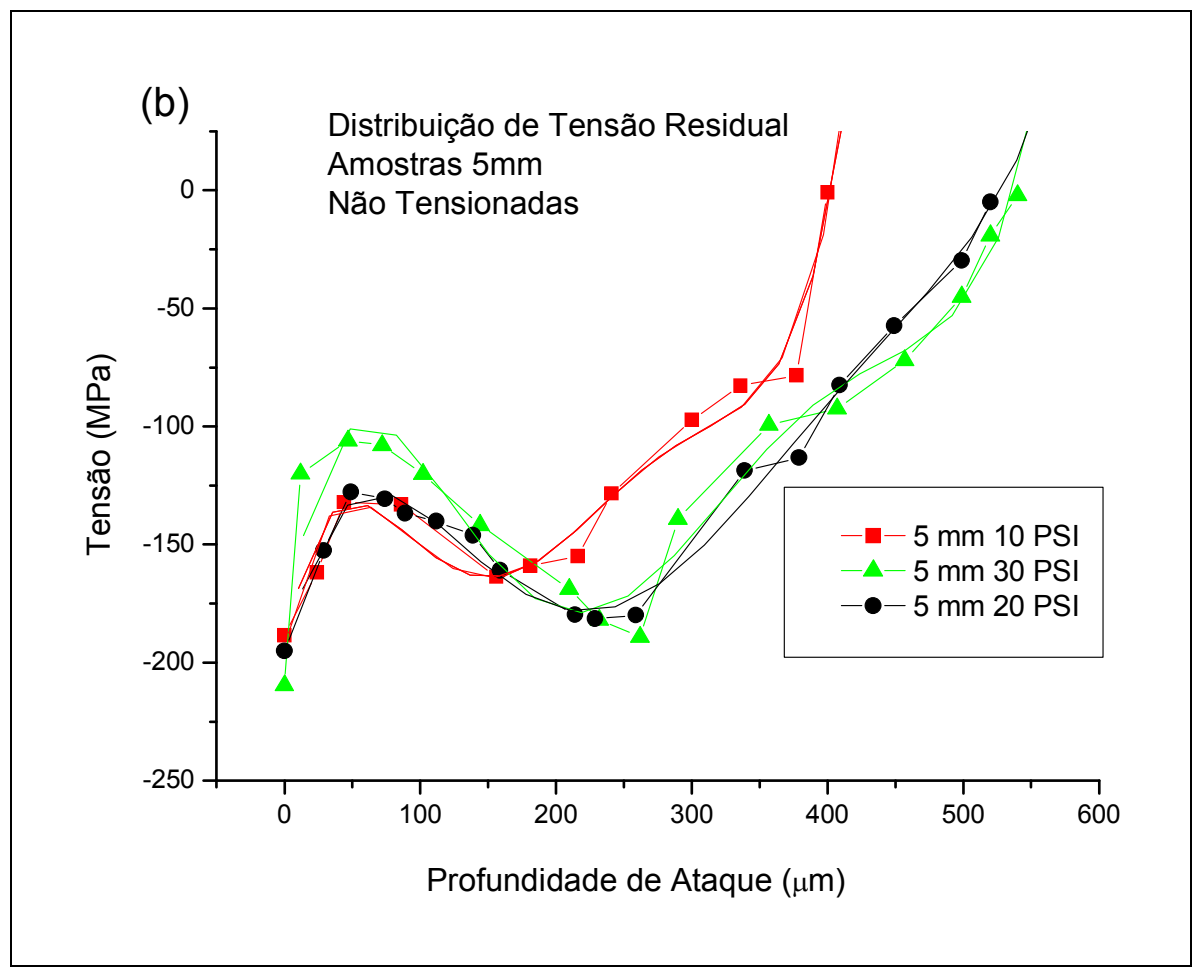

Figura 46: Distribuição de tensão residual em amostras de $5 \mathrm{~mm}$ de espessura sem a aplicação do pré tensionamento em granalha S550. 
É observada a mudança no perfil das curvas de tensão residual em profundidade para ambas as amostras (com e sem pré tensionamento) apresentando um decréscimo inicial de tensão residual compressiva (a partir da $\left.\sigma_{\text {sup }}\right)$, atingindo o valor mínimo $\left(\sigma_{\mathrm{min}}\right)$ entre as profundidades de 40 a 100 $\mu \mathrm{m}$ e aumentando novamente até atingir um ponto de máxima tensão residual $\left(\sigma_{\text {máx }}\right)$ vindo a decrescer até passar para o regime de tração. As curvas típicas de tensão residual em profundidade são aquelas apresentadas pelas figuras $37,38,40$ e 41 , isto é, na superfície ocorre tensão residual de compressão que vai aumentando conforme aumenta a profundidade, até atingir um valor máximo, que depois vai paulatinamente aliviando até anular a começar a zona de tensões trativas. As curvas apresentadas nas figuras $45,46,48,49,52,53,54$ e 55 apresentam este comportamento diferente das curvas típicas de tensão residual, que doravante será chamado de comportamento anômalo.

As micrografias apresentadas nas figuras $47 \mathrm{a}$ e $47 \mathrm{~b}$ mostram o corte longitudinal das amostras $5 \mathrm{~mm}$ de espessura, pré tensionadas, jateadas com granalhas $\mathbf{5} 550,10$ e 20 psi, respectivamente.

(a)

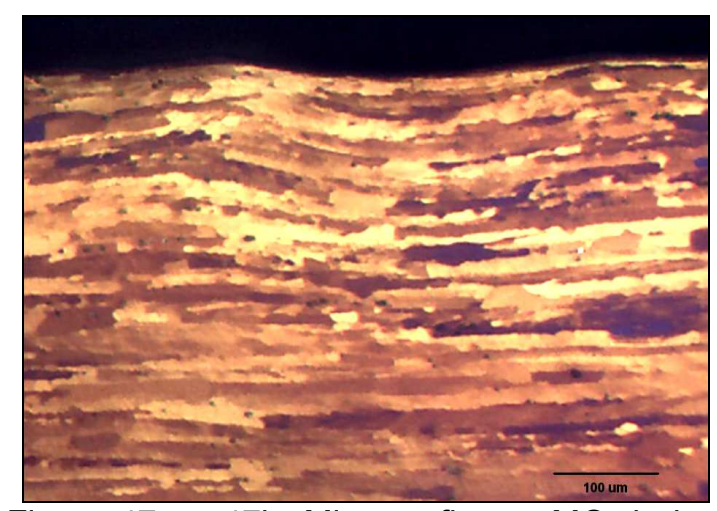

Figura 47a e 47b: Micrografia em MO de luz polarizada de Al 7050 jateada com granalha

(b)

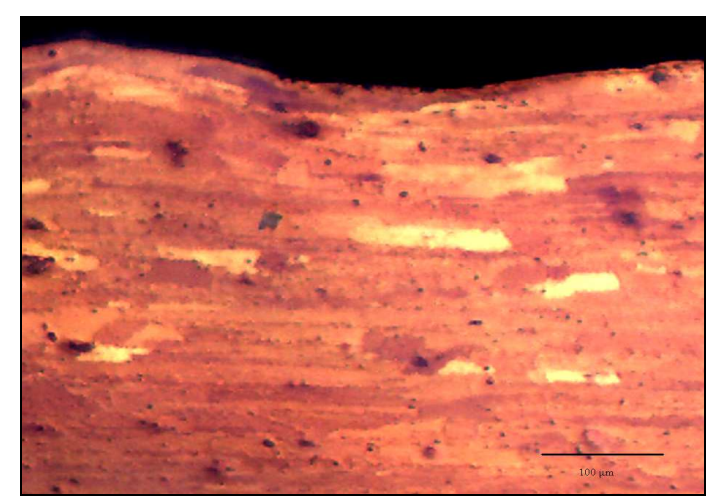

S550, 10 e 20 psi.

Perceber-se que as superfícies apresentam topografia ondulada, sugerindo que algumas regiões sofreram mais deformação plástica que outras, o que pode induzir diferentes valores de tensão residual nas sub superfícies. Pode-se também perceber que os grãos abaixo a superfície 
também apresentam comportamento alongado até aproximadamente 100 $\mu \mathrm{m}$. As micrografias apresentadas nas figuras 39a e 39b para amostras jateadas com granalhas $S 230 \mathrm{em} 2 \mathrm{~mm}$ de espessura não apresentam ondulações superficiais.

A avaliação das curvas de tensão residual está descrita na tabela 12.

Tabela 12: Relação entre pressão, tensão e profundidade para amostras $5 \mathrm{~mm}$ de espessura jateadas com S550.

\begin{tabular}{|c|c|c|c|c|c|}
\hline & Pressão(psi) & $\begin{array}{c}\boldsymbol{\mu} \boldsymbol{\sigma}_{\text {máx }} \\
(\boldsymbol{\mu m})\end{array}$ & $\begin{array}{c}\boldsymbol{\sigma}_{\text {máx }} \\
(\mathbf{M P a})\end{array}$ & $\begin{array}{c}\boldsymbol{\sigma}_{\text {sup }} \\
(\mathbf{M P a})\end{array}$ & $\boldsymbol{\mu \boldsymbol { \sigma } _ { \text { tot } } ( \boldsymbol { \mu m } )}$ \\
\hline \multirow{2}{*}{$\begin{array}{c}\mathbf{5 m m} \\
\text { Pré }\end{array}$} & 10 & 131 & -198 & -201 & 481 \\
\cline { 2 - 6 } tensionada & 20 & 285 & -369 & -288 & 697 \\
\cline { 2 - 6 } & 30 & 348 & -402 & -244 & 821 \\
\hline \multirow{2}{*}{$\begin{array}{c}\mathbf{N m m} \\
\text { Não } \\
\text { tensionada }\end{array}$} & 10 & 154 & -164 & -189 & 402 \\
\cline { 2 - 6 } & 20 & 210 & -178 & -195 & 519 \\
\cline { 2 - 6 } & 30 & 218 & -179 & -210 & 535 \\
\hline
\end{tabular}

Diferentemente dos resultados obtidos nas amostras jateadas com as granalhas S230 (tabelas 8 e 9), os resultados da tensão residual compressiva máxima $\left(\sigma_{\text {máx }}\right)$ nas amostras pré tensionadas jateadas com as granalhas S550 obtiveram maiores valores de tensão compressiva em variações maiores conforme o aumento de pressão é aplicado, variando de $198 \mathrm{MPa}$ a -402 MPa, porém o mesmo não acontece com as amostras não tensionadas, ocorrendo uma variação insignificante (-164 MPa a -179 MPa), o que leva a considerar que o pré tensionamento causaria mais influência em relação ao aumento da tensão residual compressiva máxima.

Este fato também pode ser notado na distância atingida pela máxima tensão ( $\mu \sigma_{\text {Max }}$ ), cuja variação foi maior na amostra pré tensionada (variando de 131 a $348 \mu \mathrm{m}$ ) comparada às amostras não tensionadas (variando de 151 a $218 \mu \mathrm{m}$ ) e comparadas com as amostras jateadas com granalha S230 (tabela 9), cuja variação também foi pequena (de 96 a $122 \mu \mathrm{m}$ ) para as amostras de $2 \mathrm{~mm}$ de espessura pré tensionadas e de 118 a $154 \mu \mathrm{m}$ para as amostras não tensionadas.

Igual situação ocorre para a distância total sob tensão residual compressiva $\left(\mu \sigma_{\text {tot }}\right)$ onde houve uma variação muito maior nas amostras pré 
tensionadas (variando de 481 a $821 \mu \mathrm{m}$ ) em relação às amostras não tensionadas (variação de 405 a $535 \mu \mathrm{m}$ ) além do que se observa que esta variação fica mais acentuada conforme aumenta a pressão de jateamento. Este fato pode ser notado nos gráficos de distribuição da tensão residual representados pelas figuras 45 e 46 . Não se observa variações significativas na tensão residual na superfície $\left(\sigma_{\text {sup }}\right)$, para ambos os casos apresentados nas tabelas 9 e 12.

O estudo sobre a dureza foi realizado, conforme descrito no capítulo 5.5 , porém não houve como relacionar sua distribuição em comparação à distribuição de tensão residual. Os valores variaram entre 150 e $195 \mathrm{HV}$.

A seguir serão mostrados os gráficos referentes às amostras de 10 $\mathrm{mm}$ de espessura com a aplicação do peen forming jateadas com granalhas S550. As figuras 48 e 49 descrevem o comportamento das curvas de tensão residual com a variação de pressão em 10, 20 e 30 psi para amostras pré tensionadas e não tensionadas.

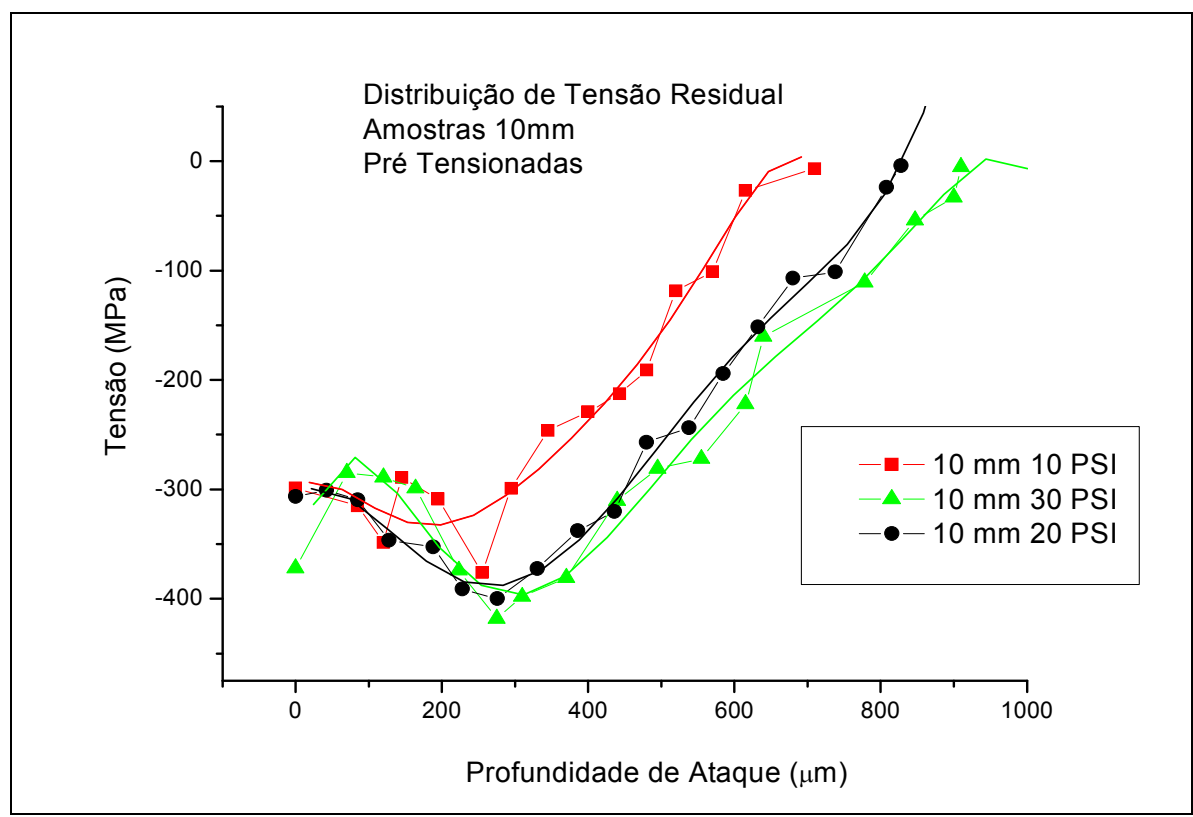

Figura 48: Distribuição de tensão residual em amostras de $10 \mathrm{~mm}$ de espessura com a aplicação do pré tensionamento em granalha S550. 


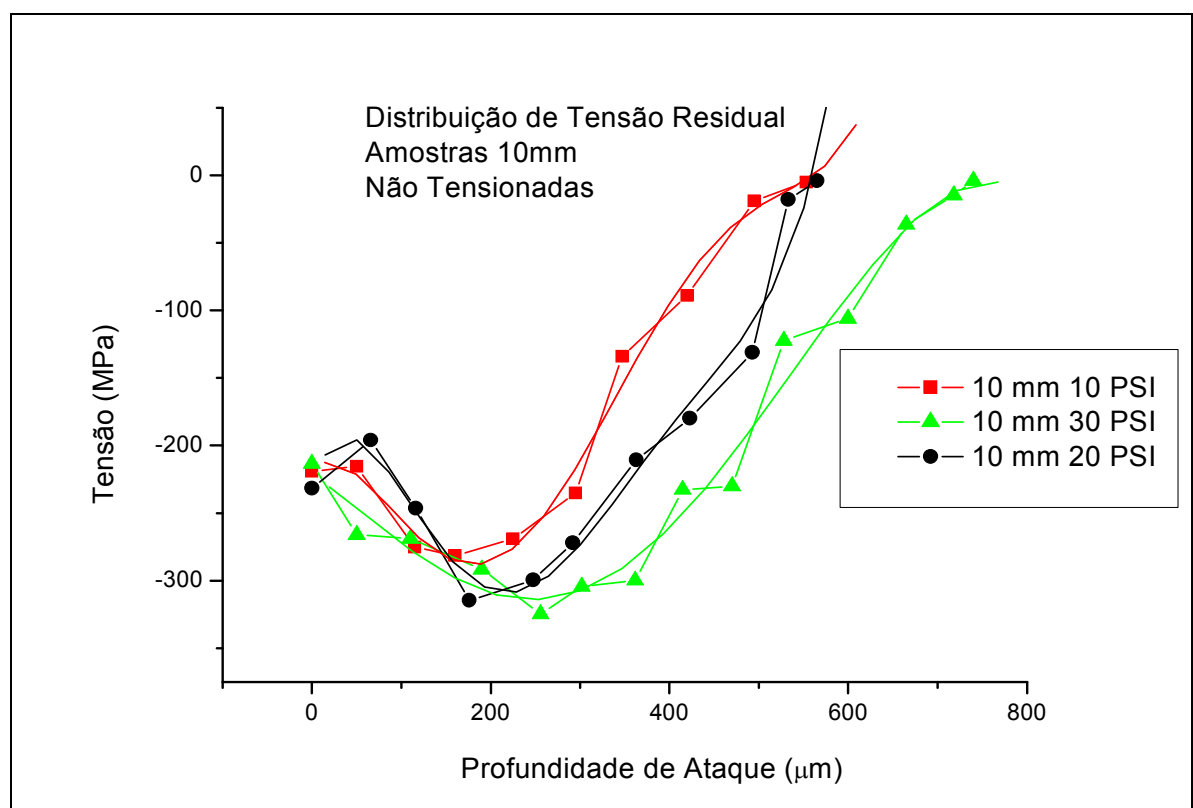

Figura 49: Distribuição de tensão residual em amostras de $10 \mathrm{~mm}$ de espessura sem a aplicação do pré tensionamento em granalha S550.

Os gráficos apresentados nas figuras 48 e 49 mostram mesmas características tanto dos gráficos apresentados nas figuras 45 e 46 tanto como as curvas típicas apresentadas nas figuras 40 e 41, mostrando que, nestas condições de jateamento em amostras com espessura maiores a tensão residual induzida está numa posição intermediária entre a curva típica e a curva do comportamento anômalo.

De qualquer forma, os valores de $\mu \sigma_{\text {máx }}, \sigma_{\text {máx }} \sigma_{\text {sup }} \mu \sigma_{\text {tot }}$ em função da pressão e do pré tensionamento estão apresentados na tabela 13:

Tabela 13: Relação entre pressão, tensão e profundidade para amostras $10 \mathrm{~mm}$ de espessura jateadas com S550.

\begin{tabular}{|c|c|c|c|c|c|}
\hline & Pressão(psi) & $\begin{array}{c}\boldsymbol{\mu} \boldsymbol{\sigma}_{\text {máx }} \\
(\boldsymbol{\mu m})\end{array}$ & $\begin{array}{c}\boldsymbol{\sigma}_{\text {máx }} \\
(\mathbf{M P a})\end{array}$ & $\begin{array}{c}\boldsymbol{\sigma}_{\text {sup }} \\
(\mathbf{M P a})\end{array}$ & $\boldsymbol{\mu \sigma}_{\text {tot }}(\boldsymbol{\mu m})$ \\
\hline \multirow{2}{*}{$\begin{array}{c}\mathbf{1 0 m m} \\
\text { Pré }\end{array}$} & 10 & 198 & -332 & -298 & 679 \\
\cline { 2 - 6 } & 20 & 283 & -387 & -317 & 827 \\
\cline { 2 - 6 } & 30 & 311 & -396 & -372 & 940 \\
\hline \multirow{2}{*}{$\begin{array}{c}\mathbf{1 0 m m} \\
\text { nâo }\end{array}$} & 10 & 189 & -287 & -219 & 558 \\
\cline { 2 - 6 } & 20 & 193 & -304 & -231 & 568 \\
\cline { 2 - 6 } & 30 & 253 & -313 & -213 & 770 \\
\hline
\end{tabular}


Os resultados da tabela 13 embora apresentem semelhanças com a tabela 12, no que se refere ao aumento dos valores em todos os segmentos, também apresentam algumas diferenças significativas, como: a faixa dos valores da tensão residual máxima $\left(\sigma_{\text {máx }}\right)$ e a distância máxima de tensão residual $\left(\mu \sigma_{\text {Max }}\right)$ são mais estreitas se comparadas às amostras de $5 \mathrm{~mm}$, indicando que tanto a espessura quanto o pré tensionamento são fatores importantes para o estado de tensão residual. Em relação a distância total de tensão residual compressiva $\left(\mu \sigma_{\text {tot }}\right.$ ) observa-se que quanto a maior pressão, maior a profundidade, com valores superiores quando comparadas com as amostras de $5 \mathrm{~mm}$. A tensão residual na superfície ( $\left.\sigma_{\text {sup }}\right)$ apesar da alta taxa de deformação na superfície e morfologia irregular, existe porém, uma tendência de acréscimo nos valores conforme se aumenta a pressão de jateamento, no entanto não se define ao certo a representatividade em ganho na tensão residual

A avaliação da formação da altura dos arcos estão representados pelas figuras 50 e 51 para amostras de 5 e $10 \mathrm{~mm}$ respectivamente. A figura 50 apresenta a comparação entre as amostras de $5 \mathrm{~mm}$ nas condições de pré tensionamento e sem a aplicação de tensão. Nestas amostras o aumento de pressão de jateamento incrementa o valor da altura do arco formado de modo que o aumento da pressão de jateamento até $30 \mathrm{psi}$, a altura do arco aumenta de forma linear não possibilitando determinar o ponto de saturação. Comparando com os resultados obtidos com granalhas S230 para amostras de $5 \mathrm{~mm}$ de espessura, percebe-se que a altura do arco formado com 40 psi de pressão para amostras jateadas com granalhas $\$ 230$ é de $13 \mathrm{~mm}$ e 6,2 $\mathrm{mm}$ para amostras com pré tensão e sem a pré tensão respectivamente. Estes valores são mais baixos que os obtidos para granalhas S550 com pressão de jateamento de 20 psi, cujos valores obtidos são de $20 \mathrm{~mm}$ e $8 \mathrm{~mm}$ para amostras pré tensionadas e sem a pré tensão, respectivamente. Além disso, partículas de granalhas S230 com momento de $5,7 \times 10^{-5} \mathrm{Kg} \cdot \mathrm{m} / \mathrm{s}$ levaram a saturação do arco de curvatura, enquanto que as partículas de granalha $\mathrm{S} 550 \mathrm{com}$ maior energia $\left(2,9 \times 10^{-4} \mathrm{Kg} \cdot \mathrm{m} / \mathrm{s}\right)$ não atingem o ponto de saturação, mostrando claramente que o tamanho da granalha tem influência no arco de saturação. Para amostras de $10 \mathrm{~mm}$ (figura 51) já é possível definir como sendo o ponto de saturação a pressão 
de jateamento de 30 psi mostrando que a espessura também é um fator importante para definir o arco de curvatura durante o peen forming.

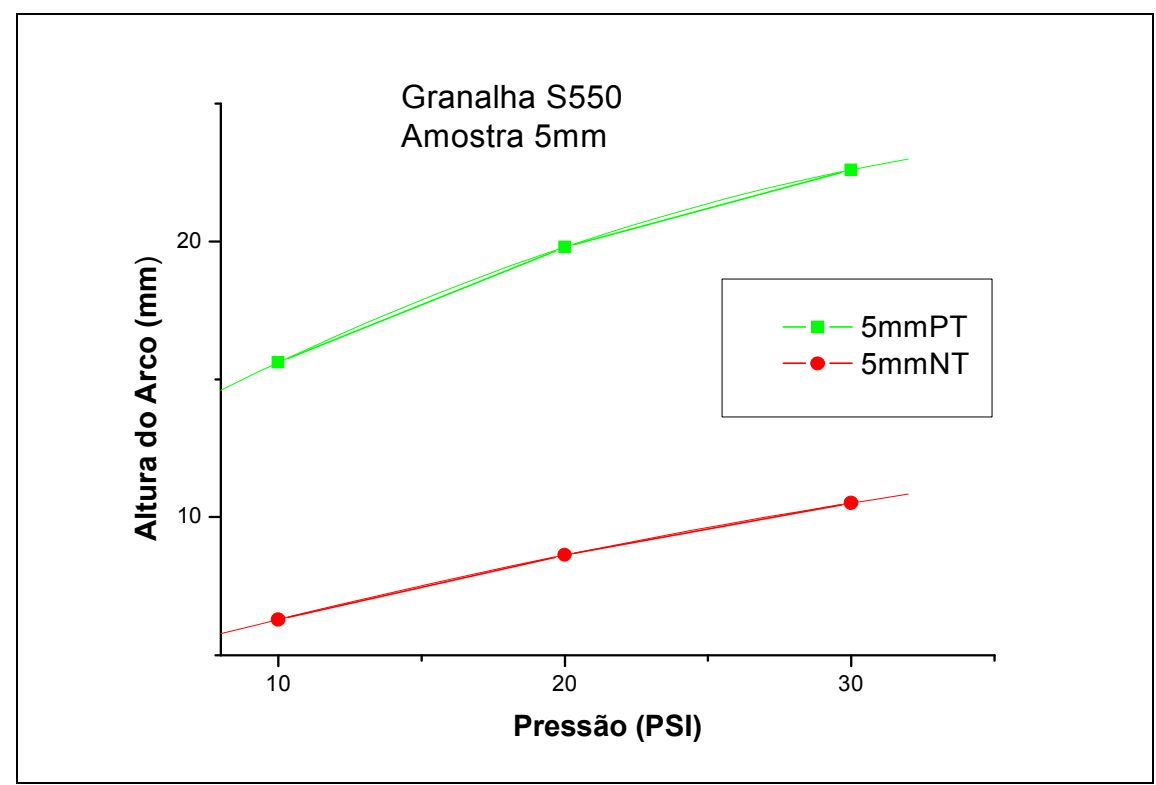

Figura 50: Formação da altura do arco pelo peen forming em amostras de $5 \mathrm{~mm}$ jateadas em S550

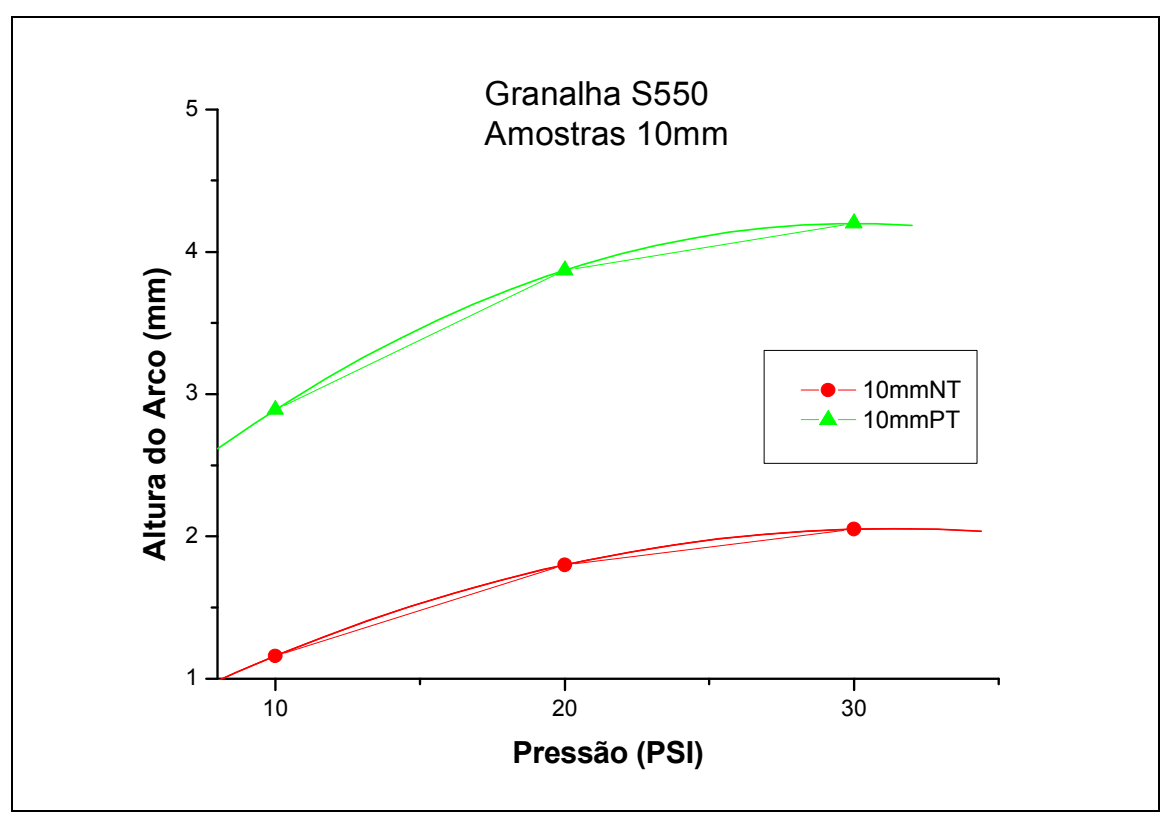

Figura 51: Formação do arco pelo peen forming em amostras de $10 \mathrm{~mm}$ jateadas em S550

Por meio da tabela 14 , os valores estão representados numericamente. 
Tabela 14: Resultados dos valores do raio de curvatura após o processo peen forming em parâmetros de regime de pressão e aplicação de pré tensão em amostras jateadas em S550.

\begin{tabular}{|c|c|c|c|c|}
\hline $\begin{array}{l}\text { Espessura } \\
\text { Granalha }\end{array}$ & Pressão (psi) & $\begin{array}{c}\text { Carregamento } \\
\mathbf{S}=\text { Pré tensionado } \\
\mathrm{N}=\mathbf{N a ̃ o} \\
\text { tensionado }\end{array}$ & $\begin{array}{l}\text { Raio de } \\
\text { curvatura } \\
(\mathbf{m m})\end{array}$ & $\begin{array}{l}\text { Altura do } \\
\text { Arco (mm) }\end{array}$ \\
\hline \multirow{3}{*}{$5 \mathrm{~mm}$} & \multirow[t]{2}{*}{10} & $\mathrm{~S}$ & 1281,23 & 15,61 \\
\hline & & $\mathrm{N}$ & 3179,65 & 6,29 \\
\hline & \multirow[t]{2}{*}{20} & S & 1010,10 & 19,80 \\
\hline \multirow[t]{3}{*}{ S550 } & & $\mathrm{N}$ & 2317,50 & 8,63 \\
\hline & \multirow[t]{2}{*}{30} & S & 884,96 & 22,60 \\
\hline & & $\mathrm{N}$ & 1901,14 & 10,52 \\
\hline \multirow{3}{*}{$10 \mathrm{~mm}$} & \multirow[t]{2}{*}{10} & S & 6920,41 & 2,89 \\
\hline & & $\mathrm{N}$ & 17241,38 & 1,16 \\
\hline & \multirow[t]{2}{*}{20} & $S$ & 5167,96 & 3,87 \\
\hline \multirow[t]{3}{*}{ S550 } & & $\mathrm{N}$ & 11111,11 & 1,80 \\
\hline & \multirow[t]{2}{*}{30} & $S$ & 4761,90 & 4,20 \\
\hline & & $\mathrm{N}$ & 9756,10 & 2,05 \\
\hline
\end{tabular}

O fator de concentração de tensão das amostras foi medido e encontra-se representado na tabela 15.

Tabela 15: Resultados dos fatores de concentração de tensão obtidos em relação ao regime de pressão e carregamento das amostras de alumínio 7050 para amostras 5 e $10 \mathrm{~mm}$, em granalhas S550

\begin{tabular}{|c|c|c|c|}
\hline $\begin{array}{l}\text { Espessura } \\
\text { Granalha }\end{array}$ & Carregamento & $\begin{array}{l}\text { Pressão } \\
\text { (psi) }\end{array}$ & $\mathrm{K}_{\mathrm{t}}$ \\
\hline \multirow{3}{*}{$5 \mathrm{~mm}$} & \multirow{3}{*}{ Pré Tensionado } & 10 & 1.11 \\
\hline & & 20 & 1.12 \\
\hline & & 30 & 1.12 \\
\hline \multirow[t]{3}{*}{ S550 } & \multirow{3}{*}{ Não Tensionado } & 10 & 1.12 \\
\hline & & 20 & 1.13 \\
\hline & & 30 & 1.16 \\
\hline \multirow{6}{*}{$10 \mathrm{~mm}$} & \multirow{3}{*}{ Pré Tensionado } & 10 & 1.11 \\
\hline & & 20 & 1.11 \\
\hline & & 30 & 1.11 \\
\hline & \multirow{3}{*}{ Não Tensionado } & 10 & 1.11 \\
\hline & & 20 & 1.14 \\
\hline & & 30 & 1.15 \\
\hline
\end{tabular}

Neste caso, a variação do fator de concentração ocorreu de forma proporcional ao regime de pressão de jateamento, semelhante às amostras 
jateadas com a granalha S230 (tabela 11), porém com valores inferiores, o que leva a suposição de que amostras jateadas com a granalha S550 estão menos susceptíveis à formação de micro trincas e expostos ao aumento da resistência à fadiga do que as amostras S230, porém este fato não pode ser conclusivo, pois como foi comentado anteriormente o desempenho da resistência a fadiga é uma combinação de vários aspectos, entre eles, o valor de tensão residual.

\subsubsection{Granalha 1/8"}

A aplicação do jateamento nas amostras de 10 e $15 \mathrm{~mm}$ de espessura, com granalhas de $1 / 8$ " nas condições de pré tensionamento e sem aplicação de pré tensão no regime de pressão de 10, 20 e 25 psi, possuem a distribuição da tensão residual em profundidade apresentas nas figuras 52 e 53 :

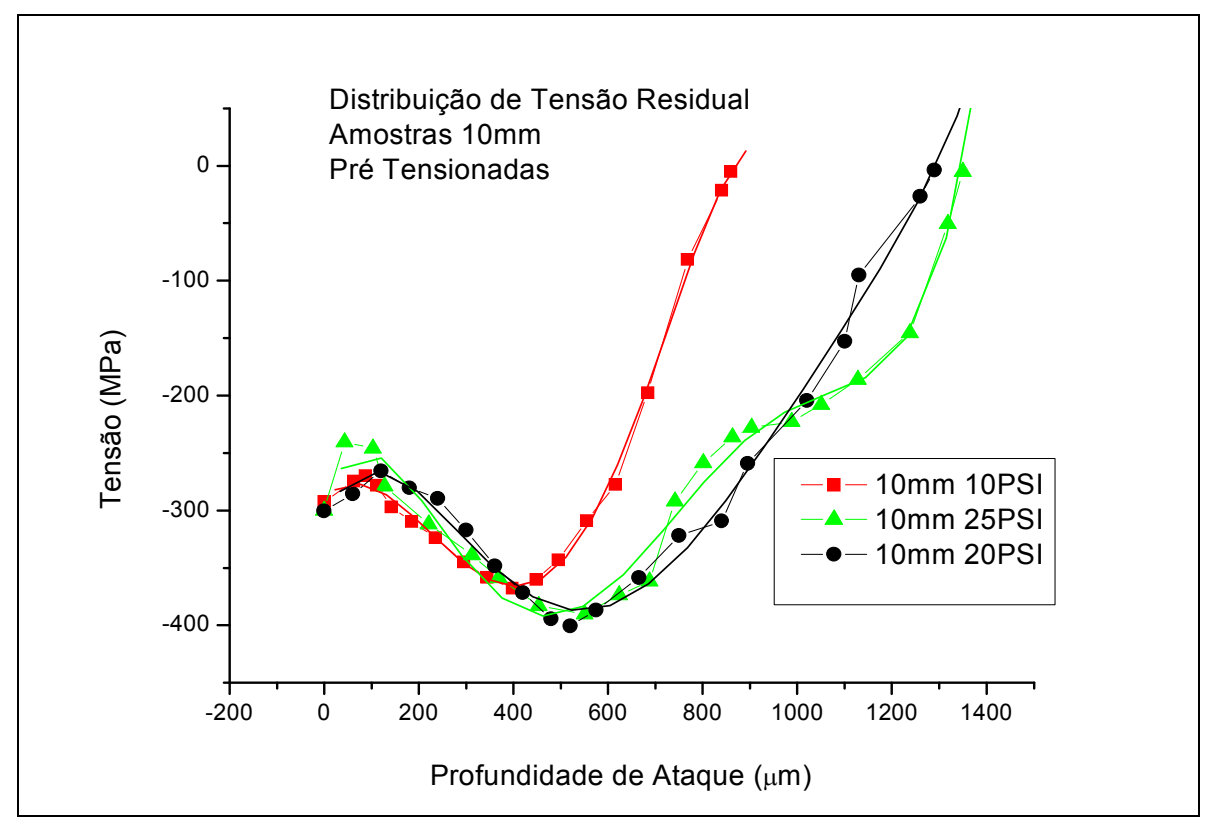

Figura 52: Distribuição de tensão residual em amostras de $10 \mathrm{~mm}$ de espessura com a aplicação do pré tensionamento em granalha 1/8". 


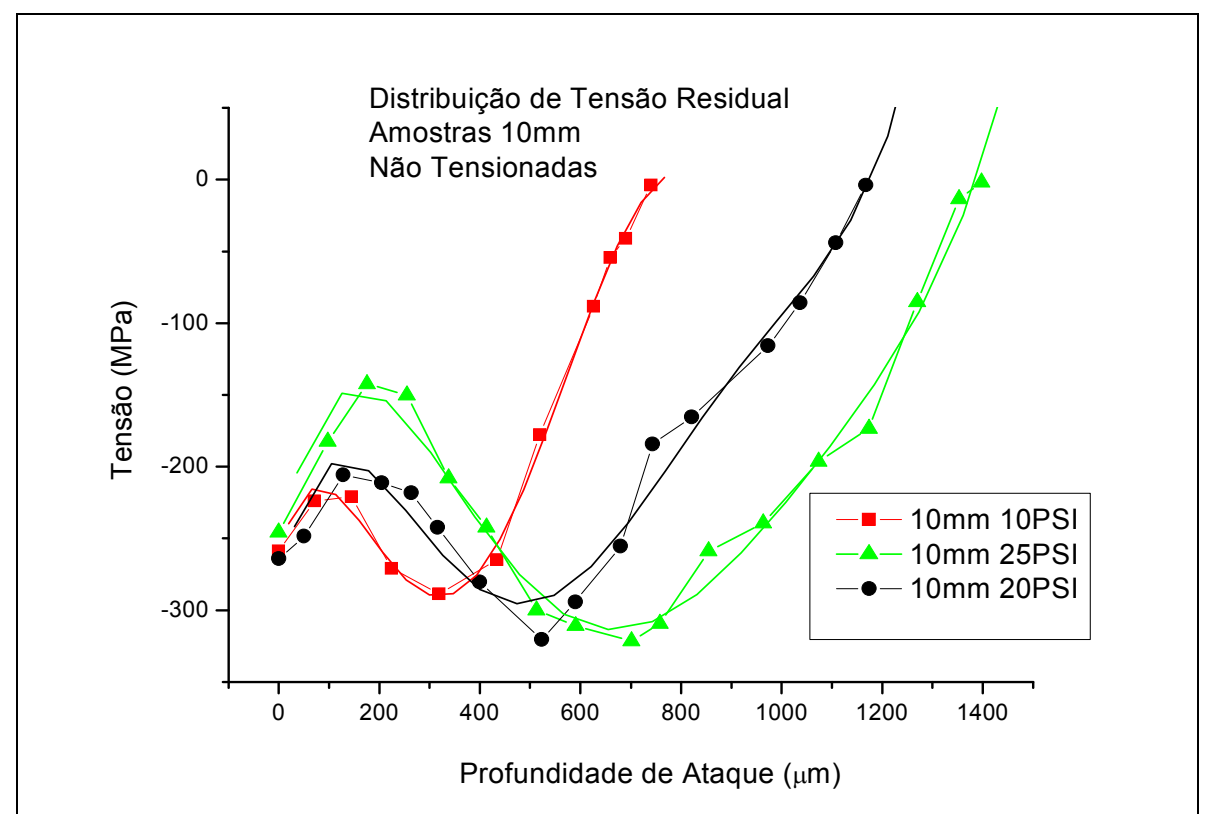

Figura 53: Distribuição de tensão residual em amostras de $10 \mathrm{~mm}$ de espessura sem a aplicação do pré tensionamento em granalha 1/8".

Nas figuras 52 e 53, o comportamento das curvas de distribuição de tensão residual apresentam o comportamento anômalo descrito nas amostras jateadas com as granalhas S550, podendo ser observado um decréscimo da tensão residual compressiva nas distâncias iniciais à superfície das amostras entre 50 a $100 \mu \mathrm{m}$ para as amostras pré tensionadas e 150 a $250 \mu \mathrm{m}$ para as amostras não tensionadas. Para profundidades maiores a tensão compressiva volta a aumentar até atingir seu máximo para profundidades de 402 a $522 \mu \mathrm{m}$ para amostras pré tensionadas e entre 346 a $654 \mu \mathrm{m}$ para amostras sem a pré tensão. Além disto, a profundidade máxima de tensão residual de compressão $\left(\mu \sigma_{\text {tot }}\right)$ é proporcional à pressão de jateamento. 
Tabela 16: Relação entre pressão, tensão e profundidade para amostras $10 \mathrm{~mm}$ de espessura jateadas com granalhas de 1/8".

\begin{tabular}{|c|c|c|c|c|c|}
\hline & Pressão(psi) & $\begin{array}{c}\mu \boldsymbol{\sigma}_{\text {máx }} \\
(\boldsymbol{\mu m})\end{array}$ & $\begin{array}{c}\boldsymbol{\sigma}_{\text {máx }} \\
(\mathbf{M P a})\end{array}$ & $\boldsymbol{\sigma}_{\text {sup }}(\mathbf{M P a})$ & $\boldsymbol{\mu} \boldsymbol{\sigma}_{\text {tot }}(\boldsymbol{\mu m})$ \\
\hline \multirow{2}{*}{$\mathbf{1 0 m m}$} & 10 & 402 & -366 & -292 & 871 \\
\cline { 2 - 6 } & 20 & 522 & -387 & -300 & 1288 \\
\cline { 2 - 6 } & 25 & 461 & -391 & -300 & 1342 \\
\hline \multirow{2}{*}{$\mathbf{1 0 m m}$} & 10 & 346 & -288 & -258 & 759 \\
\cline { 2 - 6 } $\mathbf{N T}$ & 20 & 473 & -295 & -264 & 1172 \\
\cline { 2 - 6 } & 25 & 654 & -313 & -245 & 1383 \\
\hline
\end{tabular}

Os resultados da tabela 16 complementam as informações mostradas nos gráficos apresentados nas figuras 52 e 53 , onde se obtém um comparativo entre as amostras jateadas com as granalhas $1 / 8$ " tensionadas e não tensionadas. Os resultados da tensão residual máxima ( $\left.\sigma_{\text {máx }}\right)$ apresentados na tabela 16 são semelhantes aos resultados obtidos na amostra de $10 \mathrm{~mm}$ jateadas com as granalhas S550 (tabela 13), indicando que o diâmetro da granalha, embora cause efeitos em termos de tensão residual de profundidade, não influencia no acréscimo de tensão compressiva máxima. O mesmo se aplica aos valores de tensão residual superficial $\left(\sigma_{\text {sup }}\right)$, pois os resultados são semelhantes em amostras de 10 $\mathrm{mm}$ jateadas com granalhas S550 (tabela 13), sendo as tensões residuais, obtidas nas amostras pré tensionadas, mais compressivas do que as amostras sem aplicação de pré tensão, tanto para as granalhas $1 / 8$ " como para as granalhas S550.

A distribuição de tensão residual para as amostras de $15 \mathrm{~mm}$ de espessura jateadas com granalhas de 1/8" estão apresentadas pelas figuras 54 e 55 . 


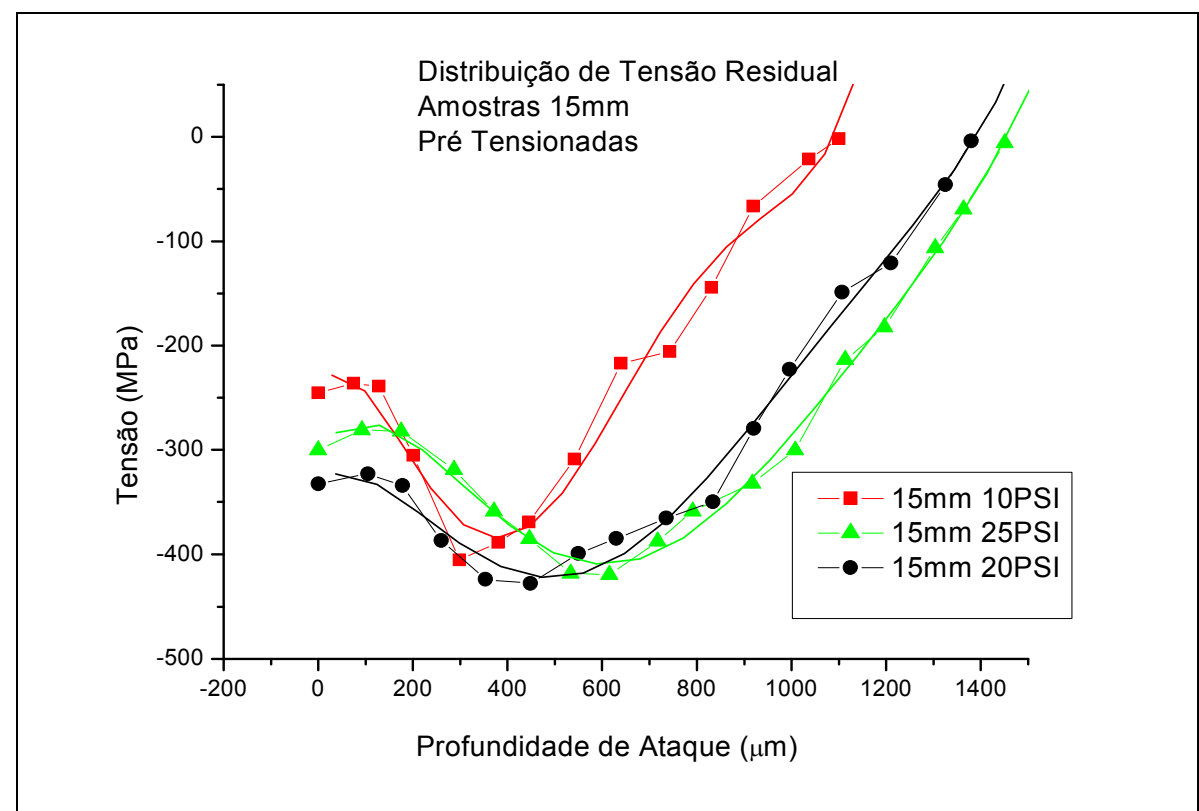

Figura 54: Distribuição de tensão residual em amostras de $15 \mathrm{~mm}$ de espessura com a aplicação do pré tensionamento em granalha 1/8".

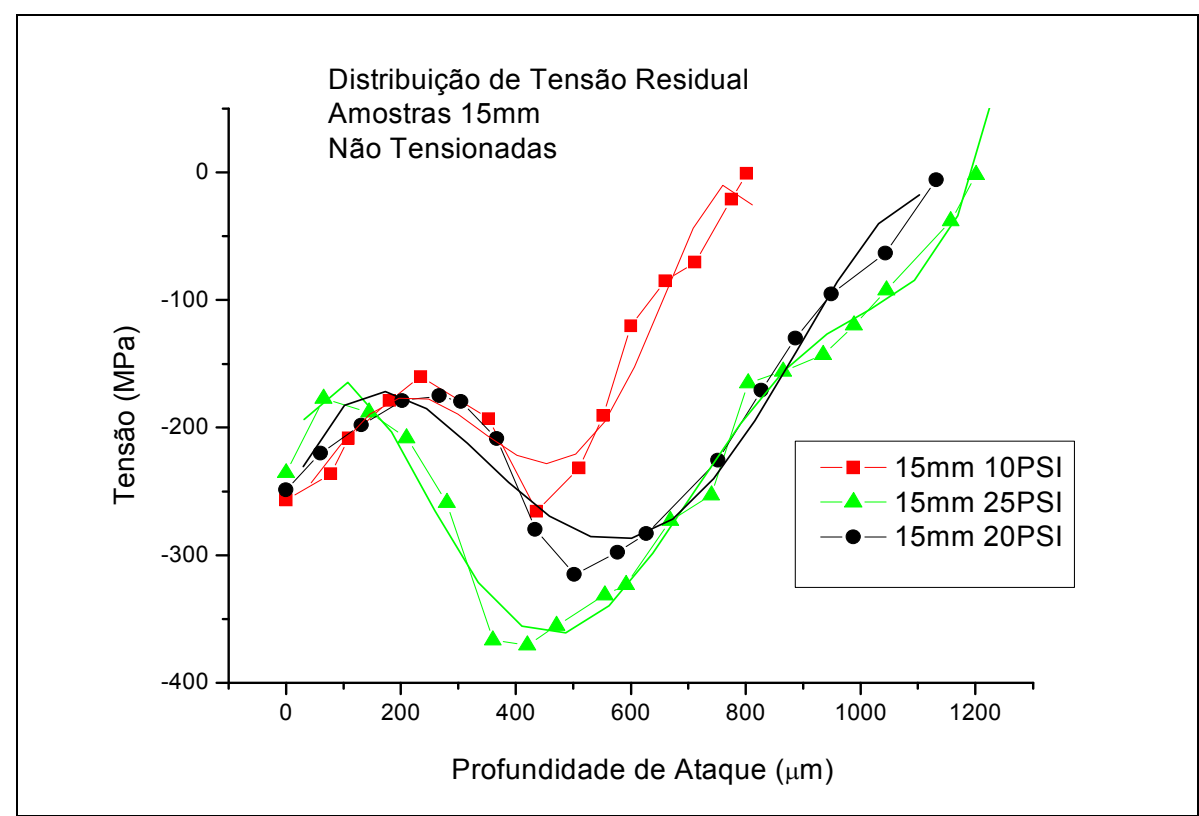

Figura 55: Distribuição de tensão residual em amostras de $15 \mathrm{~mm}$ de espessura sem a aplicação do pré tensionamento em granalha 1/8".

O comportamento apresentado pelas curvas de tensão residual em amostras de $15 \mathrm{~mm}$ de espessura jateadas com granalhas de 1/8" apresentaram o mesmo comportamento anômalo observado nas amostras de $10 \mathrm{~mm}$ jateadas nas mesmas condições (figuras 52 e 53). A tabela 17 destaca os valores de tensão compressiva máxima em profundidade ( $\mu \sigma_{\text {máx}}$ ) 
que variam de 376 a $588 \mu \mathrm{m}$ na amostras pré tensionadas e 299 a $602 \mu \mathrm{m}$ para as amostras sem pré tensão. A tensão residual compressiva máxima ficou entre -384 e -422 MPa nas amostras pré tensionadas e -228 e -360 MPa para as amostras sem pré tensão, que comparadas com os valores apresentados na tabela 16 mostram grande semelhança.

Tabela 17: Relação entre pressão, tensão e profundidade para amostras $15 \mathrm{~mm}$ de espessura jateadas com granalhas de 1/8".

\begin{tabular}{|c|c|c|c|c|c|}
\hline & Pressão(psi) & $\begin{array}{c}\boldsymbol{\mu} \boldsymbol{\sigma}_{\text {máx }} \\
(\boldsymbol{\mu m})\end{array}$ & $\begin{array}{c}\boldsymbol{\sigma}_{\text {máx }} \\
(\mathbf{M P a})\end{array}$ & $\boldsymbol{\sigma}_{\text {sup }}(\mathbf{M P a})$ & $\boldsymbol{\mu} \boldsymbol{\sigma}_{\text {tot }}(\boldsymbol{\mu m})$ \\
\hline \multirow{2}{*}{$\mathbf{1 5 m m}$} & 10 & 376 & -384 & -245 & 1085 \\
\cline { 2 - 6 } & 20 & 472 & -422 & -332 & 1385 \\
\cline { 2 - 6 } & 25 & 588 & -409 & -299 & 1451 \\
\hline \multirow{2}{*}{$\mathbf{1 5 m m}$} & 10 & 299 & -228 & -236 & 802 \\
\cline { 2 - 6 } & 20 & 602 & -287 & -249 & 1132 \\
\cline { 2 - 6 } & 25 & 486 & -360 & -235 & 1201 \\
\hline
\end{tabular}

Os resultados de tensão residual máxima $\left(\sigma_{\text {máx }}\right)$ seguem com a mesma regularidade da situação anterior (tabela 16) podendo ser observado que a intensidade de tensão residual compressiva tende a ser maior nas amostras pré tensionadas, visto que no processo de pré tensionamento, quando a força é liberada, o momento fletor é maior em relação às amostras não tensionadas. Os valores das profundidades, tanto a distância de tensão residual máxima ( $\mu \sigma_{\text {máx }}$ ) quanto a distancia de tensão residual compressiva total $\left(\mu \sigma_{\text {tot }}\right)$ encontram-se dentro do esperado para todas as condições, demonstrando que a espessura (entre 10 e $15 \mathrm{~mm}$ ) não influencia nos resultados obtidos.

Parece claro que o comportamento anômalo é dependente do diâmetro da esfera utilizada no jateamento, da energia e da espessura da chapa (quanto menor a espessura, menor a capacidade de absorção de energia e maior a alteração do seu estado de deformação).

Senão vejamos, quando incidirmos granalhas de mesmo diâmetro (S550) com momento linear entre 1,6 e 2,8 E-4 Kgm/s em chapas de espessuras diferentes ( 5 e $10 \mathrm{~mm}$ ) a chapa de $5 \mathrm{~mm}$ apresenta comportamento anômalo para todas as pressões estudadas, enquanto a 
chapa de $10 \mathrm{~mm}$ apresenta um comportamento intermediário entre as curvas típicas de deformação e a do comportamento anômalo. Quando utilizamos granalhas de 1/8" observamos que todas as curvas de tensão residual em profundidade apresentam comportamento anômalo independentemente de espessura, pressão e pré tensionamento. Vale ressaltar que o momento linear destas granalhas está em entre 1,3 e 1,9 E-3 Kgm/s.

Quando incidimos granalhas $\$ 230$ com momento linear entre 3,9 e $5,7 \mathrm{E}-5 \mathrm{Kgm} / \mathrm{s}$ as curvas de tensão residual de profundidade apresentam comportamento típico para chapas com espessura de $5 \mathrm{~mm}$.

Meguid e colaboradores (1998) utilizando simulação e modelamento pelo método de elementos finitos estudaram a tensão residual induzida pelo jateamento de granalhas de aço em aço. O modelamento foi conduzido considerando o efeito de duas granalhas encostadas uma na outra $(C / R=1)$ atingindo o alvo simultaneamente. A tensão residual em profundidade foi calculada na linha de centro de uma esfera e na linha de centro entre as duas esferas. A figura 56 apresenta o resultado mostrado no trabalho de Meguid.

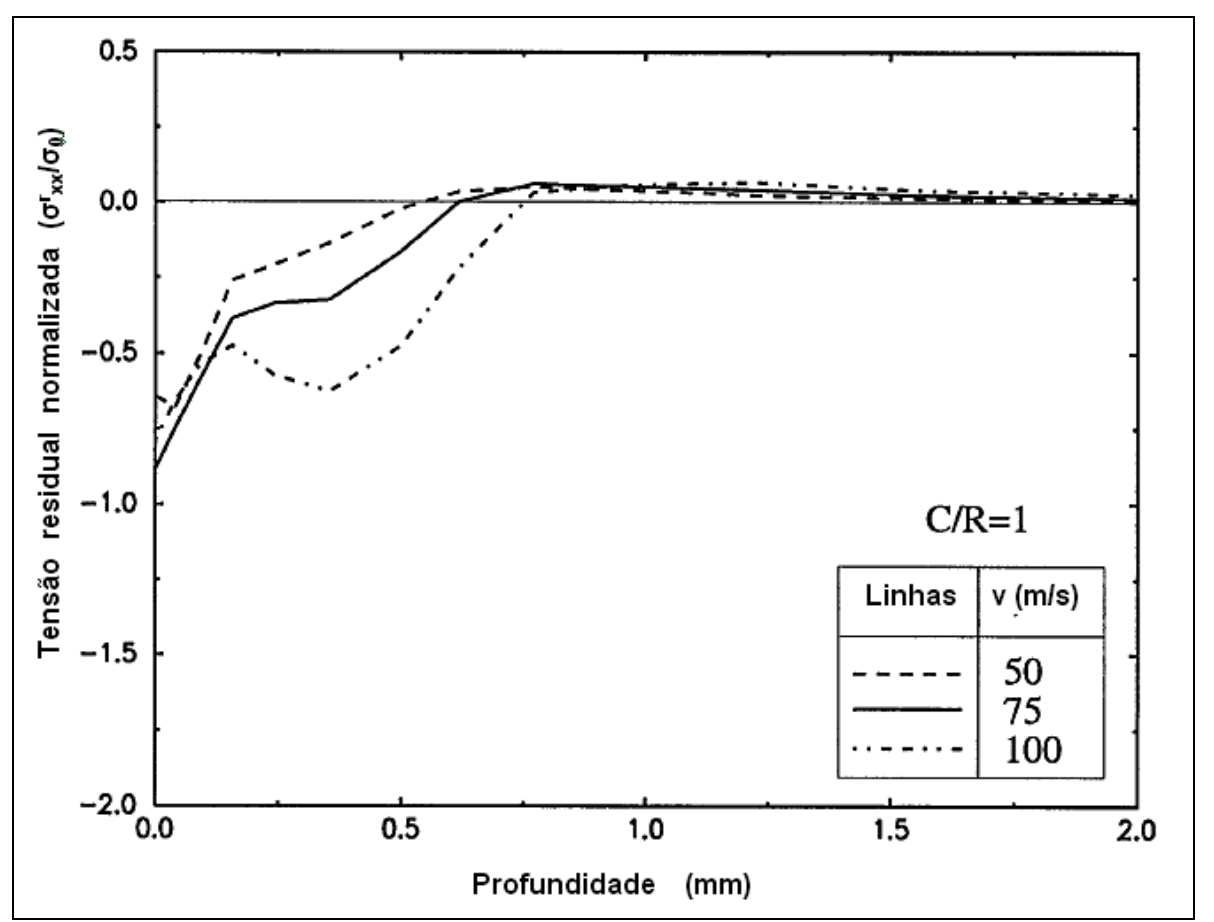

Figura 56: Resultado obtido por modelamento em jateamento com esfera de aço (Meguid et al, 1998). 
Verifica-se que a tensão residual em profundidade na linha de centro entre as duas esferas mostra comportamento semelhante ao obtido neste trabalho ao qual chamamos de comportamento anômalo. Este comportamento é dependente do momento linear das granalhas, de tal forma que a granalha com momento de 1,98E-04 Kgm/s apresenta o início do comportamento anômalo ou comportamento intermediário e conforme aumenta o momento, que neste caso varia para 2,97E-4 e 3,96E-4 Kgm/s, mais acentuado se torna o comportamento anômalo.

Abaixo da linha de centro da esfera o comportamento da tensão residual é típico ao obtido para jateamento com granalhas.

A tensão residual medida por difração de raios $X$ é realizada em uma região continua que engloba desde o ponto que estava abaixo da linha de centro de uma granalha ate a linha de centro entre as granalhas. Isto sugere que a tensão residual final medida por DRX deveria ser a composição das figuras $a$ e $b$ que dependendo da energia das granalhas pode favorecer $a$ ocorrência do comportamento anômalo.

Neste trabalho o início do comportamento anômalo foi verificado para esferas com momento em torno de $2 \mathrm{E}-4 \mathrm{Kgm} / \mathrm{s}$. Amostras jateadas com esferas com momento de 1,3E-3 Kgm/s (granalhas 1/8") apresentam comportamento anômalo.

Apesar das diferenças do material alvo, no nosso caso alumínio e no caso da simulação feita por Meguid, onde o material alvo era aço, o efeito anômalo pode ocorrer dependendo da energia das granalhas durante 0 jateamento.

Os arcos formados pelo peen forming aplicados às amostras de $10 \mathrm{e}$ 15 mm são apresentados nas figuras 57 e 58. A relação entre a espessura e o alongamento relativo a superfície está diretamente ligada à maior resistência encontrada entre amostras de maiores espessuras, gerando menor formação de arco. 


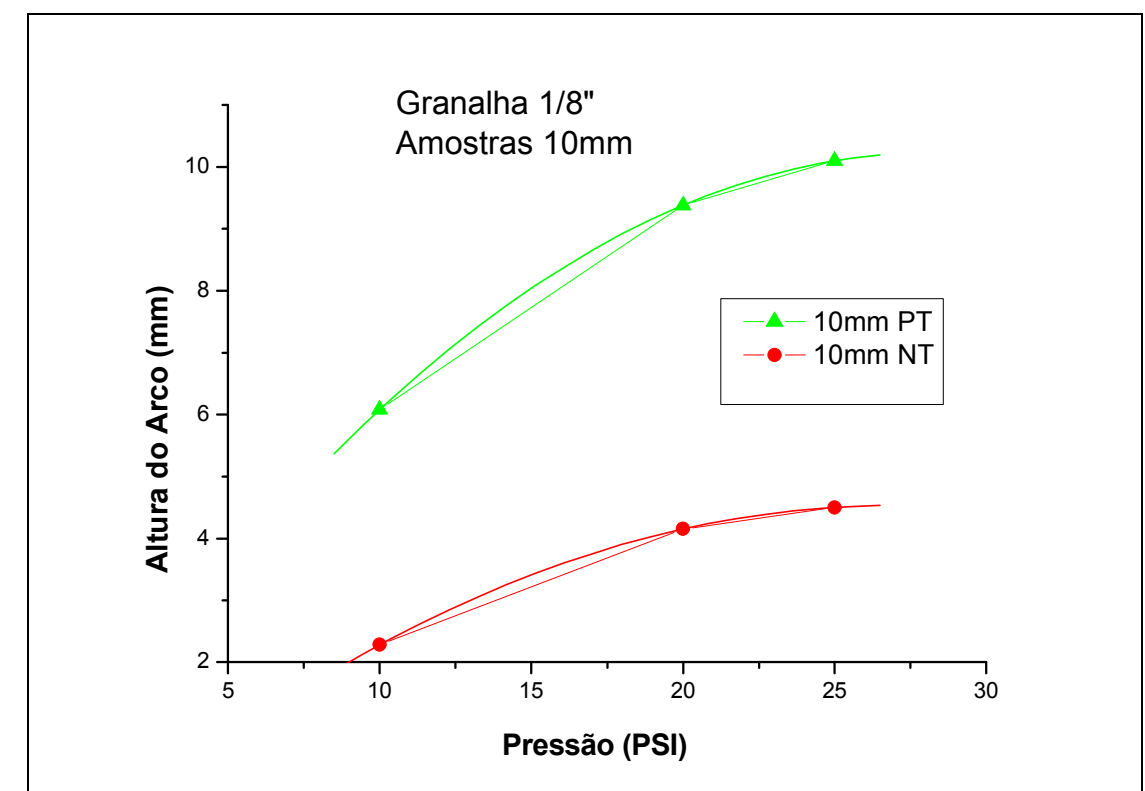

Figura 57: Formação da altura do arco pelo peen forming em amostras de $10 \mathrm{~mm}$ jateadas em 1/8"

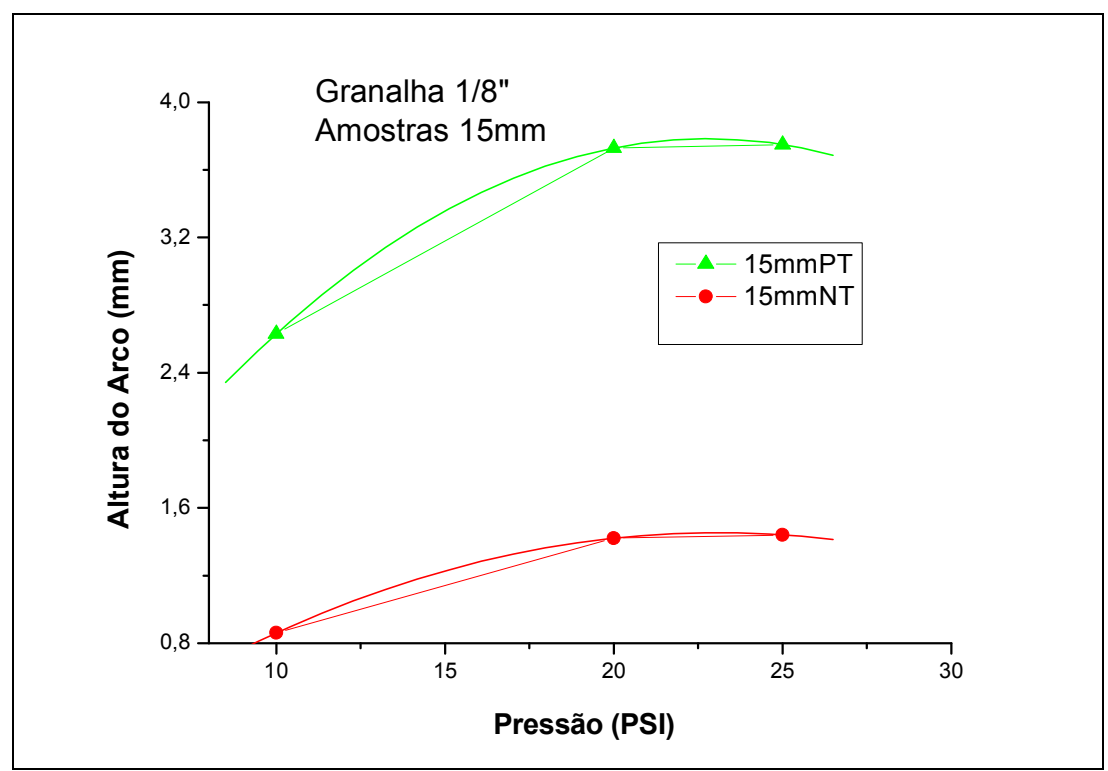

Figura 58: Formação da altura do arco pelo peen forming em amostras de $15 \mathrm{~mm}$ jateadas em $1 / 8 "$

Além disso, pode-se constatar que o ponto de saturação ainda está indefinido para a amostra de espessura de $10 \mathrm{~mm}$ com aplicação de pré tensionamento e sem pré tensão. Para as amostras de espessura de $15 \mathrm{~mm}$, a ponto de saturação é alcançado logo à pressão de 20 psi tanto para a amostra tensionada quanto para a amostra não tensionada.

A tabela 18 apresenta os valores do raio formado pela aplicação do peen forming, concomitante com as figuras 57 e 58 . 
Tabela 18: Resultados dos valores do raio de curvatura após o processo peen forming em parâmetros de regime de pressão e aplicação de pré tensão em amostras jateadas em 1/8"

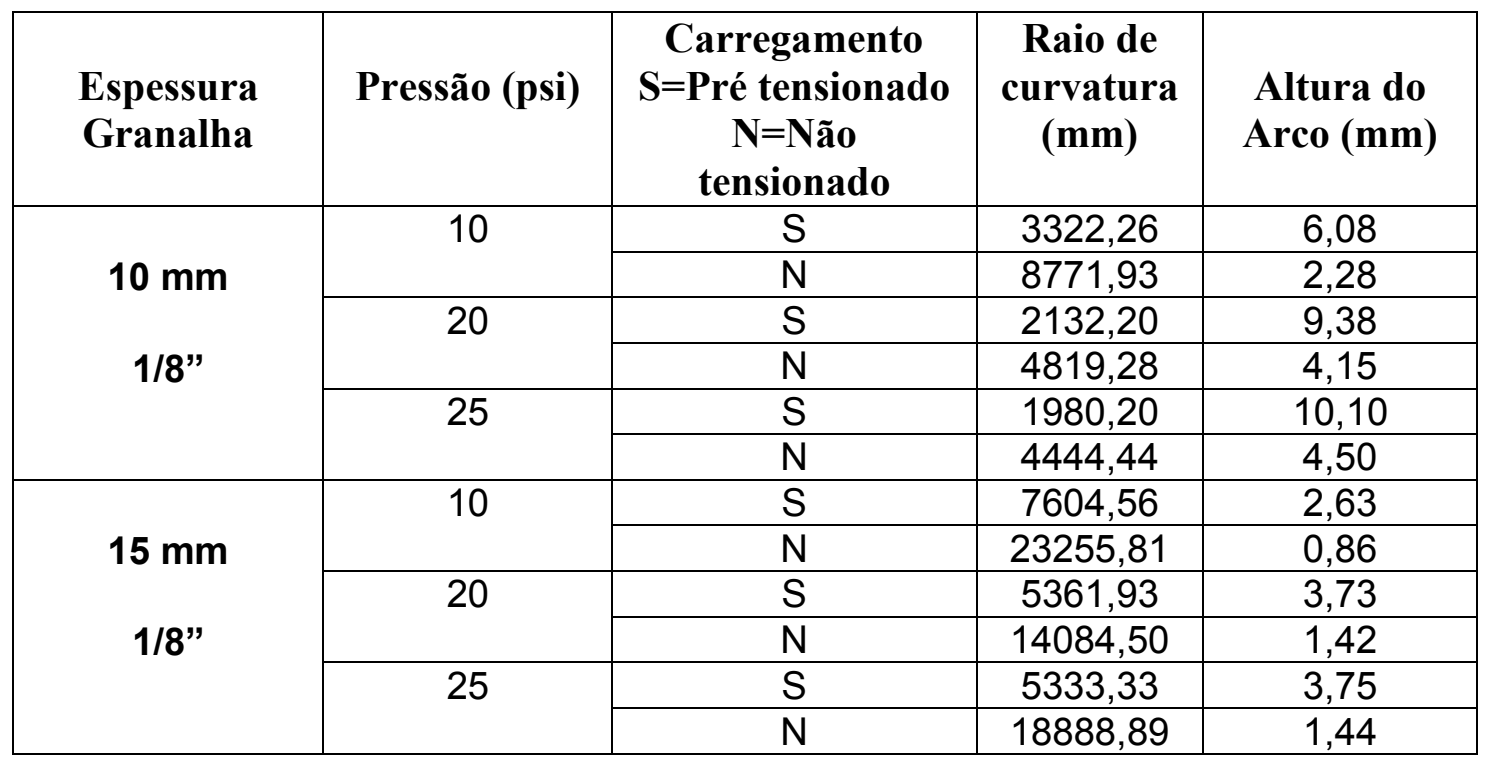

Por meio do estudo da rugosidade em função da indentação provocada pelo impacto causado pelas esferas de jateamento, o fator de concentração de tensão foi calculado e está representado pela tabela 19:

Tabela 19: Resultados dos fatores de concentração de tensão obtidos em relação ao regime de pressão e carregamento das amostras de alumínio 7050 para amostras 10 e 15mm, em granalhas $1 / 8 "$

\begin{tabular}{|c|c|c|c|}
\hline $\begin{array}{l}\text { Espessura } \\
\text { Granalha }\end{array}$ & Carregamento & $\begin{array}{l}\text { Pressão } \\
\text { (psi) }\end{array}$ & $\mathbf{K}_{\mathbf{t}}$ \\
\hline \multirow{3}{*}{$10 \mathrm{~mm}$} & \multirow[t]{3}{*}{ Pré Tensionado } & 10 & 1.06 \\
\hline & & 20 & 1.07 \\
\hline & & 25 & 1.08 \\
\hline \multirow[t]{3}{*}{$1 / 8 "$} & \multirow[t]{3}{*}{ Não Tensionado } & 10 & 1.06 \\
\hline & & 20 & 1.09 \\
\hline & & 25 & 1.09 \\
\hline \multirow{3}{*}{$15 \mathrm{~mm}$} & \multirow[t]{3}{*}{ Pré Tensionado } & 10 & 1.07 \\
\hline & & 20 & 1.07 \\
\hline & & 25 & 1.07 \\
\hline \multirow[t]{3}{*}{$1 / 8 "$} & \multirow[t]{3}{*}{ Não Tensionado } & 10 & 1.09 \\
\hline & & 20 & 1.08 \\
\hline & & 25 & 1.06 \\
\hline
\end{tabular}

Pelas observações na tabela 19 , nota-se que não há variação nos resultados de $\mathrm{K}_{t}$ obtidos em regime de pressão e condição de 
tensionamento. Conclui-se que o fator de concentração de tensão está em função da aplicação do jateamento de granalhas de diferentes sem a influência dos outros parâmetros em estudo. $O$ que se observa é que continuamente, quanto menor a granalha aplicada, maior o fator de concentração de tensões e isto se deve a forma e a quantidade com que as granalhas impactam a superfície da amostra. Granalhas de menor dimensão, lançadas a altas pressões provocam um alto grau de rugosidade quando comparadas com granalhas de maiores dimensões lançadas a um regime de pressão menor. Analisando somente pelo ponto de vista do fator de concentração de tensão $\left(\mathrm{K}_{\mathrm{t}}\right)$, afirma-se que, em amostras jateadas em granalhas de maior diâmetro possui melhores propriedades de resistência à fadiga, devido a concentrar menos pontos de tensão, pois uma superfície sem pontos de concentração de tensões (perfeitamente plana) não haveria como proporcionar um ponto que propiciaria a formação de micro trincas.

\subsection{Estudos complementares sobre microdeformação}

Este estudo tem por base a análise do alargamento dos picos obtidos por difração de raios $\mathrm{x}$.

Os parâmetros utilizados para a realização para este estudo consideraram os efeitos provocados pelo jateamento das granalhas na variação de pressão e nas superfícies em granalhas de tamanho grande (superfície jateada, superfície atacada até a tensão residual nula e superfície sem shot peening), sendo:

S230-60-5SPT: Amostra de $5 \mathrm{~mm}$ de espessura, jateada com granalhas S230 a 60 psi de pressão, sem a aplicação de pré tensão.

S230-40-5SPT: Amostra de $5 \mathrm{~mm}$ de espessura, jateada com granalhas S230 a 40 psi de pressão, sem a aplicação de pré tensão.

S230-20-5SPT: Amostra de $5 \mathrm{~mm}$ de espessura, jateada com granalhas S230 a 20 psi de pressão, sem a aplicação de pré tensão.

1/8-20-15SPT-at: Amostra de $15 \mathrm{~mm}$ de espessura, jateada com granalhas $1 / 8$ " a 20 psi de pressão, sem a aplicação de pré tensão, atacada até a profundidade onde a tensão residual é nula $\left(\mu \sigma_{t o t}\right)$. 
1/8-20-15SPT-sup: Amostra de $15 \mathrm{~mm}$ de espessura, jateada com granalhas 1/8" a 20 psi de pressão, sem a aplicação de pré tensão, na superfície $\left(\mu \sigma_{\text {sup }}\right)$.

Amostra S.Shot: Amostra de Al 7050 no estado "como recebido", sem aplicação de peen forming de espessura de $5 \mathrm{~mm}$.

Os fatores considerados para estudo do alargamento dos picos:

GU: Alargamento relacionado com a microdeformação.

LX: Alargamento relacionado ao tamanho médio do cristalito.

Os resultados estão descritos pela tabela 22:

Tabela 20: Resultados dos alargamentos em relação a microdeformação e tamanho de cristalito

\begin{tabular}{|c|c|c|c|c|}
\hline Amostras & GU & LX & $\boldsymbol{\varepsilon}(\%)$ & $\mathbf{D}(\boldsymbol{A})$ \\
\hline S230-60-5SPT & 643 & 13,6 & 1,04 & 580 \\
\hline S230-40-5SPT & 736 & 11,4 & 1,04 & 604 \\
\hline S230-20-5SPT & 592 & 11,9 & 1,01 & 663 \\
\hline Amostra S.Shot & 8,6 & 12,5 & 0,12 & 631 \\
\hline $\mathbf{1 / 8 - 2 0 - 1 5 S P T - a t}$ & 19,7 & 6,7 & 0,18 & 1178 \\
\hline $\mathbf{1 / 8 - 2 0 - 1 5 S P T - s u p ~}$ & 1022 & 8,6 & 1,32 & 918 \\
\hline
\end{tabular}

Os resultados obtidos demonstram que a microdeformação não se altera conforme o aumento no regime de pressão nas amostras de $5 \mathrm{~mm}$, jateadas com as granalhas S230, variando $0,03 \%$, porém o alargamento se deve ao fato de que o tamanho médio do cristalito diminuiu conforme a pressão de jateamento aumenta. Analisando os resultados pelo jateamento nas superfícies, é possível deduzir que a energia cinética imposta à amostra devido ao impacto das granalhas, não possui energia suficiente para provocar a deformação na rede cristalina, porém altera-se o tamanho médio do cristalito.

Os resultados para amostras que foram jateadas com granalhas $1 / 8$ " e com energia cinética maior mostram que a microdeformação na superfície 
é maior do que nas amostras jateadas com granalhas $\$ 230$. O tamanho médio dos cristalitos também é pouco menor do que seu tamanho na região livre de tensão residual onde a microdeformação é bem baixa, em torno de 0,18 . A diferença entre os tamanhos médios de cristalito entre as amostras denominadas "Amostra S.Shot" e "1/8-20-15SPT-at" se deve ao fato do grau de laminação ser maior na amostra denominada "Amostra S.Shot" cuja espessura final é de $5 \mathrm{~mm}$.

Como sugestão para futuros trabalhos, seria interessante estudos mais aprofundados analisando a deformação e o tamanho médio do cristalito nas camadas abaixo da superfície que foram jateadas com granalhas. Existe uma correlação entre a largura do pico de difração $\left(B_{1 / 2}\right)$ em cada camada com o perfil de tensão residual em profundidade. Para efeito de ilustração está mostrado nas figuras 59 e 60 o valor de $B_{1 / 2}$ e a tensão residual medida em cada profundidade.

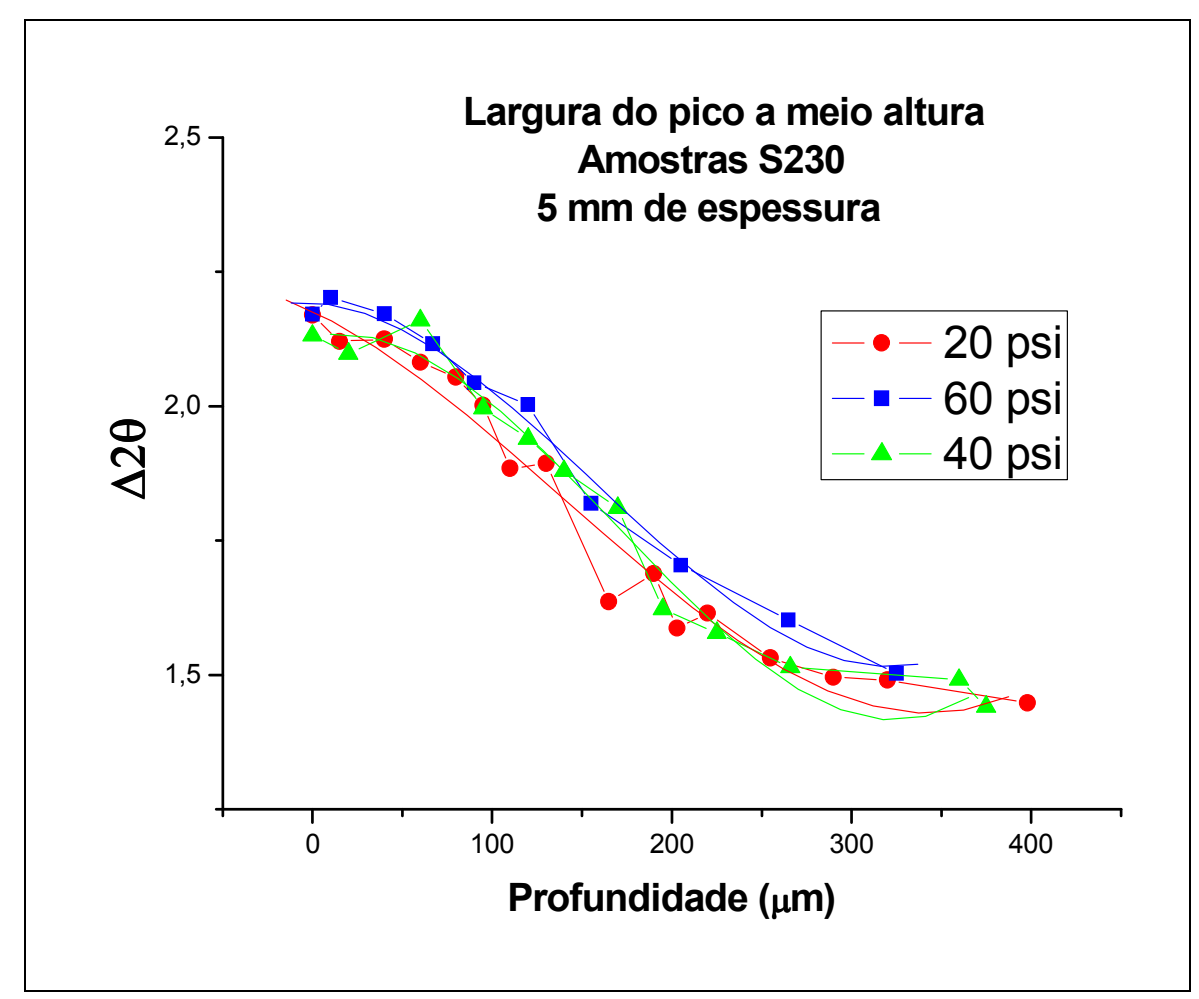

Figura 59: Distribuição em profundidade da largura do pico a meia altura para amostras S230, $5 \mathrm{~mm}$ de espessura em regime de pressão de 20, 40 e 60 psi 


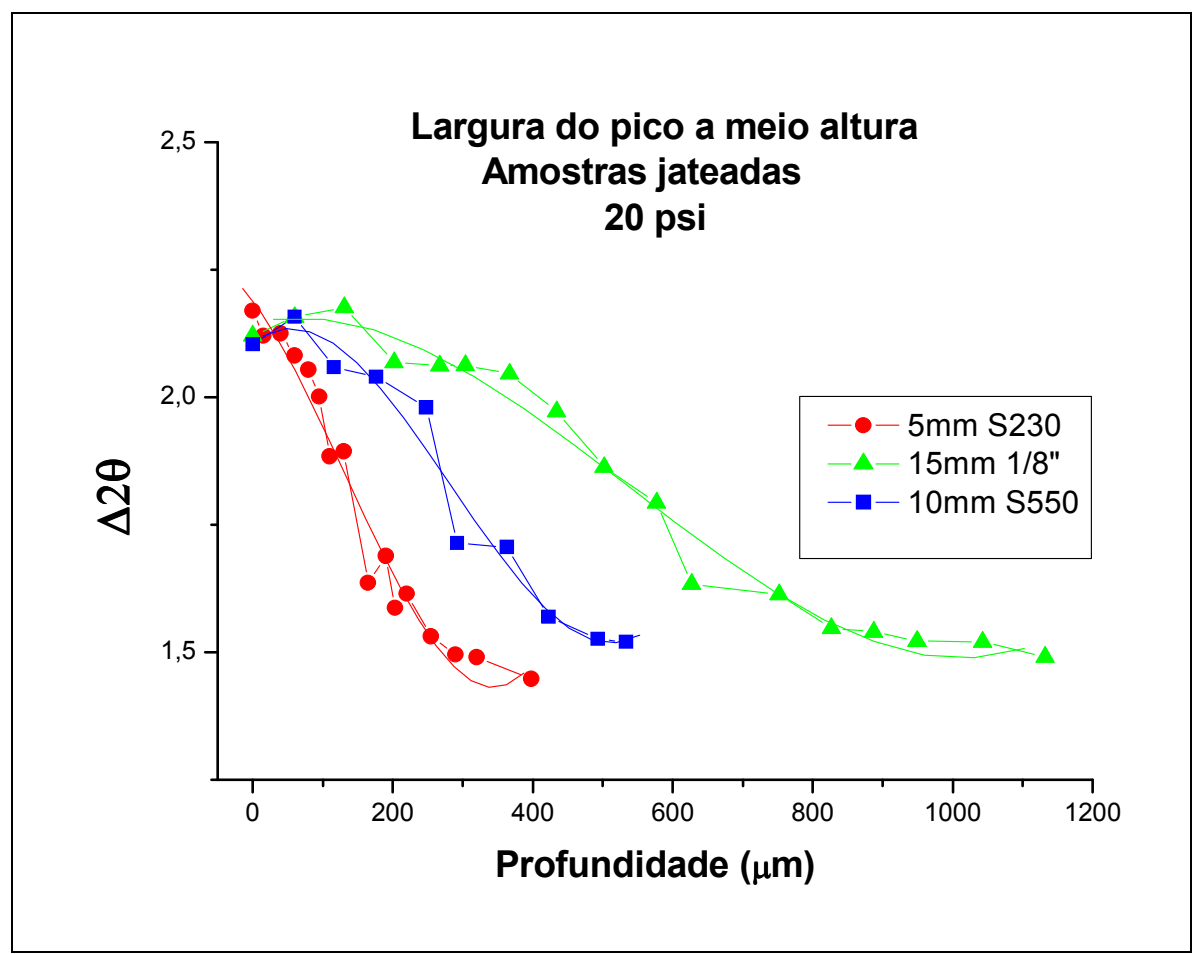

Figura 60: Distribuição em profundidade da largura do pico a meia altura para amostras jateadas em 20 psi

De cada alargamento do pico de difração, mediante tratamento matemático descrito na página 55, é possível separar as contribuições do tamanho médio do cristalito e das microtensões e com isto avaliar com mais profundidade o efeito da deformação e microdeformação no estado de tensões do material. 


\section{CONCLUSÕES}

Para amostras jateadas com as granalhas $\mathbf{S 2 3 0}$, a tensão residual compressiva máxima não se altera com a pressão de jateamento.

Para amostras jateadas com as granalhas $\mathbf{2 3 0}$, a tensão residual na superfície decresce com o aumento de pressão de jateamento.

A profundidade máxima de tensão residual aumenta com o acréscimo da pressão de jateamento, e com o tamanho de granalhas.

Os valores de arco formado são maiores quando aplicados nas amostras:

a) De menor espessura.

b) Pré tensionadas.

c) Com maior pressão de jateamento.

O fator de concentração de tensão é inversamente proporcional ao tamanho das granalhas.

Para amostras jateadas com as granalhas $S 550$ e 1/8" a tensão residual máxima é maior em condição de pré tensionamento, para as amostras 5, 10 e $15 \mathrm{~mm}$ de espessura.

A variação do alargamento dos picos de difração por raios $x$ é devido a microdeformação na rede cristalina.

A saturação da altura do arco de curvatura depende do tamanho das granalhas. 
Apêndice A - Trabalho apresentado em congresso:

$19^{\circ}$ Congresso Brasileiro de Engenharia e Ciência dos Materiais

21 a 25 de novembro de 2010

Campos do Jordão - SP

Avaliação da tensão residual em alumínio 7050 conformado pelo processo peen forming 


\section{REFERÊNCIAS BIBLIOGRÁFICAS}

ALMEN, J.O.; BACK, P.H.; Residual stresses and fatigue in metals. Mc Graw-Hill, cap. 6, p. 61-62, apêndice A-12, p. 200-201, New York, 1963.

AMERICAN SOCIETY FOR METALS. ASM Handbook; Introduction to aluminum and aluminum alloys. Disponível em: < Erro! A referência de hiperlink não é válida.> acesso em 25 nov 2009.

AMERICAN SOCIETY FOR METALS. ASM Metals Handbook. Fundamentals of corrosion. Vol13. $9^{\text {th }}$ edition. OH, EUA, 1990.

AMERICAN SOCIETY FOR METALS. ASM Metals Handbook:, Properties and selection: Nonferrous alloys and special-purpose materials Vol. 2. $\mathrm{OH}, \mathrm{EUA}, 1992$.

ASSIS, J.T.; MONIN, V.I.; SOUZA, P.S.; WEIDLICH, M.C.; GUROVA, T.; TEODOSIO, J.R. Processamento dos dados de difração de raios $x$ para medição de tensões. Disponível em: < http: //www.sbmac.org.br /bol/ boletim_2002/ assis-monim-souza-weidlich-4emc.pdf >. Acesso em: 20 set. 2010.

ASSOCIAÇÃO BRASILEIRA DE ALUMINIO ABAL; Fundamentos do alumínio e suas aplicações..p - 81. São Paulo, 2004

ASSOCIAÇÃO BRASILEIRA DE ALUMINIO, ABAL; Aluminio-Aplicações. Disponível em http://www.abal.org.br/ligas trabalháveis> acesso em 27 jul 2010

BIALLAS, G., BRAUN, R.; DONNE, C. D.; STANIEK, G., KAVSSER, W. A. Mechanical properties and corrosion behaviour of friction stir welded 2024T3" in 1st International Friction Stir Welding Symposium, California, USA, 1999.

BOTTARO, M. Estudo do envelhecimento de um tubo de raios $x$ por métodos não evasivos.Dissertação (mestrado). Instituto de Pesquisas Energéticas e Nucleares, São Paulo, 2007.

BRAGA, A.P.V.; Caracterização de ligas de alumínio conformadas por jateamento de esferas. Qualificação (mestrado). Instituto de Pesquisas Tecnológicas. São Paulo, SP, 2010.

BYSTRITSKII, V.; GARATE, E.; EARTHMAN, J.; KHARLOV, A.; LAVEMIA, E.; PENG, X. Fatigue properties of 2024-T3, 7075-T6 aluminum alloys modified using plasma-enhanced ion beams, Theoretical. Applied. Fracture. Mechanics., 32(1), p. 47-53. 1999. 
CAMARGO, J.A.M.; $\boldsymbol{A}$ influência do shot peening e das anodizações crômica, sulfúrica e dura sobre a resistência à fadiga da liga 7050-t7451 de uso aeronáutico. 2007, tese (doutorado) Faculdade de Engenharia Campus de Guaratinguetá da UNESP.

CAO, W., FATHALLAH, R., CASTEX, L., Correlation of Almen arc height with residual stresses in shot peening process. Materials Science and Technology. v.11, p. 967-973, 1995.

CIENFUEGOS, F; VAITSMAN, D; Análise instrumental. Interciência, Rio de Janeiro, 2000, cap. 13, p.461-465.

CLAUSEN, R., STANGENBERG, J., Device for the determination of impact particles on shot peening. Proceedings of the 8th International Conference on Shot Peening, pp. 16-20, 2002

CONSERVA, M.; DONZELLI, G.; TRIPPODO, R.; Aluminum and its applications.- Classification of aluminum Alloys and their tempers. $p$. 76-77. Edimet, IT, 1992

CRC Handbook of Chemistry e Physics. Section 4, p.3. $91^{\text {st }}$ edition. National Institute of Standards and Technology. Gaithersburg, MD, 2010.

CULLITY, B.D.; Elements of $x$-ray difraction. $2^{\text {th }}$ Ed. Addison-Wesley Publishing Company Inc. Reading, MA, 1978.

CULLITY, B.D.; STOCK, S.R.; Elements of $x$-ray difraction. $3^{\text {th }}$ ed. Prentice Hall, Cap 1, p. 1 cap 15, p.435-469. Upper Saddle River, NJ, 2001.

CURTIS, S.A.; ROMERO, J.S.; RIOS, E.R.; RODOPOULOS, C.A. and LEVERS, A.; Predicting the interfaces between fatigue crack growth regimes in 7150 - T651 aluminum alloy using the fatigue damage map. International Journal of Fatigue. 25 - p. 59-66. 2003

DAVIS, J.; American Society for Metals Specialty Handbook: Aluminum and Aluminum Alloys. OH, EUA. p-784, 1993

DIEPART, C.P.; Modeling of shot peening residual stresses - practical applications. Materials Science Forum, v. 163-165, p. 457-464, Stafa, Zurich, 1994.

EASTMAN KODAK COMPANY (Rochester, New York). Howard T. Hodges; Edwin J. McGuire. Method and apparatus for forming sheet metal. United States Patent Office. Ser.№ 654.861 3 Claims. Cl 153-32. April, 24, 1957.

FRANÇOIS, M. ; SPRAUEL, J.M.; DEHAN, C.F.; JAMES, M.R.; CONVERT, F.; LU, J.; LEBRUN, J.L.; LI, N.; HENDRICKS, R.W. ; X-Ray difraction method. In: Handbook of measurement of residual stresses. Society for Experimental Mechanics; Fairmont Press,. cap. 5. Lilburn, GA, 1996 
FRANKEL, G. S.; XIA, Z. Loacalized corrosion and stress corrosion cracking resistance of friction stir welded aluminum alloy 5454, Corrosion, 55(2), p. 139-150. 1999.

GALVELE, R.; MICHELI, S.M. Mechanism of Intergranular Corrosion of Al-Cu Alloys, Corrosion. Society., 10, p. 795-807, 1970

GUAGLIANO, M., VERGANI, L.; An approach for prediction of fatigue strength of shot peened components. Engineering fracture mechanics. $v$. 21.171, p. 501-512, 2004.

GUROVA, T.; QUARANTA, F.; ESTEFEN, S. Monitoramento do estado das tensões residuais durante a fabricação de navios. In: 21 Congresso Nacional de Transportes Marítimos, Construção Naval e Offshore, 27.11-01.12.2006, p.1-9, Rio de Janeiro, RJ, 2006.

HANDBOOK Infomet. cap. Metais e ligas - aluminio - AA7050. Disponível em: < Erro! A referência de hiperlink não é válida. acesso em 20 jan 2009.

HANNOUR, F.; DAVENPORT, A. J.; STRANGWOOD, M.; Corrosion of friction stir welds in high strength aluminium alloys, in: 2nd International Friction Stir Welding Symposium The Welding Institute TWI, Gothenburg, Sweden, 2000

HANNOUR, F.; DAVENPORT, A. J.; WILLIAMS, S. W.; MORGAN, P. C.; FIGGURES, C. C.; Corrosion behaviour of laser treated friction stir welds in high strength aluminium alloys. In: 3rd International Friction Stir Welding Symposium., Kobe, Japan, 2001.

HE, J.H.; SHOENUNG, J.M.Nanostrutured coatings. Materials Science e Engineering. Value 336, p. 282-284, 25 set 2002.

HERZOG, R., ZINN, W., SCHOLTES, B., WOHLFAHRT, H.; The significance of Almen intensity for the generation of shot peening residual stresses. In: International Conference on Shot Peening. p. 270-281. São Francisco,CA, 1996.

HOLLINGSWORTH, E. H.; HUNSICKER, H. Y. Corrosion of aluminum and aluminum alloys. in Metal Handbook 9th ed., 13, Corrosion, p. 583-609. 1987

INTERNATIONAL ALUMINIUM INSTITUTE; Story of aluminium. Disponivel em <http://www.world-aluminium.org/About+Aluminium/Story+of> acesso em 09 set 2009

JAMES, M.R.; LU, J. INTRODUCTION. IN: LU, J. Handbook of measurement of residual stresses; Society for Experimental Mechanics; Fairmont Press; cap. 1; dez. 1996.

JEFFERY, J.W. Methods in x-ray crystallography. Academic Press, London e New York. P. 33, 1971 
JOHNS, H.E. The physics of radiology, $4^{\text {a }}$ ed. Charles C. Thomas Publisher. Springfield, IL, 1983

KARHAUSEN, K.F.; KORHONEN, A.S.; Rolling of aluminium. In Handbook of Aluminium. V1, p 351-383. Taylor e Francis, New York, 2003.

KALPAKDJIAN, S.; SHIMID, D. S. R.; Manufaturing engineering and technology. Prentice Hall, $4^{\text {th }}$ Ed., Upper Saddle River, N.J, 2001.

LARSON, A.C.; VonDREELE, R.B. General Structure Analysis System Manual. Lansce, MS- H805, Los Alamos National Laboratory. P. 163-165, 2004.

LI, J.K.,YAO,M.,WANG, D.,WANG, R. An analysis of stress concentrations caused by shot peening and its application in predicting fatigue strength. Fatigue Fracture Engineering Materials Structure. 15(12), p. $1271,1992$.

LIAO, C.M.; OLIVE, M.J.; GAO, M.; WEI, R.P. Monitoring of pitting corrosion in aluminum alloy 2024", Corrosion, 54(6), p. 451-458. 1998

LUMDSEM, J.B.; MAHONEY, M.W., POLLOCK, G.; RHODES, C.G.; Intergranular corrosion following friction stir welding of aluminum alloy 7075-T651, Corrosion, 55(12), p.1127-1135. 1999.

MEGUID, S.A.; SHAGAL, G.; STRANART, J.C.; DALY, J. Threedimensional dynamic finite element analysis of shot peening induced residual stresses. Finite Element in Analysis an Design 31. p 179-191, 1999.

MIC; Shot peening applications. Metal Improvement Company - $9^{a}$ ed., 62p. Disponível em: <Erro! A referência de hiperlink não é válida.> Acesso em: 15 dez. 2008.

MIL-Handbook 5J. Metallic materialsand elements for aerospace vehicle structures. Department of Defense of United States of America. Cap 3, 2003

O'HARA, P.; Peen-Forming-A Developing Technique. In: Lothar Wagner 8th International conference on Shot Peening, Garmisch-Partenkirchen. Weinheim, WILEY-VCH, 2003, S. 17-226. 16. - 20. September 2002,

OLIVEIRA, J.C.P.T; Evolução da microestrutura e da textura durante a laminação a frio e a recristalização de alumínio com diferentes níveis de pureza, 2009. Tese (doutorado). Escola Politécnica da Universidade de São Paulo, São Paulo

PADILHA, A. F.; AMBROZIO FILHO, F. Técnicas de analise micro estrutural, Hemus, $1^{\mathrm{a}}$ ed., 2004, cap. 2. 
PERINI, R.; $O$ uso de raios-x para determinação da tensão residual induzida pelo processo de roleteamento de uma camisa de cilindro de motor diesel. Dissertação (mestrado). Instituto de Pesquisas Energéticas e Nucleares. São Paulo, SP, 2008.

PONGE, D.; BREDEHÖFT,M.; GOTTSTEIN,G.; Dynamic recrystallization in high purity aluminium. Scripta Materialia, v.37, n.11, p. 1769-1775, 1997.

POSTEK, M. T.; HOWARD, K. S.; JOHNSON, A.; MacMICHAEL, K. L. Scaning electron microscopy a student's handbook, Ladd Research, Vemont, , cap. 4, p. 69-74, 2001.

REGONE, N. N.; Determinação de Tensão Residual em Camadas Superficiais. Dissertação (Mestrado). Universidade Estadual de Campinas. Campinas, SP., 2000.

RIAHIFAR, R.; SERAJZADEH, S.; Three-dimensional modelo for hot rolling of aluminum alloys. Materails and design. V.28, p. 2366-2372, 2007.

RIGAKU. Residual stress data process program 2 (ver. 2.0) d/max-2000 instruction manual, Rigaku Corporation, 2006. $10^{\mathrm{a}} \mathrm{ed}$.

RIOS, P.R.; PADILHA, A.F. Transformações de fase. Artliber Editora. P. 45-50. São Paulo, 2007.

ROBINSON, D. L.; HUNTER, M. S. Interrelation of tem-microstructure, composition, tensile properties, and corrosion-resistance of Al-Cu-MgMn alloys., Metall Trans 3(5), p.1147, 1972

SAE INTENATIONAL. Standards. Disponível em http :// standards.sae.org I materials/materials-properties/ acesso em 02 fev 2009.

SCHERRER, P.;Nachr. Gesellschaft der Wissenschaften zu Göettingen. Math. Phys. KI 2, 98, 1918.

SECRETARIA DE GEOLOGIA, MINERAÇÃO E TRANSFORMAÇÃO MINERAL. Anuário estatístico, 2007.p-128. Brasilia

SELLARS, C.M.; Modeling microstrutural development during hot rolling. Materials Science and Technology, v.6, p. 1072-1081, 1990.

SHARP, P.K.;CLAYTON, J.Q.; CLARK, G.; The fatigue resistance of peened 7050-T7451 aluminum alloy repair and re-treatment of a component surface. Fatigue e Fracture of Engineering Materials e Structures, 17 (3), p. 243-252, 1994.

SONG, P. S., WEN, C. C., Crack closure and crack growth behavior in shot peened fatigued specimen. Engineering Fracture Mechanics. v. 63, p. 295304, 1999. 
SPRAWLS, P.Physical principles of medical imaging. Medical Publishing. Madison,WI, 1985.

SURYANARAYANA, C.; NORTON, M.G. X- ray diffraction - a practical approach. Plenun Press. p. 207-218. New York, 1998.

TORRES, M. A. S.; Uma avaliação do efeito do shot peening na vida em fadiga do Aço ABNT $4340 \mathrm{com}$ e sem revestimento de cromo duro. Tese (Doutorado) - FEG/UNESP, Guaratinguetá, SP, 2002.

TORRES, M. A. S.; VOORWALD, H. J. C.; An evaluation of shot peening, residual stresses and relaxation on the fatigue life. International Journal of Fatigue, v.24, pp 877-866, 2002.

UFRGS. Fisica Moderna, cap 5.,Produção de raios $x$. Disponivel em http://www.if.ufrgs.br/tex/fis142/fismod/mod05/m_s01.html. Acesso em 22 out 2009.

USGS, Imagem disponível em:<http://pubs.usgs.gov/of/2001/of01-041/ htmldocs/images/xrdtube.jpg>.Acessado em 23 mar. 2010

Van HORN, K.R.; American Society for Metals.;Aluminium vol1.Properties, physical metallurgy and phase diagrams. Metal Park, OH, 1967.

VIEIRA, C.;MAZZOLENIS,S. A história do alumínio no Brasil, 30 anos. Editora Antonio Belline. P-120.São Paulo, 2000.

WANG, S.; YAO, M.; WANG, R.; Fatigue limits of shot peened metals. Journal of Materials Processing Technology. v. 73, p. 57-63, 1998.

WANG, T.;PLATTS, M.J.;LEVERS,A.; A Process Model for Shot Peen Forming. In: Journal of Materials Processing Technology.172. p 159-162, 2006.

WEI, R. P.; LIAO, C. M.; GAO, M.; A transmission electron microscopy study of constituent-particle-induced corrosion in 7075-T6 and 2024-T3 aluminum alloys., Metall. Mater. Trans. A, 29A, p.-1153-1160, 1998

WOLBARST, A.B. Physics of radiology. Appleton e Lange. Norwalk, CT, 1993

WULPI, D. J.; Understanding how components fail, ASM American Society for Metal. cap. 7, Metals Park, OH, 1985. 